\title{
Sit Less or Exercise More?
}

Citation for published version (APA):

Duvivier, B. M. F. M. (2017). Sit Less or Exercise More? Impact of interventions reducing sedentary behaviour on cardiovascular risk factors. [Doctoral Thesis, Maastricht University]. Maastricht University. https://doi.org/10.26481/dis.20171027bmd

Document status and date:

Published: 01/01/2017

DOI:

10.26481/dis.20171027bmd

Document Version:

Publisher's PDF, also known as Version of record

\section{Please check the document version of this publication:}

- A submitted manuscript is the version of the article upon submission and before peer-review. There can be important differences between the submitted version and the official published version of record.

People interested in the research are advised to contact the author for the final version of the publication, or visit the DOI to the publisher's website.

- The final author version and the galley proof are versions of the publication after peer review.

- The final published version features the final layout of the paper including the volume, issue and page numbers.

Link to publication

\footnotetext{
General rights rights.

- You may freely distribute the URL identifying the publication in the public portal. please follow below link for the End User Agreement:

www.umlib.nl/taverne-license

Take down policy

If you believe that this document breaches copyright please contact us at:

repository@maastrichtuniversity.nl

providing details and we will investigate your claim.
}

Copyright and moral rights for the publications made accessible in the public portal are retained by the authors and/or other copyright owners and it is a condition of accessing publications that users recognise and abide by the legal requirements associated with these

- Users may download and print one copy of any publication from the public portal for the purpose of private study or research.

- You may not further distribute the material or use it for any profit-making activity or commercial gain

If the publication is distributed under the terms of Article $25 \mathrm{fa}$ of the Dutch Copyright Act, indicated by the "Taverne" license above, 


\section{SIT LESS OR EXERCISE MORE?}

IMPACT OF INTERVENTIONS REDUCING SEDENTARY BEHAVIOUR ON CARDIOVASCULAR RISK FACTORS 


\title{
Sit Less or Exercise More?
}

\author{
Impact of interventions reducing \\ sedentary behaviour on cardiovascular \\ risk factors
}


The research presented in this thesis was funded by a Kootstra Talent Fellowship from Maastricht University Medical Centre+, Unilever, Novo Nordisk BV and the Netherlands Cardiovascular Research Initiative: an initiative with support of the Dutch Heart Foundation (CVON2014-02 ENERGISE). Consumables were supplied by Medtronic and Roche. Publication of this thesis was financially supported by Maastricht University and Maastricht Instruments BV.

Cover design Stefanie van den Herik, www.proefschriftmaken.nl

Layout Bernard Duvivier, www.proefschriftmaken.nl

Printing www.proefschriftmaken.nl

(C) Bernard Duvivier, Maastricht 2017

All rights reserved. No parts of this publication may be reproduced or used in any manner whatsoever without prior written permission from the author 


\section{Sit Less or Exercise More?}

\section{Impact of interventions reducing sedentary behaviour on cardiovascular risk factors}

\section{PROEFSCHRIFT}

Ter verkrijging van de graad van doctor aan de Universiteit Maastricht op gezag van de Rector Magnificus

Prof. dr. Rianne M. Letschert

volgens het besluit van het College van Decanen, in het openbaar te verdedigen op vrijdag 27 oktober 2017 om 12.00 uur

door

Bernard Maria Francis Marcel Duvivier Geboren op 24 maart 1988 te Hasselt 


\section{Promotores}

Prof. dr. H.H.C.M. Savelberg

Prof. dr. N.C. Schaper

\section{Copromotor}

Dr. ir. A. Koster

\section{Beoordelingscommissie}

Prof. dr. E.E. Blaak (voorzitter)

Prof. dr. J.M.M. Chin A Paw (VU Medisch Centrum)

Prof. dr. L.J.C. van Loon

Prof. dr. J.W.M. Muris

Dr. T. Yates (University of Leicester, United Kingdom) 


\section{Table of contents}

$\begin{array}{lll}\text { Chapter } 1 \text { General introduction } & 7\end{array}$

$\begin{array}{lll}\text { Chapter } 2 \text { Minimal intensity physical activity (standing and walking) } & 15\end{array}$

of longer duration improves insulin action and plasma lipids more than shorter periods of moderate to vigorous exercise (cycling) in sedentary subjects

Chapter 3 Benefits of substituting sitting with standing and walking in free-living conditions for cardiometabolic risk markers, cognition and mood in overweight adults

Chapter 4 Breaking sitting with light activities vs structured exercise: a randomised crossover study demonstrating benefits for glycaemic control and insulin sensitivity in type 2 diabetes

Chapter 5 Reducing sitting time versus adding exercise: differential 65 effects on biomarkers of endothelial dysfunction and metabolic risk

Chapter 6 General discussion 79

Chapter 7 Valorisation 93 Summary 99

Samenvatting 103

References 109

Dankwoord

Curriculum vitae

List of publications 



\section{CHAPTER 1}

GENERAL INTRODUCTION 


\section{Physical activity and cardiovascular disease}

Cardiovascular disease (CVD) has become the leading cause of mortality worldwide due to changes in factors such as lifestyle, socio-economic circumstances and environment [1]. By improving behavioural risk factors such as tobacco use, unhealthy diet and physical inactivity many CVDs can be prevented [1]. In the last decades, we have become increasingly more physically inactive [2]; and in order to increase physical activity, the World Health Organization (WHO) advises to perform $150 \mathrm{~min} /$ week of moderate-tovigorous physical activity (MVPA) [3]. This amount of MVPA has been associated with a wide range of health benefits including a lower risk of cardiovascular disease, type 2 diabetes, metabolic syndrome, and all-cause mortality $[4,5]$. Observational studies report a strong relationship between MVPA and CVD, with the physically active people generally demonstrating CVD rates that are half of the most inactive people [6-8]. Also in the treatment of CVD, MVPA has proven its efficacy [9], this is in particular the case for people suffering from coronary artery disease, in whom MVPA reduces both cardiac and overall mortality [10]. Taken together, most of the currently available evidence indicates that MVPA is an effective strategy in the prevention as well as treatment of CVD.

\section{Physical activity and type 2 diabetes}

The incidence of type 2 diabetes has dramatically increased in recent decades [11]. While there are some genes known to increase the risk of developing type 2 diabetes, the dramatic increase in type 2 diabetes incidence cannot be explained by DNA changes in the last decade as such changes occur much more slowly. Rather, environmental changes seem responsible for the diabetes epidemic, including food intake, obesity and physical inactivity. Therefore, in the prevention of type 2 diabetes, engaging in MVPA can be an effective strategy. Several studies have shown that engaging in MVPA improves insulin sensitivity [12]. Randomised clinical trials involving over 500 participants demonstrated that a lifestyle-modification programme involving $>150 \mathrm{~min} /$ week MVPA and weight loss is highly effective in the prevention of type 2 diabetes $[13,14]$. Interestingly, the reduction in type 2 diabetes incidence by this lifestyle programme (58\%) was about two times higher than that achieved by medical treatment with an insulin sensitising drug (31\%) [13]. Also in the treatment of type 2 diabetes, MVPA is a highly effective strategy to improve glycaemic control $[15,16]$; reflected in lower 24-h glucose levels [16] and lower HbA1c levels [15] when engaging in MVPA regularly.

\section{Cardiovascular risk factors}

A dysfunction in glucose metabolism, lipid metabolism and endothelial function plays an important role in the development of type 2 diabetes and/or CVD [9]. Therefore, circulating markers of glycaemic control, lipid metabolism and endothelial function are often used in clinical practice as cardiovascular risk factors to predict the risk of 
developing cardiovascular disease and type 2 diabetes. Since it generally takes many years for these diseases to develop, cardiovascular risk factors are often used as intermediate outcomes instead of cardiovascular events or the development of type 2 diabetes as outcome measures to assess the effect of an intervention study. It is generally assumed that by improving these cardiovascular risk factors by an intervention, the risk of developing type 2 diabetes and cardiovascular disease can be reduced.

\section{Sitting}

Despite the positive health benefits of MVPA, adherence to the MVPA guidelines is low. Questionnaire studies reported an adherence rate of about $40-60 \%[17,18]$. However, when MVPA is measured objectively with accelerometry, adherence to these guidelines is even lower and is $10-40 \%$ in healthy adults [19]. Even for people adhering to the physical activity guidelines ( $0.5 \mathrm{~h} /$ day MVPA), there are about 15.5 waking $\mathrm{h} /$ day left that can be spent sitting. In the last decades, our society has become increasingly more sedentary [2]. Nowadays, the majority of the Western population spends approximately half of the waking day sedentary $[20,21]$, e.g. driving the car, office work and watching TV or other screens. A large body of evidence indicates that prolonged sitting is detrimental to health [22-25]. In particular adults spending over $10 \mathrm{~h} /$ day sedentary seem most at risk of dying early [23, 24]. Interestingly, a meta-analysis concluded that prolonged sitting was associated with deleterious health outcomes, regardless of MVPA [22]. Thus, in addition to MVPA, decreasing sitting time seems also necessary to improve health.

\section{Light physical activity}

In addition to sitting and MVPA, the other part of our waking day is spent in light physical activity (LPA). When physical activity is measured objectively, time spent in MVPA is on average $0.2 \mathrm{~h} /$ day, while time spent in LPA covers on average $7.8 \mathrm{~h}$ of our day, as demonstrated in Fig. 1 [20, 26]. LPA is defined as physical activity with an intensity of 1.52.9 times the energy expenditure of sitting quietly [27]. In comparison, MVPA is defined as physical activity with an intensity more than 3 times the energy expenditure of sitting quietly. LPA includes daily activities such as standing, light-intensity walking and household activities. These activities are often performed not planned or unconsciously, e.g. chatting while standing, getting a coffee, walking to the printer, cooking or doing the dishes. The amount of LPA largely differs between people [23, 24], e.g. an office worker spending $8 \mathrm{~h} /$ day sitting versus a salesclerk who is standing or stepping most of its time.

As recently pointed out by the American Heart Association, in contrast to MVPA, little is known about sedentary behaviour and LPA [28]. Observational studies reported that increased time spent in LPA, like standing and light walking, was associated with lower cardiovascular risk factors [29] and lower risk of metabolic syndrome [30] and mortality 
$[24,31]$. In the last couple of years, experimental studies have provided further evidence for the beneficial effect of breaking up prolonged sitting with LPA on postprandial glucose and insulin levels [32-35]. These studies were, however, strictly controlled in laboratory conditions and were limited by their short duration (about $8 \mathrm{~h} /$ day). Therefore, studies in free-living conditions of longer duration are needed. In addition to glucose metabolism, the effects on other parameters such as lipid metabolism, endothelial function still need to be explored.

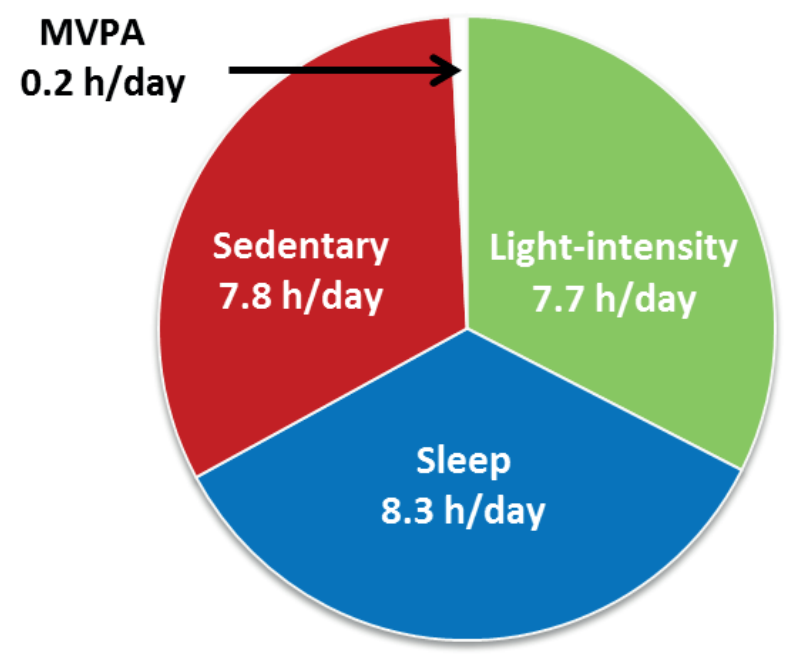

Fig. 1. Estimated daily time spent in different activities among adults. Based on the National Health and Nutrition Examination Survey [20, 26]. MVPA, moderate-to-vigorous physical activity. Figure adapted from Young et al., Circulation 2016 [28].

\section{Energy balance versus use-it-or-lose-it}

One of the questions that needs to be addressed in future research is whether sitting time should be substituted with LPA or with MVPA? It is usually assumed that the beneficial effects of physical activity increase in parallel to its intensity, 'the more the better'. This is understandable from a perspective of balancing energy intake and energy expenditure ('energy balance paradigm'). When assuming that energy balance is of most importance for cardiometabolic health, one could argue that when performing all of the recommended MVPA (150 $\mathrm{min}$ ) on the first day of the week, it is not necessary to perform any other physical activity during the rest of the week. However, as recent observational studies observed that prolonged sitting was associated with negative health outcomes independent of MVPA [22], this suggests that the other 9,930 min of the week may also be of importance.

Another mechanism that is of importance for the effect of physical activity in health, is the 'use-it-or-lose paradigm'. For instance, when muscles are not used for a few days, muscle mass will start to waste. This appears for instance during the recovery of a broken leg in plaster cast. The same phenomenon has been observed after a hospital visit and space 
flights. Therefore, it is necessary to perform physical activity regularly. One could argue that $150 \mathrm{~min} /$ week of MVPA is not enough to compensate for the negative effect of sitting during the rest of the week. As discussed above, a large body evidence suggests that sitting has negative effects on cardiometabolic health, independent of MVPA. Moreover, Bey and Hamilton reported that muscle inactivity (sitting/lying) activates different metabolic mechanisms in muscle tissue compared to mechanisms that are activated by MVPA [36]. Thus, a lack in daily (light) activity seems to affect the body differently than a lack in structured MVPA. Therefore, it seems plausible that the negative metabolic effect of sitting $15.5 \mathrm{~h}$ daily -by not engaging in LPA- cannot be compensated by a 30 min MVPA bout only. As a consequence, it is possible that decreasing sitting time -and substituting it with LPA- may of more importance than to focus on energy balance. To compare the useit-or-lose-it hypothesis with the energy balance hypothesis, we designed a study concept in which we compared the cardiometabolic effects of a 'SitLess regimen' with an 'Exercise regimen'. The SitLess regimen (substituting sitting time with LPA) and Exercise regimen (one daily MVPA bout) were comparable in energy expenditure. These conditions were compared to a 'Sit regimen' in which sitting time was high and energy expenditure was low. Thus, the Sit and Exercise regimens were comparable in sitting time but differed in energy expenditure, and the Exercise and SitLess regimens differed in sitting time but were comparable in energy expenditure. This study design enabled us to investigate the effects of decreasing sitting time (use-it-or-lose-it hypothesis), independent of an increase in energy expenditure. Thus, if the Exercise regimen would be equally beneficial than the SitLess regimen, this would favour the energy balance hypothesis, suggesting that reducing sitting time is not important for cardiometabolic health. In contrast, if the SitLess regimen would be more beneficial than the Exercise regimen, these results would favour the use-it-or-lose-it hypothesis, suggesting that in addition to energy balance, also a decrease in sitting time is necessary for cardiometabolic health. To this end, we performed three intervention studies to answer these research questions.

\section{Study design}

We performed intervention studies with a randomised cross-over design in three different populations. Firstly, we investigated whether we were able to observe effects on cardiovascular risk factors in a physically inactive but otherwise healthy and lean group (chapter 2). Based on these findings, we performed a second study in overweight and physically inactive adults who are at a higher risk of developing cardiometabolic disease (chapter 3). Lastly, we performed a study in type 2 diabetic adults (chapter 4) who are at highest risk of developing cardiovascular disease. The aim of the last study was to provide insight in the possible prevention of cardiovascular disease (cardiovascular risk factors) by LPA and MVPA but also to provide information on the comparative efficacy of these interventions in improving glycaemic control in type 2 diabetes. In all studies, the participants followed a Sit and a SitLess regimen (chapters 2-4). In two of the three 
studies, the participants also followed an Exercise regimen (chapters 2 and 4). Each intervention lasted 4 days. Physical activity was objectively measured $24 \mathrm{~h} /$ day with accelerometry (activPAL) and diet was standardised during each intervention. Outcome measures were circulating markers of cardiovascular risk factors, including insulin sensitivity, glycaemic control, circulating lipids and endothelial dysfunction markers.

\section{Objectives of this dissertation}

The main objective of this dissertation was to examine the effect of substituting sitting with LPA and MVPA on cardiometabolic health, when energy expenditure was comparable. Therefore, we examined the effects of LPA and MVPA on cardiovascular risk factors.

\section{Outline of this dissertation}

In chapter 2, we examined the difference between substituting sitting with LPA versus MVPA in relationship to insulin sensitivity and circulating lipids in healthy adults.

In chapter 3, we examined the effects of substituting sitting with LPA on insulin sensitivity, circulating lipids, mood and cognition in overweight/obese adults.

In chapter 4, we examined the difference between substituting sitting with LPA versus MVPA in relationship to glycaemic control, insulin sensitivity and circulating lipids in adults with type 2 diabetes.

In chapter 5, we examined the difference between substituting sitting with LPA versus MVPA in relationship to circulating endothelial markers, circulating lipids and insulin sensitivity in healthy adults, overweight/obese adults and adults with type 2 diabetes.

In chapter 6, we discussed the main results described in earlier chapters and placed these in a broader context including methodological considerations, implications for clinical practice and directions for future research. 



\section{CHAPTER 2}

MINIMAL INTENSITY PHYSICAL ACTIVITY (STANDING AND WALKING) OF LONGER DURATION IMPROVES INSULIN ACTION AND PLASMA LIPIDS MORE THAN SHORTER PERIODS OF MODERATE TO VIGOROUS EXERCISE (CYCLING) IN SEDENTARY SUBJECTS

BERNARD M.F.M. DUVIVIER, NICOLAAS C. SCHAPER, MICHELLE A. BREMERS, GLENN VAN CROMBRUGGE, PAUL P.C.A. MENHEERE, MARLEEN KARS, HANS H.C.M. SAVELBERG 


\section{Abstract}

Background Epidemiological studies suggest that excessive sitting time is associated with increased health risk, independent of the performance of exercise. We hypothesised that a daily bout of exercise cannot compensate the negative effects of inactivity during the rest of the day on insulin sensitivity and plasma lipids.

Methods Eighteen healthy subjects, age $21 \pm 2$ years, BMI $22.6 \pm 2.6 \mathrm{~kg} / \mathrm{m}^{2}$ followed randomly three physical activity regimens for four days. Participants were instructed to sit $14 \mathrm{~h} /$ day (sitting regimen); to sit $13 \mathrm{~h} /$ day and to substitute $1 \mathrm{~h}$ of sitting with vigorous exercise $1 \mathrm{~h}$ (exercise regimen); to substitute $6 \mathrm{~h}$ sitting with $4 \mathrm{~h}$ walking and $2 \mathrm{~h}$ standing (minimal intensity physical activity (PA) regimen). The sitting and exercise regimen had comparable numbers of sitting hours; and the minimal intensity PA and exercise regimen were designed to have comparable energy expenditure. PA was assessed continuously by an activity monitor (ActivPAL) and a diary. Measurements of insulin sensitivity (oral glucose tolerance test, OGTT) and plasma lipids were performed in the fasting state, the morning after the 4 days of each regimen.

Results In the sitting regimen, daily energy expenditure was about 300 and 500 kcal lower than in the exercise and minimal intensity PA regimens respectively. Area under the curve for insulin during OGTT was significantly lower after the minimal intensity PA regimen compared to both sitting and exercise regimens $6727.3 \pm 4329.4$ vs $7752.0 \pm 3014.4$ and $8320.4 \pm 5383.7 \mathrm{mU} \times \mathrm{min} / \mathrm{ml}$, respectively. Triglycerides, non-HDL cholesterol and apolipoprotein $B$ plasma levels improved significantly in the minimal intensity PA regimen compared to sitting and showed non-significant trends for improvement compared to exercise.

Conclusions One hour of daily physical exercise cannot compensate the negative effects of inactivity on insulin level and plasma lipids if the rest of the day is spent sitting. Reducing inactivity by increasing the time spent walking/standing of longer duration is more effective than shorter periods of physical exercise. 


\section{Introduction}

Balancing energy intake and expenditure is the current paradigm in promoting lifestyle related health behaviour and is the basis for many physical activity (PA) guidelines [37]. From the point of thermodynamics this focus is understandable and it is usually assumed that the beneficial effects of PA increase in parallel to its intensity, 'the more the better'. However, evidence is growing that sedentary time is a health risk factor on its own, independent of the practice of exercise. Television viewing time or sitting time in general is associated with increased mortality in epidemiological studies [38]. As reviewed elsewhere there is observational evidence for a positive relationship between sitting time and the risk of type 2 diabetes [22]. Experimental data from studies in rodents [39], as well as data from cross-sectional studies in humans [40-42], suggest that excessive sitting time is associated with adverse changes in circulating lipids and insulin sensitivity. Recent intervention studies also showed that short-term reduction of daily PA negatively affects insulin sensitivity. Reducing habitual physical activity during 2 weeks to approximately $15 \%$ resulted in a $17 \%$ decline of glucose infusion rate in a hyperinsulinaemic-euglycaemic clamp procedure [43]. In another more acute experiment, energy expenditure was reduced to $\sim 75 \%$ of the normal level during $24 \mathrm{~h}$, with and without a compensatory decrease in energy intake [44]. In the condition where energy intake was not decreased, insulin sensitivity was $39 \%$ lower; when the reduction in energy expenditure was compensated with a decrease in energy intake, insulin sensitivity was reduced by $18 \%$. These data suggest that inactivity may have negative effects on insulin sensitivity independent of energy balance.

Insulin resistance is thought to play a central role in the development of type 2 diabetes. Several lines of evidence indicate that physical inactivity can lead to skeletal muscle insulin resistance and possibly to lipid abnormalities [39-42]. Moderate to vigorous PA can markedly improve the metabolic consequences of a sedentary lifestyle, by increasing daily energy expenditure (DEE) and augmenting muscle insulin signalling [45]. Several research groups have shown that regular exercise can prevent type 2 diabetes and current guidelines recommend at least 150 minutes/week of moderate-to-vigorous PA [3]. Unfortunately, in our society many adults do not reach this activity goal [46]. Moreover, current guidelines provide no guidance how, besides the 150 minutes of moderate-tovigorous PA/week, the other 9930 minutes of the week should be spent. In the present study we tested the hypothesis that the negative metabolic effects of excessive sitting cannot be compensated by $1 \mathrm{~h}$ of daily physical exercise. We used activity monitors that measure 24/7 energy expenditure and posture allocation, enabling us to distinguish the effects of sedentarism from minimal daily physical activities. Under free living conditions, sitting time, physical exercise and daily energy expenditure were manipulated in healthy 
volunteers in three well controlled experimental conditions in order to determine the independent effects of excessive sitting on insulin sensitivity and circulating lipids.

\section{Methods}

\section{Subjects}

Twenty healthy volunteers (students of the Maastricht University, 17 females and 3 males) were recruited via advertisement. To be included in the study, participants had to perform physical exercise less than $1 \mathrm{~h} /$ week, their BMI should be between $20-30 \mathrm{~kg} / \mathrm{m}^{2}$ and their age between 18 to 30 years. Exclusion criteria were any drug use (except oral contraceptives); diseases which interfered with physical activities; frequent alcohol use (more than two units/day); fasting triglycerides $>3.0 \mathrm{mmol} / \mathrm{l}$ and a fasting plasma glucose $>6.0 \mathrm{mmol} / \mathrm{I}$. The study complied with the Declaration of Helsinki and was approved by the Local Ethics Committee of Maastricht University Medical Centre+; all participants gave written informed consent. The study was registered as NCT01299311 at ClinicalTrials.gov.

\section{Study design}

The study was performed under free living conditions and all participants were instructed to follow three activity regimens of four days each. A counterbalanced, randomised crossover design was used, in which participants served as their own controls (Fig. 1). In the sitting regimen subjects were instructed to sit $14 \mathrm{~h} /$ day, to walk $1 \mathrm{~h} /$ day, to stand 1 $\mathrm{h} /$ day and to spend $8 \mathrm{~h} /$ day sleeping or supine. In the exercise regimen $1 \mathrm{~h}$ of sitting was replaced by $1 \mathrm{~h}$ vigorous supervised bicycling per day, the rest of the day was spent similarly as during the sitting regimen. In the minimal intensity PA regimen subjects were instructed to replace $6 \mathrm{~h}$ of sitting with $4 \mathrm{~h}$ of walking at a leisure pace and with $2 \mathrm{~h}$ of standing. The sitting and exercise regimen had only $1 \mathrm{~h}$ difference in sedentary behaviour, but had considerably different energy expenditure. The exercise and minimal intensity PA regimens differed largely in time spent sitting or lying but were designed to have comparable energy expenditure. The intensity/duration of the physical exercise and duration of extra standing/walking during the exercise and minimal intensity PA regimens were chosen to result in the same increase in DEE (450 kcal) compared to the sitting regimen. The order of regimens was randomised. Besides vigorous cycling for $1 \mathrm{~h} / \mathrm{day}$ during the exercise regimen, any other kind of exercise was not allowed. Between every activity regimen a washout period of at least 10 days was scheduled. Subjects were asked to maintain their usual pattern of daily activities during these washout periods.

Subjects were instructed to consume the same caloric intake during each regimen and to maintain their usual dietary habits during the three activity regimens but dietary intake was not controlled, e.g. by providing meals or food ingredients. Subjects were not restricted in foods consumed except that they were asked to refrain from alcohol. During 
each activity regimen participants kept a food diary in which daily intake was entered and after each activity regimen they filled out a questionnaire on changes in health, medication and impact of the study on daily activities.

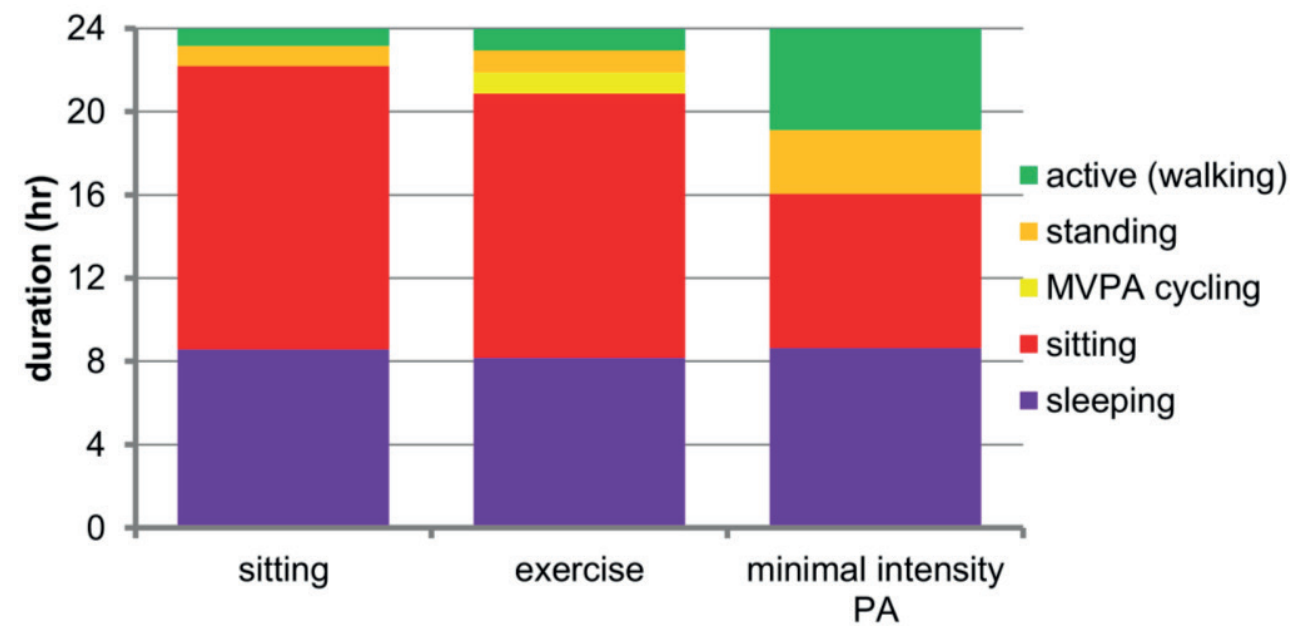

Fig. 1. Time spent on different activities per activity regimen. Graphical overview of time spent in different activity categories (sleeping, sitting, standing, MVPA cycling and activity (walking)) in the three regimens followed by the participants.

\section{Assessment of physical activity, postural allocation and energy expenditure}

During the four days of a regimen participants wore continuously ( $24 \mathrm{~h} /$ day) an ActivPAL ${ }^{\mathrm{TM}}$ activity monitor (PAL Technologies, Glasgow, Scotland) to quantify daily PA and postural allocation. The monitor was attached to the skin on the anterior aspect of the thigh using Tegaderm (3M $\left.{ }^{\mathrm{TM}}\right)$; non-wear was therefore not an issue. Waterproof wrapping of the monitors allowed wearing during water activities such as bathing. This accelerometerbased activity monitor discriminates time spent sitting or lying, standing and active. In addition stepping bouts and activity intensity were determined and energy expenditure was estimated. Validity and reliability of the ActivPAL in assessing activity pattern of free living healthy subjects has been shown previously [47]. In addition, participants reported in a diary every 15 minutes the time spent walking, standing and/or sitting during waking hours using a stopwatch. To ensure that the daily activities were according to the study protocol, all subjects performed a run-in day before the start of the activity periods; the activity pattern recorded on that day was used to formulate tailor-made instructions on how to change daily activities during the different regimens. Moreover, the ActivPAL data were evaluated and discussed after the first day of each regimen; subsequently subjects mailed their diary data every day and received electronic advice on their daily activities and posture allocation. In the exercise regimen, participants cycled for $1 \mathrm{~h}$ at Maastricht University Medical Centre+ on a bicycle ergometer (Bodyguard cardiocycle 975). To 
control intensity and energy expenditure of cycling the participants' heart rate was monitored continuously (Polar, Kempele, Finland). The model by Hiiloskorpi et al. [48] was used to calculate for each individual the heart rate that corresponded with $450 \mathrm{kcal}$ energy expenditure.

Based on the diaries the sleeping time was determined. To calculate sitting time the sleeping time was subtracted from the ActivPAL class 'sitting/lying'. In addition to the posture allocation, the ActivPAL assessed energy expenditure as metabolic equivalents (MET). By multiplying MET-values by estimated basal metabolic rate (BMR, HarrisBenedict equation), estimated energy expenditure as kcal was obtained. For the exercise condition $450 \mathrm{kcal}$ spent cycling was added. Data of posture allocation and energy expenditure were averaged over four days for each regimen.

\section{Insulin sensitivity and lipid metabolism assessment}

Measurements of insulin sensitivity (oral glucose tolerance test, OGTT) and plasma lipids were performed in the fasting state, the morning after the 4 days of each activity regimen at the Clinical and Translational Research Centre facility. The OGTT was chosen as a measure for insulin sensitivity because of its relative simplicity enabling a large number of measurements and its acceptable correlation with the gold standard (i.e. hyperinsulinaemic-euglycaemic clamp). The minimum time between the last bicycle exercise bout during the exercise regimen and the OGTT was $16 \mathrm{~h}$ (mean interval $20 \pm 2.6$ h). An i.v. catheter was placed in an antecubital vein for blood sampling. At baseline blood was sampled for analysis of glucose, insulin, C-peptide, triglycerides, total cholesterol, high- (HDL-C) and low-density-lipoprotein cholesterol (LDL-C), non-HDL cholesterol, apolipoprotein A-I and B (apo A-I and apo B). After ingestion of $75 \mathrm{~g}$ of glucose in $250 \mathrm{ml}$ of water, blood samples were drawn for glucose, insulin and C-peptide levels at 15, 30, 45, 60,90 , and 120 minutes.

Blood samples for glucose, total cholesterol, HDL-C, LDL-C, non-HDL cholesterol and triglycerides were determined the same day. Samples for insulin, C-peptide, apo A-I and apo $\mathrm{B}$ were stored at $-20^{\circ} \mathrm{C}$ until analysis after the end of the study. Plasma glucose, total cholesterol, HDL-C, triglycerides were colometric analysed on a Synchron LX20 Pro (Beckman Coulter). Insulin was measured with a double antibody radioimmunoassay Auto-Delfia (Perkin Elmer) and C-peptide with a double chemiluminiscent immunometric Immulite 2000 (Siemens). Apo A-I and apo B were nefelometric determined with a BN ProSpec (Siemens). LDL-C was calculated using the Friedewald formula [49].

\section{Statistical analysis and calculations}

If in the series of seven OGTT sample points one or two values missed, polynomial regression was used to assess the best fitting second or third degree polynomial through 
the available sample points. The best fitting polynomial was used to determine the missing sample points. For each of the OGTT measurement intervals, the product of the duration of the interval and the average insulin, glucose and C-peptide level respectively was calculated. The area under the curve for insulin, glucose and C-peptide curves for the $2 \mathrm{~h}$ period of the OGTT was calculated as the sum of these intervals. As a measure of insulin sensitivity, the insulin sensitivity index (ISI) was assessed [50].

All statistical analyses were executed with SPSS (SPSS 18, Chicago, IL, USA). Values are reported as mean \pm standard deviations. Variables were tested for normality and homogeneity. Repeated measures ANOVA was applied to evaluate the influence of the different regimens on plasma lipids, on areas under the curve (AUC) of insulin, glucose and C-peptide and on ISI. P-values of $\leq 0.05$ were considered statistically significant. If the repeated measures ANOVA revealed a statistically significant effect of the intervention, conditions were pairwise compared using a Least Significant Difference (LSD) test. Since the LSD test does not correct for multiple testing, only p-values less than $0.017(0.05 / 3)$ were considered significant in the pairwise comparison. To test whether changes in insulin sensitivity were associated with adaptations in plasma lipids, Pearson's correlation coefficients were calculated between changes in triglyceride concentration over the regimens and changes in ISI.

\section{Results}

Two subjects (one male, one female) withdrew before completing the protocol. The participants were on average 21 years of age, had a normal BMI with normal plasma lipid and glucose values (Table 1).

Table 1. Subject characteristics

\begin{tabular}{ll}
\hline Variables & Mean \pm SD \\
\hline $\mathbf{N}$ & 18 \\
\hline Age (years) & $21 \pm 2$ \\
\hline Height $(\mathrm{m})$ & $1.68 \pm 0.07$ \\
Weight $(\mathrm{kg})$ & $63.9 \pm 7.8$ \\
BMI $\left(\mathrm{kg} / \mathrm{m}^{2}\right)$ & $22.6 \pm 2.6$ \\
Fasting glucose $^{\mathrm{A}}(\mathrm{mmol} / \mathrm{l})$ & $4.61 \pm 0.31$ \\
Total cholesterol $^{\mathrm{A}}(\mathrm{mmol} / \mathrm{I})$ & $4.64 \pm 0.70$ \\
Triglycerides $^{\mathrm{A}}(\mathrm{mmol} / \mathrm{l})$ & $0.89 \pm 0.25$ \\
HDL-cholesterol $^{\mathrm{A}}(\mathrm{mmol} / \mathrm{l})$ & $1.45 \pm 0.34$ \\
LDL-cholesterol $^{\mathrm{A}}(\mathrm{mmol} / \mathrm{l})$ & $2.77 \pm 0.56$ \\
\hline${ }_{\mathrm{n}=17}$ &
\end{tabular}




\section{Physical activity, postural allocation and energy intake and expenditure}

The number of hours slept did not differ between the regimens and the study succeeded in manipulating independently inactivity time, walking/standing time and physical exercise (Table 2). During the exercise regimen all participants had a daily, $1 \mathrm{~h}$ bicycle exercise with a mean increase of heart rate of $52 \pm 3$ beats/min, resulting in an estimated energy expenditure of $367 \pm 5 \mathrm{kcal}$. Compared to the sitting regimen the time spent active (i.e. not sitting) but not exercising was somewhat higher during the exercise regimen, with approximately an extra of 1700 steps/day (table 2). Standing ( 2 h) and walking time (almost $4 \mathrm{~h}$ ) were markedly increased during the minimal intensity PA regimen compared to both other regimens; consequently the number of steps was 5 to 6 times higher during this regimen (Table 2). Based on the 24h ActivPAL data, energy expenditure during walking in the minimal intensity PA regimen was estimated to equal an average of 3 METs; this is classified as light intense physical activity [51]. Compared to the sitting regimen, estimated DEE was about 300 and $500 \mathrm{kcal}$ higher during the exercise and minimal intensity PA regimens respectively; estimated DEE was $238 \mathrm{kcal} /$ day higher during the minimal intensity PA in comparison to the exercise regimen: 2248 vs $2486 \mathrm{kcal} / \mathrm{day}(p<0.001)$. The self-reported caloric intake and the macronutrient composition did not differ between the regimens.

\section{Insulin sensitivity}

In six of 54 insulin and C-peptide curves and in 7 of 54 glucose curves one or two sample points were missing, these data were inputted using polynomial regression. In one glucose curve three sample points were missing, the remaining data were not used in the analyses. Insulin levels differed significantly between the regimens, insulin sensitivity index was nearly significant $(p=0.052)$. The ISI showed a trend for improvement after the minimal intensity PA regimen. Pairwise comparison revealed that the AUC for insulin in the OGTT was significantly smaller after the minimal intensity PA regimen than after the sitting $(p=0.010)$ and the exercise regimen $(p=0.002$; Table 2, Fig. $2 A)$. No major differences were observed in the glucose and $\mathrm{C}$-peptide levels before and during the OGTT after each regimen (Table 2, Fig. 2B and 2C).

\section{Plasma lipids}

Triglycerides $(p=0.007)$, non-HDL cholesterol $(p=0.011)$ and apo B concentrations $(p=0.022)$ were significantly affected by the different regimens; pairwise comparison revealed that, in comparison to the sitting regimen, these lipid measures were significantly reduced after the minimal intensity PA regimen (with approximately $22 \%, 10 \%$ and $8 \%$, respectively, Table 2). Triglycerides and non-HDL cholesterol showed a statistically, nonsignificant trend of improvement after the minimal intense PA condition compared to exercise. No effect of the exercise regimen was observed compared to the sitting regimen (Table 2). No major changes were observed in LDL-cholesterol, HDL-cholesterol and apo A- 
I. Changes over conditions in triglycerides concentration and ISI did not correlate. Pearson's correlation coefficient for changes in triglycerides and ISI between sitting and minimal intensity PA was $-0.113(p=0.665)$; for the changes between sitting and exercise it was $-0.388(p=0.112)$.
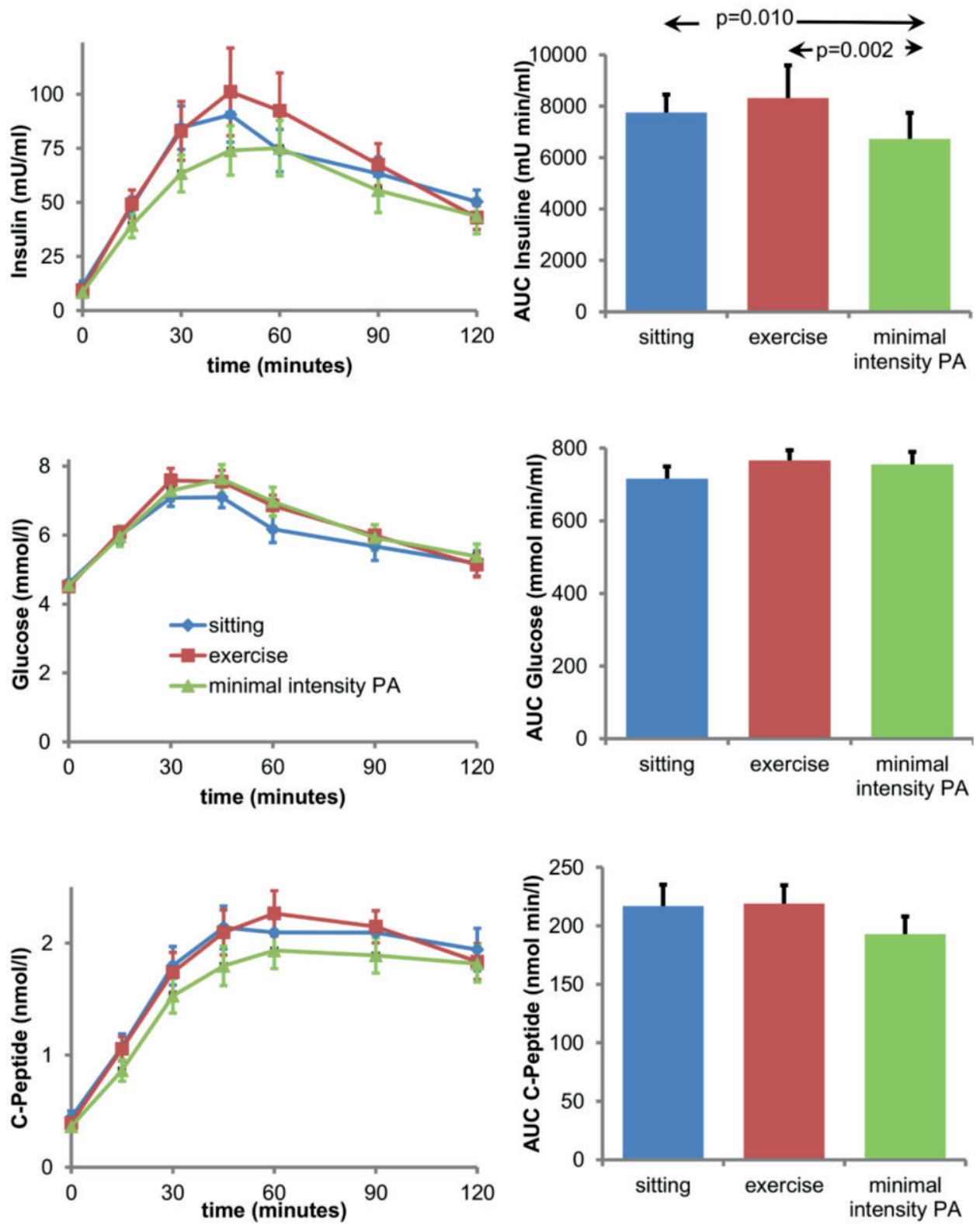

Fig. 2. Insulin, glucose and C-peptide concentration during oral glucose tolerance test. Average insulin, glucose and C-peptide levels for each of the three regimens during the oral glucose tolerance tests that were performed after each regimen (left hand panel) and average area under the curve for each of the three regimens (right hand panel). 
Table 2. Daily energy intake and energy expenditure, time spent in activity categories and glucose metabolism and plasma lipids

\begin{tabular}{|c|c|c|c|c|c|c|c|}
\hline Variables & Sitting & Exercise & $\begin{array}{l}\text { Minimal } \\
\text { Intensity PA }\end{array}$ & $\begin{array}{l}\text { P- } \\
\text { values }\end{array}$ & $\begin{array}{l}\text { P SIT } \\
\text { vs } \\
\text { EXE } \\
\end{array}$ & $\begin{array}{l}\text { P SIT } \\
\text { vs } \\
\text { MIPA }\end{array}$ & $\begin{array}{l}\text { P EXE } \\
\text { vs } \\
\text { MIPA }\end{array}$ \\
\hline El (kcal/d) & $1539(427)$ & $1477(352)$ & $1394(292)$ & 0.136 & & & \\
\hline Protein (g/d) & 61.1(14.8) & $59.7(13.5)$ & $55.6(13.4)$ & 0.165 & & & \\
\hline Fat $(g / d)$ & $54.5(14.7)$ & $50.2(19.6)$ & $50.1(12.2)$ & 0.248 & & & \\
\hline $\begin{array}{l}\text { Carbohydrate } \\
\text { (g/d) }\end{array}$ & 199.0(68.9) & 196.7(48.9) & $180.0(51.2)$ & 0.227 & & & \\
\hline $\mathrm{EE}^{\mathrm{A}}(\mathrm{kcal} / \mathrm{d})$ & 1934(88) & 2248(93) & $2486(121)$ & $<0.001$ & $<0.001$ & $<0.001$ & $<0.001$ \\
\hline Sitting $^{B}(h / d)$ & $13.6(1.2)$ & $12.7(1.7)$ & $7.4(1.3)$ & $<0.001$ & 0.002 & $<0.001$ & $<0.001$ \\
\hline $\begin{array}{l}\text { Standing } \\
\text { (h/d) }\end{array}$ & $0.99(0.50)$ & $1.08(0.48)$ & $3.08(0.88)$ & $<0.001$ & 0.166 & $<0.001$ & $<0.001$ \\
\hline $\begin{array}{l}\text { Walking }{ }^{B} \\
\text { (h/d) }\end{array}$ & $0.81(0.29)$ & $1.01(0.26)$ & $4.85(0.63)$ & $<0.001$ & 0.001 & $<0.001$ & $<0.001$ \\
\hline $\begin{array}{l}\text { Sleeping } \\
\text { (h/d) }\end{array}$ & $8.58(0.74)$ & $8.17(1.37)$ & $8.65(0.93)$ & 0.200 & & & \\
\hline Steps/day ${ }^{\mathrm{A}}$ & $4324(1485)$ & $6049(1402)$ & $27590(3724)$ & $<0.001$ & $<0.001$ & $<0.001$ & $<0.001$ \\
\hline $\begin{array}{l}\text { Triglycerides } \\
\text { (mmol/l) }\end{array}$ & $0.90(0.26)$ & $0.85(0.35)$ & $0.70(0.23)$ & 0.007 & 0.326 & 0.002 & 0.029 \\
\hline $\begin{array}{l}\text { Total Chol. } \\
\text { (mmol/l) }\end{array}$ & $4.20(0.67)$ & $4.11(0.60)$ & $3.96(0.50)$ & 0.171 & & & \\
\hline $\mathrm{HDL}$ (mmol/l) & $1.26(0.34)$ & $1.27(0.28)$ & $1.30(0.30)$ & 0.686 & & & \\
\hline $\begin{array}{l}\text { Non-HDL } \\
\text { (mmol/l) }\end{array}$ & $2.94(0.47)$ & $2.84(0.57)$ & $2.65(0.48)$ & 0.011 & 0.275 & 0.007 & 0.048 \\
\hline LDL (mmol/l) & $2.53(0.51)$ & $2.45(0.57)$ & $2.34(0.49)$ & 0.094 & & & \\
\hline Apo A-I (g/l) & $1.57(0.24)$ & $1.57(0.21)$ & $1.55(0.21)$ & 0.905 & & & \\
\hline Apo B (g/I) & $0.75(0.12)$ & $0.70(0.16)$ & $0.69(0.14)$ & 0.022 & 0.052 & 0.005 & 0.627 \\
\hline $\begin{array}{l}\text { Insulin } \\
\text { Sensitivity }\end{array}$ & $20.4(8.2)$ & $22.8(9.9)$ & $26.3(11.7)$ & 0.052 & 0.246 & 0.051 & 0.036 \\
\hline $\begin{array}{l}\text { Fasting } \\
\text { Glucose }^{\text {B }} \\
\text { (mmol/ml) }\end{array}$ & $4.6(0.4)$ & $4.5(0.3)$ & $4.5(0.4)$ & 0.681 & & & \\
\hline $\begin{array}{l}\text { Fasting } \\
\text { Insulin } \\
\text { (mU/ml) }\end{array}$ & $11.5(9.0)$ & $9.4(4.4)$ & $8.5(4.0)$ & 0.310 & & & \\
\hline $\begin{array}{l}\text { AUC Glucose } \\
(\mathrm{mmol} \\
\mathrm{min} / \mathrm{ml})\end{array}$ & 715.7(135.7) & 765.8(115.9) & $754.9(141.8)$ & 0.171 & & & \\
\hline $\begin{array}{l}\text { AUC insulin } \\
\text { (mU } \mathrm{min} / \mathrm{ml} \text { ) }\end{array}$ & $\begin{array}{l}7752.0 \\
(3015.4)\end{array}$ & $\begin{array}{l}8320.4 \\
(5383.7)\end{array}$ & $\begin{array}{l}6727.3 \\
(4329.4)\end{array}$ & 0.005 & 0.841 & 0.010 & 0.002 \\
\hline $\begin{array}{l}\text { AUC } \\
\text { C-peptide } \\
\text { (nmol } \mathrm{min} / \mathrm{I} \text { ) }\end{array}$ & $217.4(76.6)$ & $219.2(67.4)$ & 193.0(63.7) & 0.104 & & & \\
\hline
\end{tabular}

Data are presented as mean (SD). The fifth column represents the level of significance for repeated measurements ANOVA. Column six to eight give the statistical significance for pairwise comparisons of the regimens. For pairwise comparing, $p$-values less than 0.017 were considered statistically significant. ${ }^{A} n=16$; ${ }^{B}=17$; Chol., cholesterol; $E E$, Energy expenditure; El, Energy Intake; EXE, Exercise, MIPA, minimal intensity physical activity; SIT, sitting. 


\section{Discussion}

A sedentary lifestyle has become a major health threat in our affluent society [3]. Current guidelines on the prevention of cardiovascular disease promote at least $1 / 2 \mathrm{~h}$ moderate-tovigorous physical activity (MVPA) at least 5 days/week. They do not answer the question if, when DEE is held constant, such short bouts of exercise can compensate for the negative metabolic effects of inactivity. The present study, performed under free living conditions, suggests that $1 \mathrm{~h}$ of daily physical exercise cannot compensate for the negative effects of inactivity on insulin sensitivity and plasma lipids if the rest of the day is spent sitting. Vice versa, reducing sitting time by walking/standing was more effective in improving insulin level and lipid parameters than $1 \mathrm{~h}$ of moderate-to-vigorous bicycle exercise. This novel observation may have important health policy implications.

In the present study subjects were instructed during a run-in phase about the activity pattern and they received daily feedback. Subjects with a sedentary lifestyle were selected; both the ActivPAL data during the run-in phase and the questionnaires obtained at the end of the study suggested that the sitting regimen reflected their daily activities. During the sitting regimen they took approximately 4300 steps/day; less than 5000 steps/day is considered sedentary [52]. Participants followed the imposed regimens well and sleeping time was the same in the three regimens. While this study was designed to result in comparable DEE during the exercise and minimal intensity PA regimens, estimated DEE was about $200 \mathrm{kcal}$ higher during the minimal intensity PA regimen compared to the exercise regimen. As BMR was not measured, we cannot exclude that different activity regimens had different effects on BMR; this remains to be determined in future studies. Participants were instructed to consume the same caloric intake during the three regimens, and energy intake as well as meal composition were monitored with food diaries. Although such diaries are probably unreliable in absolute terms, participants probably did not alter their diet as no changes in energy intake and macronutrient composition were reported during the experimental conditions. Another limitation was that participants were not balanced over both sexes; the majority of subjects were females. Although, some studies have indeed shown sex differences in lipid metabolism, other authors did not show gender differences in insulin sensitivity or lipid metabolism in adaptation to physical activity. In previous bed rest studies inactivity led in both sexes to the development of insulin resistance [53] and resulted in similar effects on serum lipid and lipoprotein concentration for men and women [54]. In addition, Magkos et al. [55] showed that lipid metabolism was not influenced by menstrual cycle phase. Yeung et al. [56] reported change in insulin resistance over the menstrual cycle. In this study we did not control menstrual cycle. As the chance that menstrual phases match for all female participants similarly with the regimen is small, it is unlikely that the menstrual cycle affected the results. 
In line with earlier studies, we observed a positive, non-significant effect of physical exercise on triglycerides, non-HDL cholesterol and apo B as well as a (non-significant) $12 \%$ increase in insulin sensitivity. Physical exercise is currently seen as one of the cornerstones in the treatment of (sedentary) subjects with the metabolic syndrome and type 2 diabetes. However, MVPA seems to be a bridge too far for many of these subjects, due to lack of motivation, lack of time or physical impairments [46]. For instance, a 1 year walking programme had a drop-out rate of $65 \%$ in type 2 diabetic subjects [57]. The efficacy of such simple exercise programmes is hampered by the limitations caused by the underlying disease and by its complications. In a small population study in subjects with relatively well controlled type 2 diabetes we found that factors such as reduced muscle strength and diabetic neuropathy (present in $44 \%$ of the patients) were each associated with a reduction of the number of steps per day with approximately 30\% [58]. Moreover, when healthy subjects (mean age of 59 years) performed daily exercises in line with current guidelines, total DEE remained unaltered as the increase in energy expenditure was compensated with longer periods of inactivity during the rest of the day [59]. These studies suggest that especially for groups at risk both low compliance and compensatory behaviour can compromise the effect of MVPA on health.

Several epidemiological studies suggest that too much inactivity is detrimental for health [23, 40, 42, 60-62], data from experimental, interventional inactivity studies are however scarce. Traditionally, bed rest studies have been performed as model of inactivity, and already 3 days of bed rest can negatively affect insulin sensitivity [63], probably by disrupting muscle insulin signalling, and can result in a rise of fasting triglycerides [64]. However, it is questionable whether strict bed rest is a valid model for a sedentary lifestyle. An increase in sitting time for 2 weeks resulted in impaired peripheral insulin sensitivity in healthy volunteers [43]. However, it was not clear to which extent a positive energy balance contributed to this effect. This was addressed in a recent study, in which physical activity was reduced during 1 day in healthy volunteers, resulting in a decrease in DEE of approximately $800 \mathrm{kcal}$, with and without balancing energy intake. Although the largest effect was seen after a positive energy balance, insulin action was also impaired after inactivity when energy expenditure and intake were in balance [44]. However, this latter study did not address the question on how inactivity should be reduced, by a relative short bout of physical exercise or by substituting sitting with light intensity activities such as standing and walking at a leisurely pace. Recently, Dunstan et al. [65] showed that interrupting sitting time independent of the intensity of walking performed during the breaks had positive acute, effects on postprandial glucose and insulin levels, but in this study energy expenditure was not controlled. It cannot be concluded whether this positive effect of breaking sitting time is caused by the reduction of the sitting time or by the increased energy expenditure that concurred. 
To our knowledge this is the first study that separately manipulated sitting time, physical exercise and DEE in healthy, but sedentary subjects and the novel finding was that a 1 hour bout of physical exercise cannot completely compensate for the negative effects of inactivity on insulin, triglycerides, apo B and non-HDL cholesterol levels. From a traditional exercise physiological point of view, the results of this study might appear surprising; walking at a leisurely pace and standing were more effective than a high intensity physical exercise alternative. As argued by Hamilton et al. [66], we seem to have forgotten to ask 'what does inactivity do?'. The human body not only adapts to exercise initiated stresses, but as our results underline, it also reacts to inactivity, that is increasingly becoming the dominant lifestyle in westernised societies. In addition, this study underlines the importance of using strict definitions of terms like 'sedentary', 'inactivity', 'active', 'sports' and 'exercise' $[67,68]$. With respect to insulin and plasma lipid levels 'not participating in exercise or sports' does not necessarily have an identical effect as 'being sedentary', and oppositely 'to exercise daily' does not exclude a 'sedentary lifestyle' with negative metabolic effects, as shown in this study. Given the results of the present study, it is questionable whether replacing sitting by a daily bout of exercise would be desirable in sedentary subjects with the metabolic syndrome or with type 2 diabetes. This remains to be determined in further studies. The 22000 steps/day that concurred with the minimal intensity PA regimen seem to be quite a challenge, if it comes to implementation in daily living. Future studies need to explore the dose-response relation of minimal intensity PA.

Reducing sitting time with approximately $6 \mathrm{~h}$ resulted in this study in a marked $15 \%$ reduction in insulin levels and a non-significant $11 \%$ reduction in C-peptide levels. The lack of statistically significant differences in C-peptide levels was probably caused by a lack of statistical power due to the variability of the responses to the OGTT, as discussed above. Moreover, in comparison to the sitting regimen, triglycerides, non-HDL-cholesterol and apo $\mathrm{B}$ levels were $22 \%, 10 \%$ and $8 \%$ lower during minimal intensity PA. How, i.e. by which mechanism, inactivity and minimal intensity PA affect insulin sensitivity and plasma lipids remains to be determined. Given the short duration of each (in)activity regimen in our study, changes in microvascular perfusion or mitochondrial function seem less likely. The reduction in triglycerides is compatible with a beneficial effect of minimal intensity PA on free fatty acids (FFA) clearance and/or lipid oxidation and impaired lipid oxidation is thought to be one of the fundamental steps in inactivity induced insulin-resistance [64]. Adenosine monophosphate-activate protein kinase (AMPK) plays an important role in both insulin signalling and FFA oxidation, it is stimulated by muscle contractions and loss of AMPK activity might therefore be one of the detrimental consequences of inactivity [45]. Another possible mechanism underlying the changes in triglycerides might be a change in lipoprotein lipase (LPL) activity. As reviewed elsewhere, inactivity induces a decrease in LPL levels which can result in a blunted plasma triglyceride uptake; minimal intensity PA instead increases LPL activity and hereby increases triglyceride cellular uptake 
[66]. Indeed in our participants the greatest differences were found in triglyceride plasma levels and a decrease in LPL activity due to a prolonged sitting time may thus be -at least partially- responsible for the higher triglyceride levels in both the sitting and the exercise regimens.

In previous exercise studies, the activities during the rest of the day were often not controlled, in the present study we strictly controlled (in)activity behaviour $24 \mathrm{~h} /$ day. However, the duration of the interventions in the present study was relatively short (4 days) and in future studies the effects of the duration of inactivity need to be addressed, preferably also over longer periods. Moreover, more detailed assessment of insulin sensitivity, such as hyperinsulinaemic-euglycaemic clamp techniques, should be used to unravel the underlying mechanisms.

\section{Conclusions}

One hour of daily physical exercise cannot compensate for the negative effects of inactivity on insulin sensitivity and plasma lipids if the rest of the day is spent sitting. Reducing inactivity by low intensity activities such as walking at a leisurely pace and standing is more effective than physical exercise in improving these parameters in sedentary subjects. Our study suggests that in addition to health interventions that stress the importance of spending enough energy to maintain a neutral energy balance, a minimal daily amount of non-sitting time should also be promoted. 



\section{CHAPTER 3}

BENEFITS OF SUBSTITUTING SITTING WITH STANDING AND WALKING IN FREELIVING CONDITIONS FOR CARDIOMETABOLIC RISK MARKERS, COGNITION AND MOOD IN OVERWEIGHT ADULTS

BERNARD M.F.M. DUVIVIER, NICOLAAS C. SCHAPER, ANNEMARIE KOSTER, LINH VAN KAN, HARRY P.F. PETERS, JOS J. ADAM, TIMO GIESBRECHT, ESTHER KORNIPS, MARTINE HULSBOSCH, PAUL WILLEMS, MATTHIJS K.C. HESSELINK, PATRICK SCHRAUWEN, HANS H.C.M. SAVELBERG 


\begin{abstract}
Background We investigated whether substituting sitting with standing and selfperceived light walking in free-living conditions would improve cardiometabolic risk factors, mood and cognition in overweight/obese adults.
\end{abstract}

Methods In a randomised, cross-over study, 24 (m/f: 13/11) sedentary overweight/obese participants (64 \pm 7 years, BMI $29 \pm 2 \mathrm{~kg} / \mathrm{m}^{2}$ ) followed two activity regimens of each four days in free-living conditions: 'Sit': sitting $13.5 \mathrm{~h} / \mathrm{day}$, standing 1.4 $\mathrm{h} /$ day, self-perceived light-intensity walking $0.7 \mathrm{~h} /$ day; for 'SitLess' these activities lasted 7.6, 4.0 and $4.3 \mathrm{~h} /$ day, respectively. Meals were standardised and physical activity was assessed by accelerometry (activPAL). Insulin sensitivity (expressed as Matsuda-index based on an oral glucose tolerance test), circulating lipids, blood pressure, mood (pleasantness and arousal) and cognition were assessed on the morning after the activity regimens. Quality of life and sleep were assessed on the last day of the activity regimens.

Results We observed that AUC (0-190 min) for insulin decreased by $20 \%$ after SitLess vs. Sit (10125 [656] vs. 12633 [818]; p=0.006). Insulin sensitivity improved by $16 \%$ after SitLess vs. Sit (Matsuda-index, mean [SEM]: 6.45 [0.25] vs. 5.58 [0.25] respectively; $\mathrm{p}=0.007)$. Fasting triglycerides, non-HDL-cholesterol and apolipoprotein B decreased by $32 \%, 7 \%$ and $4 \%$ respectively, whereas HDL-cholesterol increased by $7 \%$ after SitLess vs. Sit (all $p<0.01$ ). Diastolic blood pressure was lower after SitLess vs. Sit $(p<0.05)$. Pleasantness (as one marker of mood status) after the oral glucose tolerance test was higher after SitLess vs. Sit $(p<0.05)$. There was no significant difference between regimens for cognition, quality of life and sleep.

Conclusions Reducing sitting time in free-living conditions markedly improved insulin sensitivity, circulating lipids and diastolic blood pressure. Substituting sitting with standing and self-perceived light walking is an effective strategy to improve cardiometabolic risk factors in overweight/obese subjects. 


\section{Introduction}

Observational studies suggest that the majority of the Western population spends more than half of the waking day sedentary $[20,21]$. Mounting evidence shows an association between a high sitting time and obesity [69-71]. In addition to the health risks associated with overweight and obesity [72, 73], a sedentary lifestyle has been associated with an increased risk of type 2 diabetes, metabolic syndrome, and premature mortality [21, 22]. This negative consequence of sitting seems to be independent of the time spent in moderate-to-vigorous physical activity [21,22]. Hence, interventions reducing sitting time may improve cardiometabolic health in these individuals. Indeed, laboratory studies showed beneficial effects on circulating glucose and insulin in overweight and obese adults when sitting was interrupted every 20-30 min with light walking [33, 34, 74]. However, as recently pointed out by the American Heart Association, interventions in free-living conditions that reduce sitting time are very scarce [28].

Apart from its cardiometabolic consequences, obesity has also been associated with an increased risk of mood disorders [75] and reduced cognitive function [76]. This increased risk may partly originate from obesity related insulin resistance in the brain [77]. Vice versa, improvements in insulin sensitivity have been linked to improvements in mood and cognition [78, 79]. Several studies have shown that engaging in moderate-to-vigorous physical activity not only improves insulin sensitivity [12], but also mood [80] and cognition [81]. However, to which extent these beneficial effects also hold true for light physical activity is unclear.

In the present study, we investigated whether substituting sitting with standing and selfperceived light walking in free-living conditions improved insulin sensitivity and other cardiometabolic risk factors in sedentary overweight/obese individuals. Moreover, we explored whether reducing sitting time also improved mood and cognition.

\section{Methods}

\section{Participants}

Adults aged $40-80$ years with a BMI between $25-35 \mathrm{~kg} / \mathrm{m}^{2}$, were recruited through paper advertisements at Maastricht University and through online and newspaper advertisements outside Maastricht University. During screening, every individual performed a 1 day try-out of the SitLess regimen to ensure that the participant was able to carry out the SitLess regimen in free-living conditions. Physical activity was measured during 4 days (including one weekend day) in free-living conditions before the start of the study. Exclusion criteria were more than $2.5 \mathrm{~h} /$ week of moderate-to-vigorous physical activity based on self-report, diseases which interfered with physical activities, weight loss (>2 kg) in the last three months, alcohol abuse, experimental drug use, use of glucose 
lowering drugs, corticosteroids or coumarins or fasting plasma glucose $>6.9 \mathrm{mmol} / \mathrm{l}$. Throughout the study, drug administration and usage remained unaltered. All participants provided written informed consent. The study was conducted at Maastricht University between February and September 2015. (www.clinicaltrials.gov, NCT02394249).

This study was carried out in accordance with the recommendations of the Local Ethics Committee of the Maastricht University Medical Centre+ with written informed consent from all subjects. All subjects gave written informed consent in accordance with the Declaration of Helsinki. The protocol was approved by the Local Ethics Committee of the Maastricht University Medical Centre+.

\section{Study design}

The primary outcome was Area Under the Curve (AUC) for plasma insulin during an Oral Glucose Tolerance Test (OGTT). Based on an earlier study in healthy subjects with a similar design [82], the number of subjects required was calculated. Based on mean difference \pm SD in AUC for insulin (1257.5 $\pm 2293.5 \mathrm{mU} / \mathrm{I} \times \mathrm{min}$ ) between the two activity regimens and a two-sided alpha of 0.05 , we calculated that 21 subjects would be needed to detect a difference of $1500 \mathrm{mU} / \mathrm{I} \times$ min between the SitLess and the Sit regimen with a power of $80 \%$ using a paired-samples t-test. To account for a $15 \%$ drop-out after randomisation, 25 subjects were included.

\section{The activity regimens}

All participants were instructed to follow two activity regimens in free-living conditions, lasting four days each (Sit and SitLess). The study had a randomised cross-over design. Randomisation was performed by a computer programme with a block size of two intervention orders; each pair of included persons received another regimen order. The study design is displayed in Fig. 1. During Sit, participants were instructed to restrict walking and standing to $\leq 1 \mathrm{~h} /$ day each, spending the remainder of the waking day sitting. During SitLess, participants were instructed to substitute at least $7 \mathrm{~h} /$ day of sitting with $\geq 4$ $\mathrm{h}$ of self-perceived light walking and $\geq 3 \mathrm{~h}$ of standing; and to interrupt sitting preferably every $30 \mathrm{~min}$ with standing/walking bouts. Subjects were instructed to walk at a selfperceived light-intensity. Adherence to these instructions was monitored by accelerometry (see below). There was a wash-out period of at least 10 days between the screening session and the first activity regimen, and between the two activity regimens. During the wash-out, participants were instructed to maintain their habitual pattern of daily life activities, not to perform more than $1 \mathrm{~h} /$ week of moderate-to-vigorous physical activity and to consume a maximum of 1 unit/day of alcohol. 


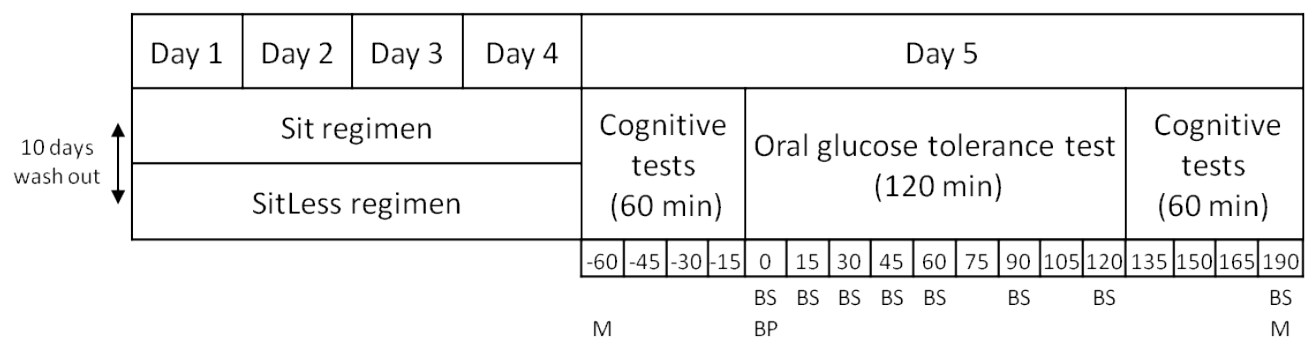

Fig. 1. Study design. BP, blood pressure; BS, blood sample; M, mood assessment.

\section{Meal standardisation}

During the activity regimens, subjects were instructed to adhere to their normal diet. During the first regimen, participants carefully recorded everything they ate and drank of these consumptions in a diary. These records were returned to the participants who were instructed to consume the same diet during the second activity regimen. Alcohol was not permitted during the activity regimens. In order to achieve identical energy intake and meal composition in the $12 \mathrm{~h}$ before the final measurements, participants received identical pre-packaged meals for dinner on the last day of each activity regimen. The prepackaged meals included a main meal (vegetables, potatoes and chicken or pork, 409 $437 \mathrm{kcal}, 11.3$ - $15.8 \mathrm{~g}$ fat, 45.0 - $51.8 \mathrm{~g}$ carbohydrates, 20.3 - 22.5 g protein) and a dessert (yoghurt, $150 \mathrm{kcal}, 3.8 \mathrm{~g}$ fat, $13.1 \mathrm{~g}$ carbohydrates, $2.9 \mathrm{~g}$ protein). The subjects were instructed to consume this meal at home before 22.00 and to refrain from food or drinks after this meal except for water.

\section{Assessment of physical activity}

Physical activity and posture allocation were measured $24 \mathrm{~h} /$ day using an activPAL3 activity monitor (PAL Technologies, Glasgow, Scotland). The monitor was attached waterproof to the skin on the anterior thigh using Tegaderm (3M, St. Paul, Minnesota, USA) at least one day before each activity regimen. This accelerometer accurately discriminates between time spent inactive (sitting or lying), standing, walking [83] and step number [84]. Since the activPAL programme does not provide sleeping time automatically, sleeping time was determined with a validated algorithm [85], which was implemented as a Matlab (Mathworks, Natick, MA) programme. Diary data for selfreported physical activity were compared with the activPAL3 data to formulate tailormade instructions on how to change daily activities after the first and third days of each activity regimen to guarantee optimal compliance to each activity regimen.

\section{Oral glucose tolerance test}

After each activity regimen (day 5), the subjects came to the research centre between 8:30 and 9:30 AM after an overnight fast and an OGTT was performed. After an 
acclimatisation period of $10 \mathrm{~min}$, blood pressure was measured three times with an Omron 705IT blood pressure monitor (Omron Healthcare Europe B.V., Hoofddorp, The Netherlands). An i.v. catheter was placed in an antecubital vein for blood sampling. At baseline, blood was sampled for analysis of glucose, insulin, C-peptide, triglycerides, free fatty acid (FFA) levels, total cholesterol, high-density-lipoprotein (HDL) and low-densitylipoprotein (LDL) cholesterol, non-HDL-cholesterol, apo A-I and B100. After ingestion of 75 $\mathrm{g}$ of glucose in water (200 $\mathrm{ml}$ in total), blood samples were drawn for glucose, insulin and C-peptide levels at 15, 30, 45, 60, 90, 120 and $190 \mathrm{~min}$. Blood samples were stored at $80^{\circ} \mathrm{C}$ until analysis after the end of the study. Insulin and C-peptide were measured using a Human Insulin Specific RIA kit (HI-14K, Millipore) and a Human C-peptide RIA kit (HCP-20K, Millipore) respectively. Radioactivity was count on a 2470 Automatic Gamma Counter (Perkin Elmer). Plasma glucose, total cholesterol, HDL-cholesterol, triglycerides, free fatty acids, apo A-I and apo B100 were spectrophotometrically analysed on the ABX Pentra 400 (Horiba) and free glycerol on a Cobas Fara (Roche). Plasma samples were precipitated with $1 / 10$ volume of sulfosalicylic acid, placed on ice for $25 \mathrm{~min}$, and then centrifuged at maximal speed. Free glycerol was measured in the supernatant. LDL-cholesterol was calculated using the Friedewald formula [49]. Non-HDL-cholesterol was calculated as total cholesterol minus HDL-cholesterol.

\section{Mood and cognition}

Cognitive performance and mood were measured before and after the OGTT, based on the principle that by applying a challenge (in this case the glucose load), one might be better able to measure the impact of interventions, such as physical activity [86]. Mood was assessed with the Affect Grid test; which is a $19 \times 19$ single-item measure, assessing the self-reported degree of pleasantness and arousal of the participants [87]. Verbal memory (immediate and delayed) was assessed with Rey's Verbal Learning Test [88], executive function was assessed with the Trail Making Test [89, 90], and attention with the Attention Network Test covering the dimensions alerting, orienting and executive function [91]. On day 4 of each activity regimen, quality of life was assessed with a 32-item questionnaire of [92] and sleep quality was assessed with the 10-item Pittsburgh Sleep Quality Index [93].

\section{Data processing and statistical analysis}

The AUC over a period of 190 min after glucose ingestion was calculated for insulin and Cpeptide using the trapezoidal rule approach [94]. For glucose, the positive incremental area under the curve (iAUC) was calculated as the AUC above the baseline level. Insulin sensitivity, expressed as the Matsuda index, was calculated based on glucose and insulin values during the first $120 \mathrm{~min}$ of the OGTT [95]. All statistical calculations were performed using SAS (version 9.4, Cary, NC, USA) or IBM SPSS (version 21, Armonk, NY, USA). The differences in blood related outcome parameters and blood pressure between 
the activity regimens were analysed using linear mixed model analyses including the activity regimen, order of the activity regimens and baseline characteristics as fixed factors. Since associations between sedentary behaviour and cardiometabolic risk factors have previously been reported to be stronger in women [96], sex was added to the model as a co-variate. For the AUC and iAUC calculations, values at $\mathrm{t}=0$ were added as fixed factor to the model. For the mood scores (arousal and pleasantness), the linear mixed model included time as a categorical variable including its interaction with activity regime, values at $\mathrm{t}=0$ and order of testing. The residual error structure was described with an $\mathrm{ARH}(1)$-covariance matrix to handle variance heterogeneity at the time points. Similar analyses were performed for the cognitive parameters. For some subjects, part of the mood and cognition data was excluded from the statistical analysis due to technical errors during the mood and cognition tests. A log transformation was performed for glucose, insulin, C-peptide and diastolic blood pressure. Numerical variables are presented as mean \pm SD for baseline characteristics, mean \pm standard error (SEM) for cardiometabolic risk factors and LSmeans $(95 \% \mathrm{Cl})$ for mood and cognition. P-values $\leq 0.05$ were considered statistically significant.

\section{Results}

\section{Subjects}

After screening 25 subjects (13 men, 12 women) were included. Before completing the protocol, one female participant withdrew because of cholangitis. The remaining 24 participants had a mean age of $64 \pm 7$ years and BMI of $29.4 \pm 2.3 \mathrm{~kg} / \mathrm{m}^{2}$ (Table 1). Female participants had a significantly higher BMI and lower age and height than male participants.

Table 1. Subject characteristics

\begin{tabular}{|c|c|c|c|}
\hline Variables & Total & Men & Women \\
\hline $\mathbf{N}$ & 24 & 13 & 11 \\
\hline Age (years) ${ }^{A}$ & $64 \pm 7$ & $67 \pm 2$ & $59 \pm 9$ \\
\hline Height $(m)^{A}$ & $1.72 \pm 0.08$ & $1.76 \pm 0.07$ & $1.68 \pm 0.07$ \\
\hline Weight (kg) & $87.1 \pm 9.7$ & $88.3 \pm 9.6$ & $85.7 \pm 10.1$ \\
\hline BMI $\left(\mathrm{kg} / \mathrm{m}^{2}\right)^{\mathrm{A}}$ & $29.4 \pm 2.3$ & $28.5 \pm 1.7$ & $30.5 \pm 2.5$ \\
\hline Waist circumference $(\mathrm{cm})^{\mathrm{B}}$ & $104 \pm 10$ & $104 \pm 8$ & $103 \pm 11$ \\
\hline Systolic blood pressure (mmHg) & $143 \pm 17$ & $148 \pm 15$ & $136 \pm 18$ \\
\hline Diastolic blood pressure (mmHg) & $83 \pm 9$ & $83 \pm 9$ & $82 \pm 8$ \\
\hline Fasting glucose (mmol/l) & $5.5 \pm 0.6$ & $5.5 \pm 0.5$ & $5.4 \pm 0.7$ \\
\hline
\end{tabular}

Data are presented as mean \pm SD. ${ }^{A} p<0.05$ for sex; ${ }^{B} n=12$ for men, $n=10$ for women. 
Five participants were using cholesterol lowering drugs (statins) and six participants were using blood pressure lowering drugs ( 3 angiotensin receptor blockers, 2 calcium channel blockers, 1 ACE-inhibitor, 1 beta blocker).

\section{Insulin sensitivity}

After the activity regimens, there was no significant difference in the iAUC for glucose between Sit and SitLess (Table 2). AUC for insulin (Table 2; Fig. 2) decreased by $20 \%$ after SitLess vs. Sit (mean [SEM]: 10125 [656] vs. 12633 [818]; $p=0.006$ ). As a result, insulin sensitivity (Fig. 3) was 16\% higher after SitLess vs. Sit (Matsuda-index: 6.45 [0.25] vs. 5.58 [0.25] respectively; $p<0.001)$. The AUC for $C$-peptide was $7 \%$ lower $(p=0.032)$ after SitLess vs. Sit. In subgroup analyses the iAUC for glucose in women was lower after SitLess vs. Sit $(-32 \% ; p=0.006)$, while no significant difference was observed in men $(+14 \% ; p=0.266)$. No sex-differences were observed in Matsuda-index and AUC for insulin and C-peptide.

a

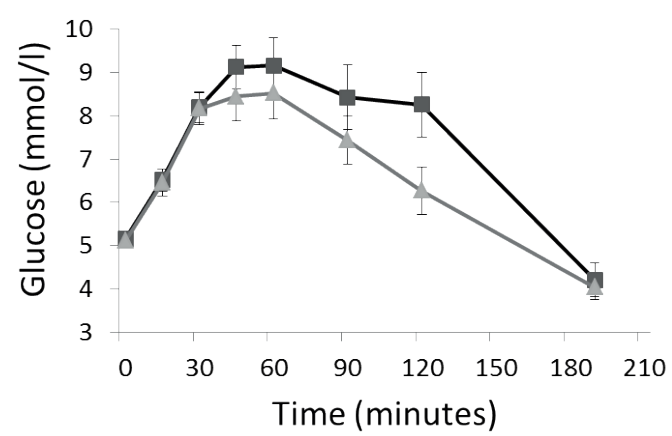

C

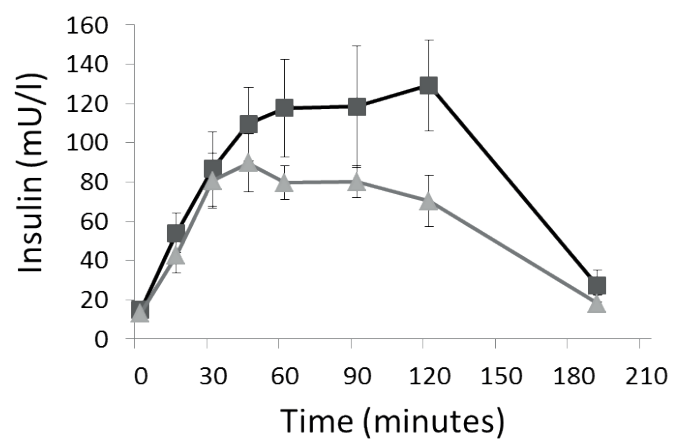

b

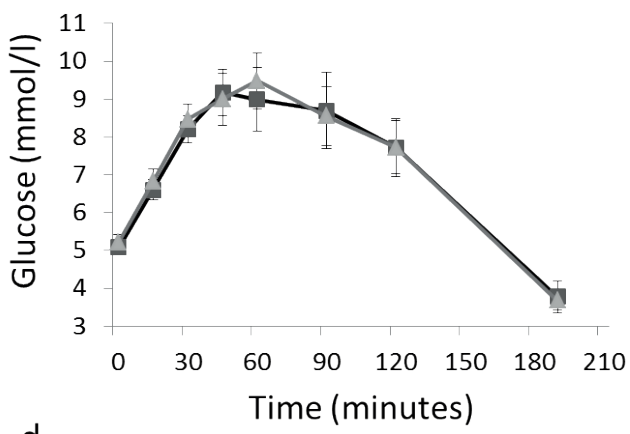

d

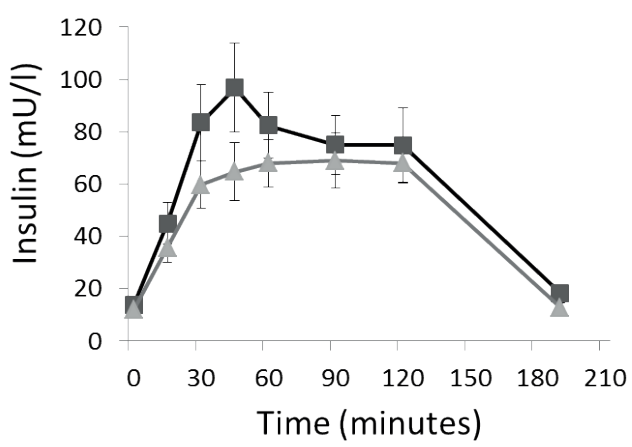

Fig. 2. Glucose and insulin responses to an oral glucose tolerance test. Measurements performed on the morning after the Sit $(\boldsymbol{\square})$ and SitLess $(\Delta)$ regimens for respectively women $(a, c)$ and men $(b$, d). iAUC for glucose in women was lower after Sitless vs. Sit $(p=0.006)$, but not in men $(p=0.266)$. AUC for insulin was significantly lower after SitLess vs. Sit in men and women $(p=0.006)$. Means and standard error bars are presented. 


\section{Circulating lipids and blood pressure}

After the activity regimens, triglycerides, total cholesterol, non-HDL-cholesterol and apolipoprotein B were lower following SitLess vs. Sit by $32 \%, 4 \%, 7 \%$ and $4 \%$ respectively (all $p<0.01$; Table 2; Fig. 3). HDL-cholesterol was $7 \%$ higher $(p<0.001)$ and FFA levels were $17 \%$ higher $(p=0.014)$ after SitLess vs. Sit. Diastolic blood pressure was lower after SitLess vs. Sit $(p=0.043)$. Systolic blood pressure, heart rate, apolipoprotein A and free glycerol did not differ significantly between Sit and SitLess. In subgroup analyses, the magnitude of triglyceride attenuation was significantly greater in men $(-38 \% ; p<0.001)$ than in women $(-27 \% ; p<0.001)$ after SitLess vs. Sit. No sex-differences were observed in the other lipid variables, blood pressure and heart rate.

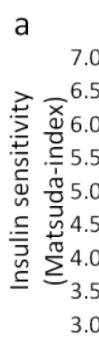

C

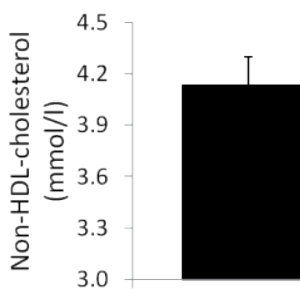

Sit

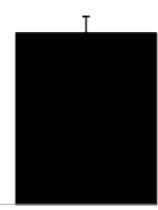

Sit b

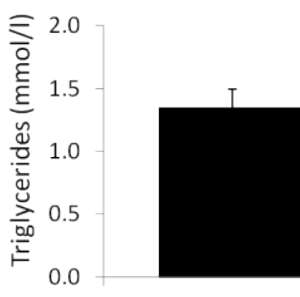

Sit

d

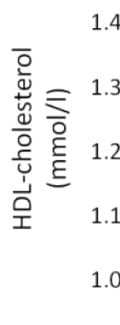

1.4

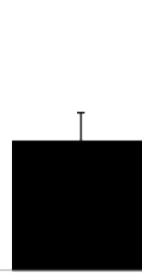

Sit

Fig. 3. Insulin sensitivity and plasma lipids. Matsuda-index as a measure for insulin sensitivity (a), triglycerides (b), non-HDL-cholesterol (c) and HDL-cholesterol (d) on the morning after the activity regimens. Means and standard error bars are presented. $* * p<0.01 ; * * * p<0.001$. 
Table 2. Cardiometabolic risk factors

\begin{tabular}{|c|c|c|c|}
\hline Variables & Sit & SitLess & P-value \\
\hline Fasting glucose (mmol/l) & $5.1(0.1)$ & $5.2(0.1)$ & 0.153 \\
\hline Glucose iAUC $(\mathrm{mmol} / \mathrm{I} \times \mathrm{min})$ & $367(40)$ & $325(36)$ & 0.159 \\
\hline Fasting insulin (mU/l) & $13.2(1.0)$ & $11.4(0.9)$ & 0.003 \\
\hline Insulin AUC (mU/I × min) & $12633(818)$ & $10125(656)$ & 0.006 \\
\hline Fasting C-peptide (ng/ml) & $1.75(0.12)$ & $1.53(0.10)$ & $<0.001$ \\
\hline C-peptide AUC $(\mathrm{ng} / \mathrm{ml} \times \mathrm{min})$ & $1187(42)$ & 1104 (39) & 0.032 \\
\hline Apolipoprotein A-I (g/I) & $1.45(0.03)$ & $1.46(0.03)$ & 0.366 \\
\hline Apolipoprotein B100 (g/l) & $1.07(0.04)$ & $1.03(0.03)$ & 0.007 \\
\hline Free fatty acids (mmol/l) & $0.59(0.03)$ & $0.69(0.04)$ & 0.014 \\
\hline Free glycerol (mmol/l) & $0.14(0.01)$ & $0.16(0.01)$ & 0.062 \\
\hline Systolic BP (mmHg) & $138(4)$ & $137(3)$ & 0.729 \\
\hline Diastolic BP (mmHg) & $81(1)$ & $79(1)$ & 0.043 \\
\hline HR (beats/min) & $64(2)$ & $62(2)$ & 0.170 \\
\hline
\end{tabular}

Data are presented as mean (SEM). bold, $\mathrm{p}<0.05$. BP, blood pressure;

$\mathrm{HR}$, heart rate; iAUC, incremental AUC.

\section{Mood and cognition}

After the activity regimens, we performed measurements of mood and cognition both before the OGTT in the fasted state, as well as after an OGTT. Before the OGTT, pleasantness was not different between the activity regimens for the total group, although a non-significant improvement $(p=0.059)$ was observed in women after SitLess vs. Sit (estimated change $2.20,95 \% \mathrm{Cl}:-0.08$ to $4.48 ; n=10$; Fig. 4). After the OGTT, pleasantness was significantly higher after SitLess vs. Sit $(1.67 ; \mathrm{Cl}: 0.09$ to $3.25 ; \mathrm{n}=21)$ in the total group; this could mainly be explained by a significant difference in pleasantness in the female subjects after SitLess vs. Sit $(2.80 ; \mathrm{Cl}: 0.52$ to $5.08 ; n=10)$. There was no significant difference in the alerting, orienting and executive dimensions of attention between the activity regimens, neither before nor after the OGTT. Only in female subjects after the OGTT, alertness was significantly higher (-14.8 msec; $\mathrm{Cl}$ : -29.1 to $-0.5 ; n=11$ ) after SitLess vs. Sit. There were no significant differences in memory, executive function, quality of life and sleep between the activity regimens. 
a
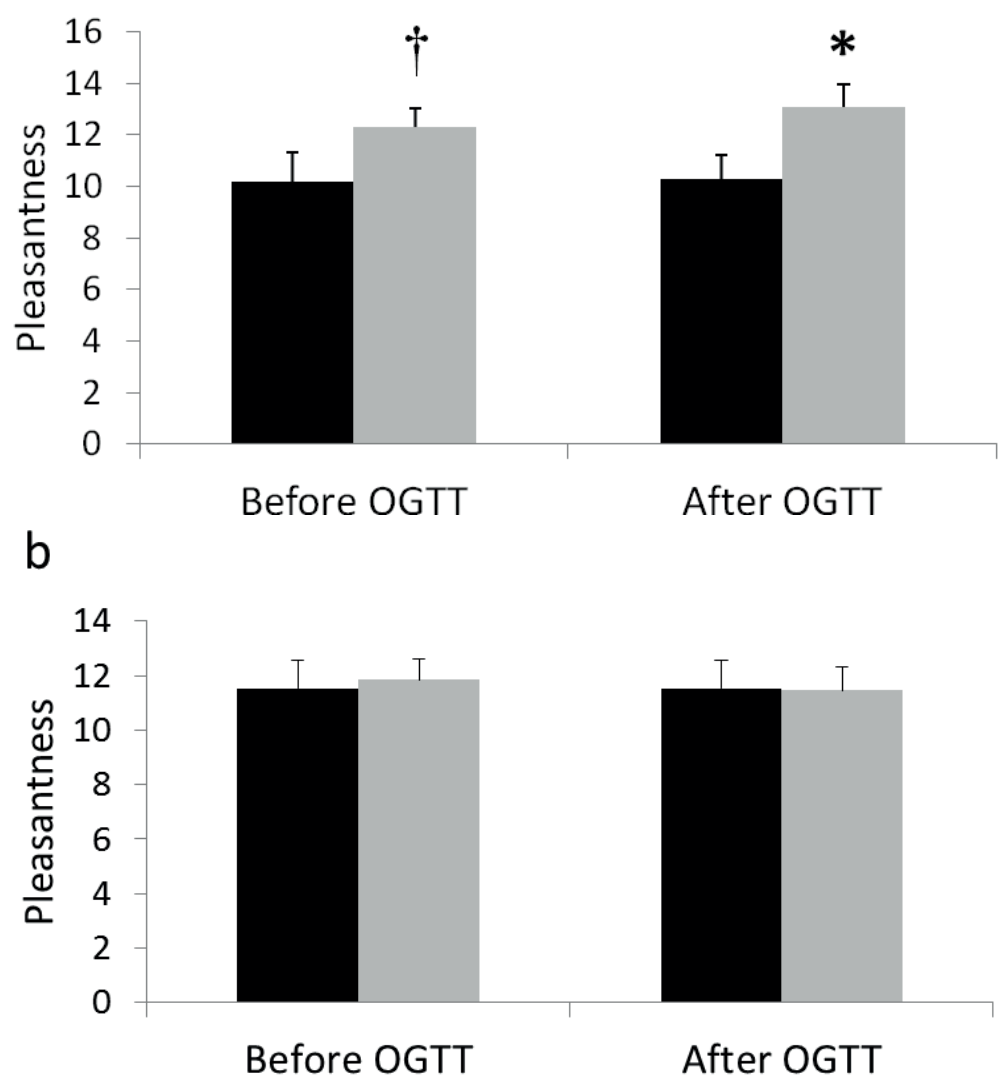

Fig. 4 Pleasantness one day after the SitLess (grey) and Sit (black) regimens in women (a) and men (b). Pleasantness was measured before (-60 $\mathrm{min})$ and $190 \mathrm{~min}$ after administering an oral glucose drink (OGTT). ${ }^{*} p<0.05 ; \mathrm{\dagger}=0.059$.

\section{Physical activity and diet}

At baseline (before the start of the study), time spent sitting/lying was $18.4 \pm 1.6 \mathrm{~h} /$ day, walking $1.8 \pm 0.6 \mathrm{~h} /$ day and standing $3.8 \pm 1.2 \mathrm{~h} /$ day. During the activity regimens, time spent sitting, walking, and standing in free-living conditions were successfully altered in accordance with the protocol (Table 3). During SitLess, time spent sitting (7.6 h/day), walking $(4.0 \mathrm{~h} /$ day) and standing $(4.3 \mathrm{~h} /$ day) were significantly different than during Sit (13.5 h/day sitting, $0.7 \mathrm{~h} /$ day walking and $1.4 \mathrm{~h} /$ day standing). Sedentary bouts $>30 \mathrm{~min}$ were significantly lower during SitLess ( 3.9 bouts) compared to Sit ( 8.5 bouts). Sleeping time was comparable between SitLess $(8.0 \mathrm{~h} /$ day) and Sit $(8.2 \mathrm{~h} /$ day). Energy intake did not differ significantly between the activity regimens, neither did the percentage macronutrients consumed (Table 3). 
Table 3. Physical activity and diet

\begin{tabular}{|c|c|c|c|}
\hline Variables & Sit & SitLess & P-value \\
\hline \multicolumn{4}{|l|}{ Physical activity } \\
\hline Sitting (h/day) & $13.5(0.2)$ & $7.6(0.3)$ & $<0.001$ \\
\hline Standing (h/day) & $1.4(0.1)$ & $4.0(0.2)$ & $<0.001$ \\
\hline Walking (h/day) & $0.7(0.1)$ & $4.3(0.1)$ & $<0.001$ \\
\hline Sleeping (h/day) & $8.2(0.2)$ & $8.0(0.2)$ & 0.027 \\
\hline Steps/day (n) & $3228(187)$ & $24626(509)$ & $<0.001$ \\
\hline Sedentary bouts $>30 \mathrm{~min}$ ( $\mathrm{n} /$ day) & $8.5(0.3)$ & $3.9(0.2)$ & $<0.001$ \\
\hline \multicolumn{4}{|l|}{ Diet } \\
\hline Energy intake (kcal/day) & $1930(77)$ & $1943(94)$ & 0.669 \\
\hline Carbohydrates (\%) & $47.3(1.4)$ & $47.9(1.3)$ & 0.422 \\
\hline Protein (\%) & $17.8(0.7)$ & $18.0(0.8)$ & 0.491 \\
\hline Fat (\%) & $34.8(1.3)$ & $34.1(1.2)$ & 0.205 \\
\hline Saturated fat (\%) & $13.3(0.5)$ & $13.3(0.5)$ & 0.723 \\
\hline
\end{tabular}

Daily activities (activPAL data) and diet (diary data) during each activity regimen. Data are presented as mean (SEM). bold, $\mathrm{p}<0.05$.

\section{Discussion}

In the current study, we observed that substituting sitting with standing and selfperceived light walking improved insulin sensitivity, circulating lipids and diastolic blood pressure in overweight/obese subjects. Interestingly, while other studies reported positive effects on plasma glucose and insulin during interruptions in sitting time [33, 35, 97], we observed improvements in insulin sensitivity one day after the SitLess intervention, suggesting that this beneficial effect persists into the next day. These results build on our previous findings in young healthy [82] and diabetic adults [98], strongly suggesting that light activities are a very effective measure to improve insulin sensitivity.

In addition to the effects on insulin sensitivity, we observed major improvements in circulating lipids after the SitLess regimen. Interestingly, the magnitude of the changes was comparable or larger than observed with exercise. Thus, exercise training has consistently been shown to increase HDL-cholesterol levels; a meta-analysis of RCT's reported an average $0.06 \mathrm{mmol} / \mathrm{l}$ increase when adhering to the exercise ( $150 \mathrm{~min} /$ week) guidelines [99]. In comparison, the SitLess regimen in our study resulted in an HDLcholesterol increase of $0.08 \mathrm{mmol} / \mathrm{l}$. To our knowledge, we are the first to show an increase in HDL-cholesterol after an acute sit less intervention. Hence, light activities such as standing and light walking seem to be effective in increasing HDL-cholesterol levels to a similar degree as exercise. In line with this result, we also observed a profound reduction in triglycerides (-32\%) as well as a reduction in non-HDL-cholesterol, apolipoprotein B and 
diastolic blood pressure after the SitLess regimen, suggesting that reducing sitting time improves the cardiometabolic profile even further.

Our results may be especially important for sedentary overweight/obese subjects as these individuals are at high risk of developing cardiometabolic disease [72, 73]. It was recently observed that each additional hour of sitting increased the odds for type 2 diabetes and metabolic syndrome by $22 \%$ respectively $39 \%$ [21]. Engaging in structured exercise as a countermeasure is a challenge for many individuals. Less than $5 \%$ of the population adheres to the exercise guidelines [100] and physical activity has been reported to be even lower in people who are obese $[70,71]$. Hence, reducing sedentary behaviour might be a more feasible alternative. Strategies to reduce sitting time are generally considered less demanding than structured exercise programmes and hence are more likely to have long term compliance [101]. Our observations suggest that substituting sitting with light activities may have major cardiometabolic benefits and could potentially reverse the adverse cardiometabolic risk that is associated with sedentary behaviour.

We observed sex-differences in glucose tolerance between the activity regimens. In comparison to the Sit regimen, SitLess lowered glucose iAUC levels significantly in female participants (-32\%), but did not differ significantly in male participants (+14\%). In contrary, the magnitude of triglyceride attenuation was significantly greater in men than in women after the SitLess regimen. These differences could not be explained by sex-differences in physical activity or diet during the activity regimens. The sex-differences for glucose are in line with a recent intervention study in obese adults with type 2 diabetes [32], in which postprandial glucose levels were also significantly lower in women (-58\%) than in men (26\%) when sitting was interrupted with self-perceived light-intensity walking. It is possible that sex-differences in adipose and lean muscle mass can explain our observations; however, these variables were not measured in our study. Further studies should shed light on the underlying mechanisms explaining these possible sex-differences.

We observed that insulin sensitivity improved after the SitLess intervention, which is consistent with previous findings reporting an upregulation of the insulin signalling pathway after 3 days of interrupting sitting with light-intensity walking [102]. The decrease in triglyceride levels after the SitLess regimen could possibly be explained by enhanced lipoprotein lipase activity; thus, physical activity increases lipoprotein lipase mRNA and typically peaks $\geq 4 \mathrm{~h}$ after physical activity [103] and our results suggest that light-intensity activity may already be sufficient to elicit such effect. An inverse relationship is known to exist between the triglycerides and HDL-cholesterol levels. During exercise, the action of cholesterol esther transfer protein (CETP) produces triglyceride-rich HDL2 particles, resulting in an HDL-cholesterol increase [104]. Therefore, the reduction in triglycerides could have contributed to the increase in HDL-cholesterol following the 
SitLess regimen. We also observed, in line with previous exercise [105] and light-intensity activity studies [34,98], that FFA levels were higher following the SitLess regimen. This increase in FFA levels was accompanied by a non-significant $(p=0.06)$ increase in free glycerol and may therefore result from elevation of adipose tissue lipolysis to fuel muscle for contractile activity [106].

In addition to cardiometabolic risk factors, we also explored the effects of reducing sitting time on mood and cognition. We observed significant improvements following the SitLess regimen in pleasantness after the OGTT in women. This result is in line with a recent study that observed sex-differences in mood response to exercise [107]. Also, alertness was somewhat higher after the OGTT in women following the SitLess regimen. Further research is necessary to assess the robustness of these sex-differences observed.

Strengths of our study include the cross-over randomised design in free-living conditions. Also, adherence to the activity regimens was according to the protocol which was measured $24 \mathrm{~h} /$ day by a validated activity monitor. Diet was standardised and energy intake and macronutrient percentage did not differ between the activity regimens. However, the study was not powered to detect differences in mood and cognition or to detect sex-differences. Hence, these findings should be considered exploratory and need replication. This study was a proof-of-concept study of short duration, and as a result the number of steps during the SitLess regimen (about 25000 steps/day) was well above what is on average observed in a healthy population (about 6000 - 13000 steps/day) [108]. Thus, the next logical step is to perform dose-response studies to inform about the optimal duration and pattern of time spent standing and light walking and its feasibility in real life circumstances. It also needs to be established whether the acute changes observed in this study persist on the longer-term.

\section{Conclusions}

In conclusion, our study suggests that substituting sitting with standing and self-perceived light walking is a very effective strategy to improve insulin sensitivity, circulating lipids and diastolic blood pressure in sedentary overweight/obese subjects. Particularly for overweight/obese individuals, these results may be important as strategies to reduce sitting time are generally considered less demanding than structured exercise programmes. 



\section{CHAPTER 4}

BREAKING SITTING WITH LIGHT ACTIVITIES VS STRUCTURED EXERCISE: A RANDOMISED CROSSOVER STUDY DEMONSTRATING BENEFITS FOR GLYCAEMIC CONTROL AND INSULIN SENSITIVITY IN TYPE 2 DIABETES

BERNARD M.F.M. DUVIVIER, NICOLAAS C. SCHAPER, MATTHIJS K.C. HESSELINK, LINH VAN KAN, NATHALIE STIENEN, BJORN WINKENS, ANNEMARIE KOSTER, HANS H.C.M. SAVELBERG 


\section{Abstract}

Background We aimed to examine the effects of breaking sitting with standing and lightintensity walking vs an energy-matched bout of structured exercise on $24 \mathrm{~h}$ glucose levels and insulin resistance in patients with type 2 diabetes.

Methods In a randomised crossover study, 19 patients with type 2 diabetes (13 men/6 women, $63 \pm 9$ years old) who were not using insulin each followed three regimens under free-living conditions, each lasting 4 days: (1) Sitting: 4415 steps/day with $14 \mathrm{~h}$ sitting/day; (2) Exercise: 4823 steps/day with $1.1 \mathrm{~h} /$ day of sitting replaced by moderate- to vigorousintensity cycling (at an intensity of 5.9 metabolic equivalents [METs]); and (3) Sit Less: 17502 steps/day with $4.7 \mathrm{~h} /$ day of sitting replaced by standing and light-intensity walking (an additional $2.5 \mathrm{~h}$ and $2.2 \mathrm{~h}$, respectively, compared with the hours spent doing these activities by the Sitting group). Blocked randomisation was performed using a block size of six regimen orders using sealed, non-translucent envelopes. Individuals who assessed the outcomes were blinded to group assignment. Meals were standardised during each intervention. Physical activity and glucose levels were assessed for $24 \mathrm{~h} / \mathrm{day}$ by accelerometry (activPAL) and a glucose monitor (iPro2), respectively. The incremental AUC (iAUC) for $24 \mathrm{~h}$ glucose (primary outcome) and insulin resistance (HOMA2-IR) were assessed on days 4 and 5 , respectively.

Results The iAUC for $24 \mathrm{~h}$ glucose (mean \pm SEM) was significantly lower during the Sit Less intervention than in Sitting $(1263 \pm 189 \mathrm{~min} \times \mathrm{mmol} / \mathrm{l}$ vs $1974 \pm 324 \mathrm{~min} \times \mathrm{mmol} / \mathrm{l}$; $\mathrm{p}=0.002$ ), and was similar between Sit Less and Exercise (Exercise: $1383 \pm 194 \mathrm{~min} \times$ $\mathrm{mmol} / \mathrm{l} ; \mathrm{p}=0.499)$. Exercise failed to improve HOMA2-IR compared with Sitting (2.06 \pm 0.28 vs $2.16 \pm 0.26 ; p=0.177)$. In contrast, Sit Less $(1.89 \pm 0.26)$ significantly reduced HOMA2-IR compared with Exercise $(p=0.015)$ as well as Sitting $(p=0.001)$.

Conclusions Breaking sitting with standing and light-intensity walking effectively improved $24 \mathrm{~h}$ glucose levels and improved insulin sensitivity in individuals with type 2 diabetes, to a greater extent than structured exercise. Thus, our results suggest that breaking sitting with standing and light-intensity walking may be an alternative to structured exercise to promote glycaemic control in patients with type 2 diabetes. 


\section{Introduction}

Moderate- to vigorous-intensity exercise is one of the cornerstones of prevention and treatment of type 2 diabetes [109, 110], with current physical activity guidelines recommending performance of at least $150 \mathrm{~min} /$ week exercise at these intensities [3]. Although this approach has proved effective in the prevention [111] and treatment [15] of type 2 diabetes, more than $90 \%$ of healthy adults do not adhere to these guidelines [19]. In view of type 2 diabetes-related comorbidities such as muscle weakness and peripheral neuropathy, which can be a barrier to physical activity [58], non-compliance may be even higher in individuals with type 2 diabetes. Alternatives to exercise are therefore needed for the treatment of type 2 diabetes.

The results of population-based studies suggest that the average adult spends more than half of the waking day sedentary, partaking in activities such as watching television and using the computer [20-22]. Recent evidence from observational studies shows an association between sedentary time and an increased risk of type 2 diabetes, independent of the time spent exercising [21, 22]. Experimental studies under laboratory conditions suggest that regular interruption of sitting using small bouts of walking may be effective in lowering glucose and insulin levels in healthy and overweight/obese adults and in individuals with type 2 diabetes [33-35, 97, 112]. We recently showed that replacing sitting time with standing and light-intensity walking in free-living conditions was more efficient at improving insulin action than replacement with one bout of moderate- to vigorous-intensity exercise (cycling) in healthy sedentary participants [82]. Since energy expenditure was comparable by design during these two conditions, these data suggest that sitting has negative effects on insulin sensitivity independent of energy expenditure.

To investigate whether these findings could be replicated in individuals with type 2 diabetes, we investigated whether, under conditions of comparable energy expenditure, breaking up sitting time with standing and light-intensity walking would improve $24 \mathrm{~h}$ glucose levels and insulin sensitivity in type 2 diabetes patients as compared with structured exercise. To our knowledge, this is the first study investigating the glycaemic effects of breaking up sitting time in people with type 2 diabetes in free-living conditions.

\section{Methods}

\section{Participants}

Adults with type 2 diabetes (minimum duration of 1 year), aged $40-75$ years and with a $\mathrm{BMI}$ of $25-35 \mathrm{~kg} / \mathrm{m}^{2}$, were recruited through online and paper advertisements. Exclusion criteria were more than $2.5 \mathrm{~h} /$ week of moderate- to vigorous-intensity exercise based on self-report, diseases that interfered with physical activity participation, alcohol abuse, experimental drug use and use of insulin, corticosteroids, coumarins or 
immunosuppressants. Participants were instructed to discontinue lipid-lowering drugs and cholesterol-lowering margarines 14 days prior to starting the first regimen. Use of other drugs was continued and maintained at the same dose during the study. Other exclusion criteria were fasting triacylglycerol $>10 \mathrm{mmol} / \mathrm{l}$, fasting plasma glucose $\geq 11 \mathrm{mmol} / \mathrm{l}$ or $\mathrm{HbA}_{1 \mathrm{c}}>10 \%$ (86 mmol/mol). All participants provided written informed consent. The study was conducted at Maastricht University between February and May 2015 in accordance with the principles of the Declaration of Helsinki, and was approved by the Local Ethics Committee of the Maastricht University Medical Centre+ (www.clinicaltrials.gov, registration no. NCT02371239).

\section{Study design}

The study used a randomised crossover design, and the analysis of the primary and secondary outcomes was performed without knowledge of which activity regimen the participant had been allocated to. Blocked randomisation was performed using a block size of six regimen orders using sealed, non-translucent envelopes. The number of participants required to detect a clinically relevant difference in $24 \mathrm{~h}$ glucose profiles between the activity regimens was calculated based on a similar study [113] with three study arms (sedentary, low-intensity exercise and high-intensity exercise), in which the mean \pm SD $24 \mathrm{~h}$ glucose was $8.7 \pm 2.1 \mathrm{mmol} / \mathrm{l}$ during the high-intensity exercise regimen. Using these data, and assuming equal SDs in each of our regimens, a correlation between repeated measurements of 0.5 and a Bonferroni corrected two-sided alpha of 0.017 $(=0.05 / 3)$, it was calculated that 19 participants were needed to detect a mean difference of $1.7 \mathrm{mmol} / \mathrm{l}$ in $24 \mathrm{~h}$ glucose between the activity regimens, with a power of $80 \%$, using a paired-samples $t$ test.

\section{Activity regimens}

All participants were instructed to follow three activity regimens ('Sitting', 'Exercise' and 'Sit Less'; see Fig. 1). The order of intervention was randomised and each regimen lasted 4 days and was carried out in free-living conditions. During the Sitting regimen, participants were instructed to restrict walking to $1 \mathrm{~h}$ /day and standing to $1 \mathrm{~h} /$ day while spending the remainder of the waking day ( $14 \mathrm{~h}$ ) sitting. During the Exercise regimen, about $1 \mathrm{~h} /$ day of sitting time was replaced with supervised cycling on an ergometer (Lode Excalibur, Groningen, the Netherlands) at our research centre. To increase the feasibility of the exercise, cycling was performed in the morning at least $2 \mathrm{~h}$ after breakfast to prevent (abdominal) discomfort during cycling. Cycling was carried out in 20 min bouts with a 5 min rest (sitting) after each bout. In the Sit Less regimen, participants were instructed to replace approximately $5 \mathrm{~h} /$ day sitting with $2 \mathrm{~h}$ walking and $3 \mathrm{~h}$ standing. Participants were instructed to break up their sitting time, preferably every $30 \mathrm{~min}$, by dividing the walking/standing activities into smaller bouts over the day. They were instructed to walk 
at a self-perceived light-intensity. Importantly, adherence to these instructions was carefully monitored by advanced accelerometry (see below).

A wash-out period of at least 10 days between the screening session and the first activity regimen, and between successive activity regimens, was applied. During the wash-out phase, participants were instructed to maintain their habitual pattern of daily life activities, not to perform more than $1 \mathrm{~h} /$ week of moderate- to vigorous-intensity exercise and to consume a maximum of 1 unit/day of alcohol.

\section{Meal standardisation}

During the first $60 \mathrm{~h}$ of each regimen, participants were instructed to adhere to their normal diet. During the last $36 \mathrm{~h}$ of each regimen, standardised pre-packaged meals were provided based on the individual's basal metabolic rate, and matched to each individual's daily energy requirements (this was calculated by multiplying the basal metabolic rate [determined during screening using a ventilated hood] by 1.4 [reflective of the physical activity level of a sedentary lifestyle]) [114]. During the first regimen, participants carefully recorded everything they ate and drank, as well as the timing of consumptions. Subsequently, these records were returned to the participants, who were instructed to consume the same diet at the same time points during the following two regimens. Alcohol was not permitted during regimen participation.

\section{Assessment of $\mathbf{2 4} \mathrm{h}$ glucose, insulin resistance and lipids}

During the activity regimens, glucose levels were continuously measured ( $24 \mathrm{~h} /$ day) with a glucose monitor (iPro2 Professional CGM MiniMed; Medtronic, Northridge, CA, USA) connected to a glucose sensor (Enlite Glucose Sensor MiniMed; Medtronic). The sensor was inserted subcutaneously on the first morning of each regimen, at $5 \mathrm{~cm}$ from the umbilicus, on the right side of the abdomen. To investigate the cumulative effects of the 4 day activity regimens, $24 \mathrm{~h}$ glucose levels were only analysed on day 4; therefore, standardised meals were provided by the research team for dinner on day 3 and for all meals and snacks during day 4.

Glucose concentration was measured in the interstitial fluid of the subcutaneous tissue every $5 \mathrm{~min}$ via the iPro2. Additionally, participants collected blood glucose measurements four times per day (before main meals and before sleep) using a capillary glucose meter (Accu-Chek; Roche Diagnostics India, Mumbai, India), which were used for calibration at the time of iPro2 data upload. On the day after the 4 day regimen, following an overnight fast, blood was collected for glucose, insulin and lipid measurements. For each participant, blood was procured at the exact same time during each regimen (between 08:30 and 09:30 AM). 


\section{Assessment of physical activity and estimated energy expenditure}

Physical activity was measured $24 \mathrm{~h}$ /day using an activPAL3 monitor (PAL Technologies, Glasgow, Scotland). The activPAL was waterproofed with a small sleeve to cover the monitor, wrapped in one piece of medical-grade adhesive dressing (Tegaderm; 3M, Saint Paul, MN, USA) and then attached to the anterior thigh using Tegaderm (3M) on the first morning of each activity regimen. As the activPAL data from day 1 did not cover the entire day, only activPAL data from the last $72 \mathrm{~h}$ of each regimen were analysed. This accelerometer accurately discriminates between time spent inactive (sitting or lying), standing and walking [83], giving step number and cadence [84]. Diary data for selfreported physical activity were compared with the activPAL data after the first and third days of each activity regimen to formulate tailor-made instructions on how to alter daily activities in order to guarantee optimal compliance with each activity regimen. Time spent sleeping was determined based on the diary data.

Daily energy expenditure was estimated using the $24 \mathrm{~h}$ activPAL data, which yielded this information as metabolic equivalents (METs). The measurement error of the activPAL in estimating this energy expenditure has been reported to be low for sedentary and lightintensity activities but high for moderate- and vigorous-intensity activities [115]. Thus, the Compendium of Physical Activities [116] was used to determine the energy expenditure of cycling by generating a linear regression line from studies in the compendium that provided MET values over a range of workloads representative of the population in our study. Consequently, the energy expenditure of cycling was determined using the following equation: $\mathrm{MET}=0.0545 \times$ watt $+1.4561 ; R^{2}=0.946$, using each participant's workload in watts to determine individual energy expenditure. The Exercise and Sit Less regimens were designed to have comparable energy expenditure. To achieve this, during screening, every individual performed a 1 day try-out of the Sit Less regimen in free-living conditions, a maximal workload capacity $\left(\mathrm{W}_{\max }\right)$ test (a progressive cycle test until exhaustion while cardiac function was monitored) and an additional $1 \mathrm{~h}$ supervised cycle test, each on separate days. Estimated energy expenditure, as derived from the activPAL data during the Sit Less try-out day, was used as the input for computing the duration ( 1 h) and workload (50-60\% $W_{\max }$ ) for cycling during the Exercise regimen. Normal daily activities were measured thirteen days prior to the start of the study ('day -13 ') and participants were asked not to cycle on this day. 


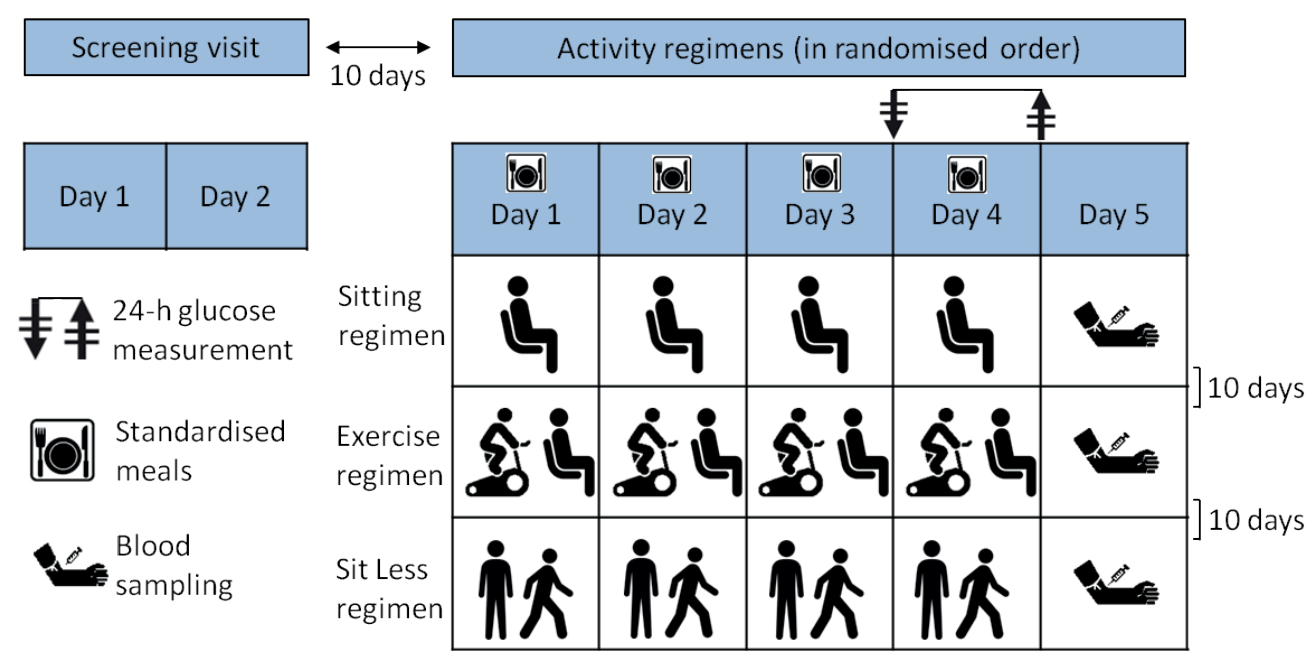

Fig. 1. Study design. Each participant followed three activity regimens under free-living conditions, each lasting 4 days: (1) Sitting: sitting 14 h/day; (2) Exercise: 1.1 h/day of sitting replaced by moderate- to vigorous-intensity cycling; and (3) Sit Less: $4.7 \mathrm{~h} /$ day of sitting replaced by standing $(2.5 \mathrm{~h})$ and light-intensity walking $(2.2 \mathrm{~h})$, relative to time spent doing these activities in the Sitting regimen.

\section{Data processing and statistical analysis}

All data were double-entered. The continuous glucose monitoring data were analysed using an iPro2 (Medtronic). The last $24 \mathrm{~h}$ of each regimen, starting with the first fingerprick before breakfast, were chosen for analysis of the $24 \mathrm{~h}$ glucose levels since meals were identical between interventions during this period. Mean $24 \mathrm{~h}$ glucose concentration was defined as the average glucose of 288 measurements equally spaced in time. The incremental AUC (iAUC) for glucose was calculated using the trapezoid rule [94]. The iAUC provides a summary measure of the increase above fasting glucose level during the subsequent $24 \mathrm{~h}$ observation period. A secondary outcome was total AUC (all values above zero). Hyperglycaemia was defined as a glucose level of $\geq 10.0 \mathrm{mmol} / \mathrm{l}$, whilst hypoglycaemia was defined as a glucose concentration $\leq 3.9 \mathrm{mmol} / \mathrm{l}$ plus clinical symptoms. To examine whether bouts of cycling or walking resulted in a rapid decrease in glucose levels, the average glucose decrease during each $30 \mathrm{~min}$ time frame was calculated using continuous glucose monitoring, resulting in 288 values over $24 \mathrm{~h}$. The HOMA2 computational method (www.dtu.ox.ac.uk, accessed 1 December 2015) [117] was used to estimate insulin resistance (HOMA2-IR) using fasting plasma glucose and insulin values measured on the day after completion of the 4 day regimen.

All statistical calculations were performed using IBM SPSS Statistics for Windows (Version 21; Armonk NY, USA). The differences in outcome between regimens were analysed using linear mixed model analyses with activity regimen and period (order of activity regimen) as fixed factors, and an unstructured covariance structure for the three repeated 
measurements for each person. Natural log transformation was performed if the outcome was not normally distributed. Likelihood-based methods were used without imputing missing outcome values. Numerical variables are presented as mean $\pm \mathrm{SD}$, or as median (first quartile, third quartile) for baseline characteristics (measured during screening) and estimated mean (SEM) for the other values. A p-value of $\leq 0.05$ was considered statistically significant. When regimens were compared pairwise, $p$-values $\leq 0.017(=0.05 / 3$, Bonferroni correction) were considered statistically significant to account for multiple testing (three pairwise comparisons).

\section{Results}

After screening, 20 participants (14 men, six women) were included in the study (see Supplemental Fig. 1 for recruitment flow chart). Before completing the protocol, one participant withdrew because of osteoarthritis-related pain during walking. The remaining 19 individuals had a mean age of 63 years and a mean BMI of $30.5 \mathrm{~kg} / \mathrm{m}^{2}$ (Table 1 ).

Table 1. Participant characteristics

\begin{tabular}{|c|c|}
\hline Variables & Mean (SD) \\
\hline $\mathbf{N}$ & 19 \\
\hline Men (n) & 13 \\
\hline Age (years) & $63(9)$ \\
\hline Duration of diabetes (years) ${ }^{A}$ & $6(4,10)$ \\
\hline Glucose-lowering drugs (n) & 14 \\
\hline Lipid-lowering drugs (n) & 13 \\
\hline Height (m) & $1.70(0.07)$ \\
\hline Weight (kg) & $88.8(12.0)$ \\
\hline BMI $\left(\mathrm{kg} / \mathrm{m}^{2}\right)$ & $30.5(3.3)$ \\
\hline Waist circumference $(\mathrm{cm})$ & $105(8)$ \\
\hline$W_{\max }(W)$ & $152(43)$ \\
\hline Systolic BP (mmHg) & $143(12)$ \\
\hline Diastolic BP (mmHg) & $82(8)$ \\
\hline Glucose (mmol/l) & $7.88(1.51)$ \\
\hline Triacylglycerol (mmol/l) & $1.51(0.55)$ \\
\hline $\mathrm{HbA}_{1 \mathrm{c}}(\%)$ & $6.7(3.0)$ \\
\hline $\mathrm{HbA}_{1 \mathrm{c}}(\mathrm{mmol} / \mathrm{mol})$ & $49.5(8.8)$ \\
\hline
\end{tabular}

Data are expressed as mean (SD) or ${ }^{A}$ median (first quartile, third quartile). 
The median duration of type 2 diabetes was 6 years and participants had a mean $\mathrm{HbA}_{1 \mathrm{c}}$ of $6.7 \%(49.5 \mathrm{mmol} / \mathrm{mol})$ and mean fasting plasma glucose of $7.88 \mathrm{mmol} / \mathrm{l}$ during screening (Table 1). Fourteen participants were using oral glucose-lowering drugs (metformin, $n=14$; sulfonylurea, $n=7$; sitagliptin, $n=2$ ), and 13 were using lipid-lowering drugs (statins, $n=12$; ezetimibe, $n=2)$.

\section{Continuous glucose monitoring}

In the Sit Less regimen, substitution of time spent sitting by ambulatory time significantly reduced $24 \mathrm{~h}$ glucose levels compared with Sitting (mean (SEM) Sit Less vs Sitting: 7.35 (0.19) vs 7.69 (0.23) $\mathrm{mmol} / \mathrm{l} ; \mathrm{p}=0.014$; Fig. 2 and Fig. 3a). In contrast, 24-hour glucose levels were not significantly different between Sit Less and the more classical Exercise regimen, involving structured exercise (Exercise: 7.29 (0.24) $\mathrm{mmol} / \mathrm{l} ; \mathrm{p}=0.741$ ). Similar results were obtained for total AUC (Table 2). Sit Less profoundly reduced glucose levels (by approximately 36\%) compared with the Sitting regimen; i.e. the iAUC for $24 \mathrm{~h}$ glucose levels reduced significantly from 1974 (324) $\mathrm{min} \times \mathrm{mmol} / \mathrm{l}$ in the Sitting regimen, to 1263 (189) $\mathrm{min} \times \mathrm{mmol} / \mathrm{l}$ in the Sit Less regimen ( $\mathrm{p}=0.002$; Figs 2 and 3a). Glucose excursion (iAUC) for $24 \mathrm{~h}$ glucose was similar between Sit Less and Exercise $(p=0.499)$. Although structured exercise also reduced the $24 \mathrm{~h}$ glucose excursion (iAUC 1383 (194) $\mathrm{min} \times$ $\mathrm{mmol} / \mathrm{l} ; \mathrm{p}=0.069$ ) compared with Sitting, this effect was not significant and, hence, less pronounced than in the Sit Less regimen.

While chronic elevated glucose levels are associated with adverse health effects, the frequency and duration of hyperglycaemia ( $\mathrm{min} /$ day that blood glucose is $>10 \mathrm{mmol} / \mathrm{l}$ ) may be of even more relevance in a clinical setting [118]. The duration of hyperglycaemia over a $24 \mathrm{~h}$ time span was almost halved (Fig. 3c), from 211 (44) min/day in the Sitting regimen to 118 (32) $\mathrm{min} /$ day in the Sit Less regimen ( $p=0.002)$. Again, intermediate results were observed for the Exercise regimen, with the duration of hyperglycaemia averaging 152 (30) min/day. Although no hypoglycaemic periods were observed during any of the regimens, the maximal fall in glucose within 30 min differed between experimental regimens (Fig. 3d). As anticipated, the maximal drop in glucose over 30 min during structured exercise $\left(-5.28(0.39) \mathrm{mmol} \mathrm{I}^{-1} \mathrm{~h}^{-1}\right)$ was larger than during the Sitting regimen (-4.15 (0.31) mmol $\left.^{-1} \mathrm{~h}^{-1} ; \mathrm{p}=0.016\right)$. Importantly, the maximal blood glucose reduction observed in the Sit Less regimen $\left(-4.69(0.39) \mathrm{mmol} \mathrm{I}^{-1} \mathrm{~h}^{-1}\right)$ was not significantly different from that observed after Sitting $(p=0.119)$, indicating that the Sit Less regimen is unlikely to increase the risk of experienced hypoglycaemia. 


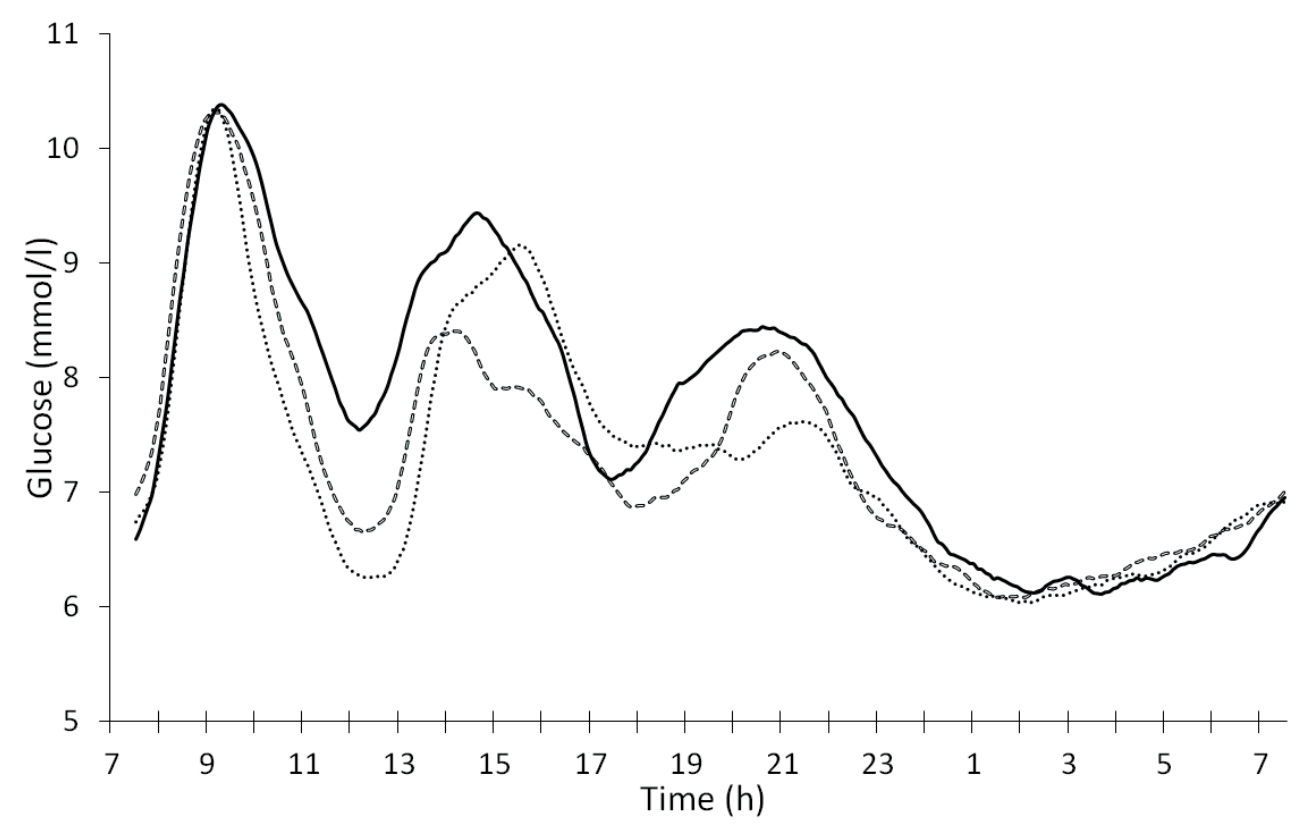

Fig. 2. Mean $24 \mathrm{~h}$ glucose profiles during the last day of each activity regimen. Solid line, Sitting regimen; dashed line, Sit Less regimen; dotted line, Exercise regimen. $\mathrm{N}=19$ individuals.

\section{Insulin resistance (HOMA2-IR) and plasma lipids}

Fasting insulin levels in the Exercise regimen were similar to those in the Sitting regimen (102 (14) vs 108 (13) pmol/l, respectively; p=0.117). In contrast, compared with Sitting, Sit Less significantly $(p=0.001)$ reduced fasting insulin levels to 95 (14) pmol/l). Since no significant differences were observed in mean glucose values after Sit Less as compared with Exercise (Table 2), this finding suggests that Sit Less, but not Exercise, improved insulin sensitivity. Likewise, Sit Less resulted in significantly lower HOMA2-IR values vs Sitting (1.89 (0.26) vs $2.16(0.26) ; p=0.001)$ and vs Exercise ( $2.06(0.28) ; p=0.015)$, whereas Exercise failed to improve this measure of insulin sensitivity (Fig. $3 b$ ) compared to the Sitting regimen $(p=0.177)$.

Both Sit Less (1.46 (0.12) $\mathrm{mmol} / \mathrm{l}$ and Exercise $(1.55(0.14) \mathrm{mmol} / \mathrm{l})$ resulted in significantly lower fasting triacylglycerol levels than were observed after Sitting $(1.93(0.17) \mathrm{mmol} / \mathrm{l}$; both $\mathrm{p}<0.01)$. We also observed that after both Sit Less and Exercise, fasting plasma NEFA levels were significantly higher (Sit Less 0.59 (0.04) mmol/l, $p=0.012$; Exercise 0.65 (0.06) $\mathrm{mmol} / \mathrm{l}, \mathrm{p}=0.017)$ than after Sitting $(0.48(0.05) \mathrm{mmol} / \mathrm{l})$. Cholesterol-related variables and free glycerol were not significantly different between any of the regimens (Table 2). 
Table 2. Effect of activity regimens on blood parameters

\begin{tabular}{|c|c|c|c|c|c|c|c|}
\hline Variables & SIT & EXE & SL & p value $^{B}$ & p EXE-SIT ${ }^{c}$ & p SL-SIT ${ }^{c}$ & p SL-EXE ${ }^{C}$ \\
\hline $\begin{array}{l}\text { Glucose } \\
\text { (mmol/l) }\end{array}$ & $\begin{array}{l}7.35 \\
(0.23)\end{array}$ & $\begin{array}{l}7.60 \\
(0.26)\end{array}$ & $\begin{array}{l}7.29 \\
(0.25)\end{array}$ & 0.121 & 0.046 & 0.616 & 0.086 \\
\hline $\begin{array}{l}\text { Insulin } \\
\text { (pmol/I) }\end{array}$ & $\begin{array}{l}108 \\
(13)\end{array}$ & $\begin{array}{l}102 \\
(14)\end{array}$ & $\begin{array}{l}95 \\
(14)\end{array}$ & 0.005 & 0.117 & 0.001 & 0.023 \\
\hline $\begin{array}{l}\text { C-peptide }{ }^{A} \\
\text { (nmol/I) }\end{array}$ & $\begin{array}{l}0.06 \\
(0.08)\end{array}$ & $\begin{array}{l}0.01 \\
(0.08)\end{array}$ & $\begin{array}{l}-0.03 \\
(0.09)\end{array}$ & 0.051 & 0.165 & 0.016 & 0.269 \\
\hline $\begin{array}{l}\text { Triacylglycerol } \\
\text { (mmol/l) }\end{array}$ & $\begin{array}{l}1.93 \\
(0.17)\end{array}$ & $\begin{array}{l}1.55 \\
(0.14)\end{array}$ & $\begin{array}{l}1.46 \\
(0.12)\end{array}$ & 0.002 & 0.003 & $<0.001$ & 0.200 \\
\hline $\begin{array}{l}\text { Total cholesterol } \\
\text { (mmol/l) }\end{array}$ & $\begin{array}{l}5.24 \\
(0.30)\end{array}$ & $\begin{array}{l}5.10 \\
(0.25)\end{array}$ & $\begin{array}{l}5.06 \\
(0.23)\end{array}$ & 0.253 & 0.439 & 0.194 & 0.611 \\
\hline $\begin{array}{l}\text { Non-HDL-C } \\
(\mathrm{mmol} / \mathrm{l})\end{array}$ & $\begin{array}{l}3.89 \\
(0.32)\end{array}$ & $\begin{array}{l}3.66 \\
(0.30)\end{array}$ & $\begin{array}{l}3.65 \\
(0.27)\end{array}$ & 0.071 & 0.212 & 0.047 & 0.890 \\
\hline $\begin{array}{l}\text { LDL-C } \\
\text { (mmol/l) }\end{array}$ & $\begin{array}{l}3.02 \\
(0.29)\end{array}$ & $\begin{array}{l}2.96 \\
(0.27)\end{array}$ & $\begin{array}{l}2.99 \\
(0.24)\end{array}$ & 0.946 & 0.751 & 0.813 & 0.770 \\
\hline $\begin{array}{l}\text { HDL-C } \\
\text { (mmol/l) }\end{array}$ & $\begin{array}{l}1.35 \\
(0.11)\end{array}$ & $\begin{array}{l}1.44 \\
(0.11)\end{array}$ & $\begin{array}{l}1.41 \\
(0.10)\end{array}$ & 0.198 & 0.082 & 0.213 & 0.340 \\
\hline $\begin{array}{l}\text { Apo B } \\
(\mathrm{g} / \mathrm{I})\end{array}$ & $\begin{array}{l}0.91 \\
(0.07)\end{array}$ & $\begin{array}{l}0.87 \\
(0.06)\end{array}$ & $\begin{array}{l}0.88 \\
(0.06)\end{array}$ & 0.514 & 0.365 & 0.314 & 0.897 \\
\hline $\begin{array}{l}\text { NEFA } \\
\text { (mmol/l) }\end{array}$ & $\begin{array}{l}0.48 \\
(0.05)\end{array}$ & $\begin{array}{l}0.65 \\
(0.06)\end{array}$ & $\begin{array}{l}0.59 \\
(0.04)\end{array}$ & 0.028 & 0.017 & 0.012 & 0.201 \\
\hline $\begin{array}{l}\text { Free glycerol } \\
\text { (mmol/l) }\end{array}$ & $\begin{array}{l}0.11 \\
(0.01)\end{array}$ & $\begin{array}{l}0.12 \\
(0.01)\end{array}$ & $\begin{array}{l}0.11 \\
(0.01)\end{array}$ & 0.288 & 0.836 & 0.557 & 0.127 \\
\hline $\begin{array}{l}24 \mathrm{~h} \text { glucose AUC } \\
(\mathrm{min} \times \mathrm{mmol} / \mathrm{l})\end{array}$ & $\begin{array}{l}1107 \\
(334)\end{array}$ & $\begin{array}{l}10503 \\
(342)\end{array}$ & $\begin{array}{l}10589 \\
(268)\end{array}$ & 0.035 & 0.064 & 0.013 & 0.742 \\
\hline
\end{tabular}

Data are presented as estimated means \pm SEM ( $n=19$ individuals). Total AUC for $24 \mathrm{~h}$ glucose was assessed during day 4 of each activity regimen. Fasting blood parameters were assessed on the morning following completion of each activity regimen. ${ }^{A} \mathrm{C}$-peptide analysis was carried out following natural log transformation. P-values were generated using linear mixed model analyses for ${ }^{B}$ overall difference and ${ }^{C}$ pairwise comparisons between activity regimens. EXE, Exercise; HDL-C, HDLcholesterol; LDL-C, LDL-cholesterol; SIT, Sitting; SL, Sit Less. 
a

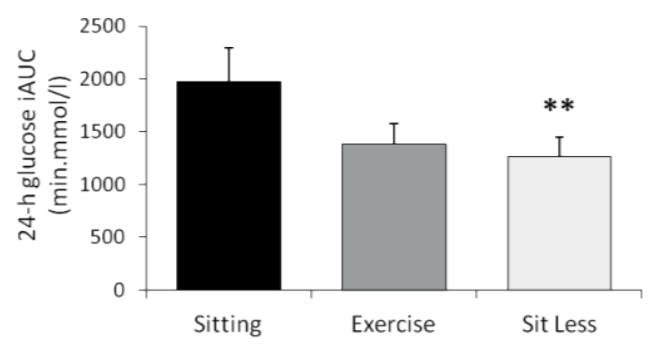

C

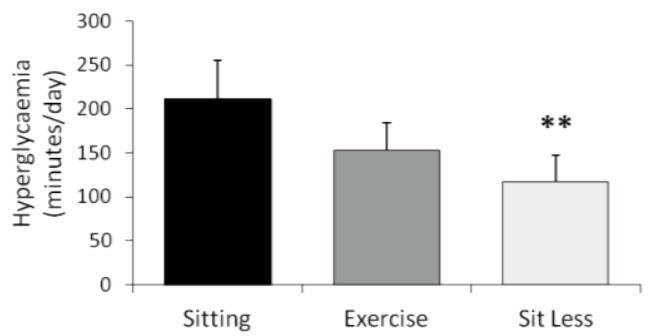

b

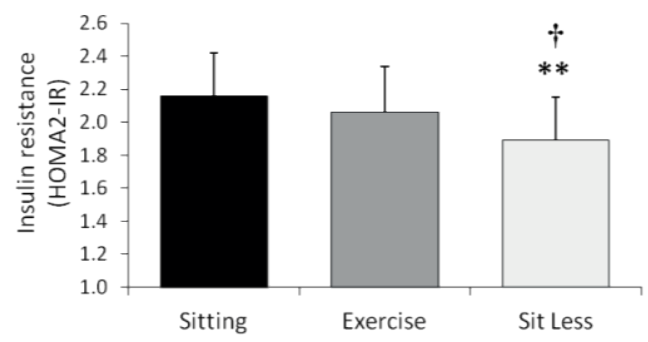

d

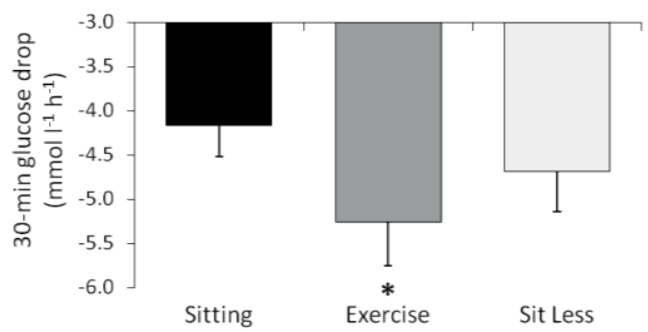

Fig. 3. Glycaemic control and insulin resistance. (a) $24 \mathrm{~h}$ glucose iAUC during the last day of each activity regimen, (b) insulin resistance expressed as HOMA2-IR on the morning after each activity regimen, (c) duration of hyperglycaemia, and (d) maximal reduction in glucose level at 30 min during the last day of each activity regimen. Data are estimated means \pm SEM ( $n=19$ individuals). ${ }^{*} p \leq 0.05$,

${ }^{* *} p<0.01$ vs Sitting regimen; $\uparrow p \leq 0.05$ vs Exercise regimen.

\section{Physical activity and diet}

Before the start of the study, the average time spent walking, standing and sitting/sleeping in free-living conditions ( $n=16$ individuals, the activPAL data were not available for the other three subjects) was 1.4 (0.2), $3.6(0.5)$ and 18.9 (0.6) h/day, respectively (data not shown). During each regimen, we successfully manipulated the time spent sitting, walking, standing and cycling so that they were close to the times stipulated for each activity/regimen in the protocol (Table 3). During Sit Less, the times spent walking ( $\sim 3 \mathrm{~h} /$ day) and standing ( $\sim \mathrm{h} /$ day) were significantly longer than in the other regimens, whereas Sitting and Exercise were not significantly different with respect to the time spent walking ( $\sim \mathrm{h} /$ day) and standing ( $\sim 1.6 \mathrm{~h} /$ day). During the Exercise regimen, on average 65 (3) min of sitting per day were substituted by cycling at an intensity of 81 (4) W, corresponding to a mean of 5.9 (0.2) MET. Walking cadence was 93 (2) steps/min during Sit Less and 83 (2) and 84 (2) during Sitting and Exercise, respectively (Table 3). By design, estimated energy expenditure was lower in the Sitting regimen (32.0 (0.1) MET $\mathrm{h}^{-1} \mathrm{day}^{-1}$ ) than in any of the other regimens $\left(36.9\right.$ (0.2) and 37.4 (0.2) $\mathrm{MET} \mathrm{h}^{-1} / \mathrm{day}^{-1}$ for Exercise and Sit Less, respectively; Table 3). There was, however, an estimated $0.5 \mathrm{MET} \mathrm{h}^{-1} / \mathrm{day}^{-1}$ difference between Exercise and Sit Less ( $p=0.008$; Table 3). Energy intake did not differ significantly between the regimens $(p=0.599$ during activity regimens and $p=0.953$ during 
the last day of each activity regimen) and neither did the percentage macronutrients consumed (Table 3 and Supplemental Table 1).

Table 3. Physical activity and diet during activity regimens

\begin{tabular}{llllllll}
\hline Variables & SIT & EXE & SL & P-value $^{\mathrm{A}}$ & p EXE-SIT $^{\mathrm{B}}$ & p SL-SIT & $\begin{array}{l}\text { p SL- } \\
\text { EXE }^{\mathrm{B}}\end{array}$ \\
\hline $\begin{array}{l}\text { Estimated EE } \\
\text { (MET } \times \text { h/day) }\end{array}$ & $32.0(0.1)$ & $36.9(0.2)$ & $37.4(0.2)$ & $<0.001$ & $<0.001$ & $<0.001$ & 0.008 \\
\hline Energy intake (kJ) & $7525(288)$ & $7632(263)$ & $7591(283)$ & 0.599 & 0.318 & 0.412 & 0.516 \\
\hline Carbohydrates (\%) & $47.1(1.0)$ & $47.6(0.7)$ & $47.3(0.6)$ & 0.272 & 0.338 & 0.806 & 0.409 \\
\hline Protein (\%) & $18.5(0.6)$ & $18.6(0.5)$ & $18.6(0.5)$ & 0.932 & 0.727 & 0.718 & 0.853 \\
\hline Fat (\%) & $34.5(1.0)$ & $34.0(0.9)$ & $34.0(0.8)$ & 0.608 & 0.328 & 0.470 & 0.798 \\
\hline Sitting (h/day) & $13.7(0.3)$ & $12.5(0.2)$ & $8.9(0.3)$ & $<0.001$ & $<0.001$ & $<0.001$ & $<0.001$ \\
\hline Walking (h/day) & $0.9(0.1)$ & $1.0(0.1)$ & $3.1(0.1)$ & $<0.001$ & 0.050 & $<0.001$ & $<0.001$ \\
\hline Standing (h/day) & $1.6(0.1)$ & $1.6(0.1)$ & $4.1(0.2)$ & $<0.001$ & 0.996 & $<0.001$ & $<0.001$ \\
\hline Cycling (h/day) & & $1.1(0.1)$ & & & & & \\
\hline Sleeping (h/day) & $7.9(0.2)$ & $7.9(0.2)$ & $7.9(0.2)$ & 0.957 & 0.810 & 0.919 & 0.863 \\
\hline Steps/day (n) & $4415(298)$ & $4823(241)$ & $17502(620)<0.001$ & 0.035 & $<0.001$ & $<0.001$ \\
\hline Cadence (steps/min) $83(2)$ & $84(2)$ & $93(2)$ & $<0.001$ & 0.281 & $<0.001$ & $<0.001$ \\
\hline
\end{tabular}

Data are presented as estimated means \pm SEM ( $n=19$ individuals). Diet during the activity regimens was assessed via diary data (from all 4 days of each regimen); activities were assessed during the last 3 days of each activity regimen using the activPAL accelerometer. P-values were generated using linear mixed model analyses for ${ }^{A}$ overall difference and ${ }^{B}$ pairwise comparisons between activity regimens. EE, Energy expenditure; EXE, Exercise; SIT, Sitting; SL, Sit Less.

\section{Discussion}

Structured exercise is a recognised cornerstone of type 2 diabetes treatment and prevention. However, sustained compliance with exercise programmes, especially by individuals with type 2 diabetes, is at best mediocre $[119,120]$. Observational studies have revealed associations between the time spent sitting and markers of metabolic disturbance [20-22]. Therefore, reducing the sitting time may improve glycaemic control and insulin sensitivity in type 2 diabetes. Strategies to reduce sitting time are generally considered to be less demanding than structured exercise programmes and hence are more likely to have long-term compliance [101]. In this study, we observed that the Sit Less regimen improved insulin sensitivity, mean $24 \mathrm{~h}$ glucose levels, $24 \mathrm{~h}$ glucose excursions, duration of hyperglycaemia (blood glucose $>10 \mathrm{mmol} / \mathrm{l}$ ) and fasting triacylglycerol levels.

We used a proof-of-concept study to determine the relative efficacy of reducing sitting time or increasing structured exercise. As a result, the number of steps during Sit Less 
(around 17500 steps/day) was well above what is generally observed in patients with type 2 diabetes (around 6500-8000 steps/day) [58, 121] and, therefore, the duration/intensity of exercise was also high ( $65 \mathrm{~min} /$ day cycling at $5.9 \mathrm{MET}$ ) and probably not sustainable on a long-term basis. The beneficial effects of Sit Less were observed in participants with type 2 diabetes, the majority of whom were men using oral glucose-lowering medication (the use of which was continued throughout the study duration). Subanalyses showed similar improvements in $24 \mathrm{~h}$ glucose iAUC during Sit Less in participants who were not taking glucose-lowering medication $(n=5)$, as well as for women only $(n=6)$.

The outcome of the present study fits the emerging picture that breaking up sedentary behaviour by light-intensity activities may help to improve glucose homeostasis in groups, ranging from young lean normoglycaemic individuals [82] to overweight/obese normoglycaemic [33] and dysglycaemic [34] participants. Very recently, Dempsey et al showed that breaking up sitting time with brief bouts of light-intensity walking or resistance exercise attenuates postprandial glucose and insulin responses in type 2 diabetes [112]. In the current study, the general effect of the Sit Less regimen on glucose homeostasis tended to be a little more potent than the effect of structured exercise. One of the effects of acute exercise on elevated blood glucose in diabetes is a post-exercise reduction in glucose levels; this can sometimes result in hypoglycaemia and can render some diabetic patients reluctant to perform structured exercise. In our study, the Sit Less regimen did not result in glucose level reductions at $30 \mathrm{~min}$ compared with the Sitting regimen, whereas $30 \mathrm{~min}$ glucose levels fell by more than $5 \mathrm{mmol} \mathrm{I}^{-1} \mathrm{~h}^{-1}$ during the Exercise regimen. These data suggest that more stable glucose levels can be achieved with light-intensity activity rather than with exercise.

For most variables, other than 24-h glucose, the structured exercise regimen (Exercise) had beneficial effects. The effect size of Exercise, however, was typically intermediate compared with the effects of Sit Less and was only greater for the increases observed in fasting plasma NEFA levels vs Sitting. These results are in line with a recent study by Henson et al showing that breaking up sitting time with walking or standing increased NEFA levels in overweight/obese postmenopausal women [34]. Although the mechanism underlying the increase in NEFA concentration after Sit Less and Exercise is incompletely understood, it probably reflects a spill-over of fatty acids from increased adipose tissue lipolysis used to fuel contractile activity. Upon cessation of contractile activity, the amount of fatty acids taken up by the muscle for oxidation decreases more promptly than the catecholamine-induced elevation of adipose tissue lipolysis, resulting in elevated plasma NEFA levels [106]. In contrast to our previous study in healthy volunteers [82], we failed to observe significant effects on cholesterol levels in individuals with type 2 diabetes. The most likely explanation for this apparent discrepancy is the fact that participants stopped 
lipid-lowering medication 2 weeks prior to the study, a period that may have been too short.

Both Sit Less and Exercise resulted in lower fasting plasma triacylglycerol levels, which may be the result of increased triacylglycerol clearance due to enhanced lipoprotein lipase activity [122]. These observed lower triacylglycerol levels after physical activity are in line with previous [82,122] but not all [35] studies. In the latter study, however, triacylglycerol levels were probably measured too soon after exercise, as lipoprotein lipase activity typically peaks $\geq 8 \mathrm{~h}$ post exercise.

In line with our previous study in healthy individuals [82], we observed that insulin sensitivity was more greatly improved after the Sit Less regimen than after the Exercise regimen. This finding may seem surprising given the high dose of exercise $(65 \mathrm{~min} / \mathrm{day}$ cycling at an intensity of 5.9 MET). It is possible that HOMA-IR was not accurate enough to detect relatively small changes in insulin sensitivity after Exercise. However, it should be noted that, during the Exercise regimen, participants spent most of the day sitting. We observed similar findings in healthy individuals [82] and we therefore suggest that one bout of exercise probably cannot fully compensate for the negative effects of sitting for the rest of the day. Thus, the duration of non-sitting activities may be more important than the intensity of these activities. Since the participants were instructed to break up sitting time every $30 \mathrm{~min}$, this may have contributed to the beneficial effects observed during Sit Less in comparison to Exercise. However, the activPAL programme did not provide information on the duration of sitting bouts; therefore, this behavioural outcome could not be well assessed. Energy expenditure was expressed in METs by the activPAL; for the sake of comparison, we also converted the external workload on the stationary bike to MET values. Although we appreciate that the conversion of measured power output to predicted MET values is a proxy for the actual energy expenditure, we believe that this method is valid when it comes to comparing the energy expenditure in Sit Less with Exercise.

\section{Conclusions}

This study suggests that breaking up sitting time by promoting time spent standing and light-intensity walking is a potent way to beneficially affect insulin resistance and other clinically relevant markers of glucose metabolism, and plasma triacylglycerol in individuals with type 2 diabetes who are taking oral glucose-lowering medication. Although an approximate energy-matched intervention with structured exercise also displayed most of the beneficial effects of breaking up sitting time, the present study provides indications favouring the implementation of interventions targeting the breaking-up of sitting time over interventions involving structured exercise. The effect of breaking up sitting time on 
insulin resistance was more pronounced than that of structured exercise. Additionally, the more abrupt and prominent reduction in blood glucose in the structured exercise intervention is proposed to increase the risk of hypoglycaemia [123]. Since the volume of activities in this proof-of-concept study was high, future long-term studies are needed to determine the volume of light-intensity activities that is feasible in daily life.

Supplemental Table 1. Physical activity and diet during last day of each activity regimen

\begin{tabular}{|c|c|c|c|c|c|c|c|}
\hline Variables & SIT & EXE & SL & $p$-value ${ }^{A}$ & $\begin{array}{l}\text { p EXE- } \\
\text { SIT }^{B}\end{array}$ & $\begin{array}{l}\text { p SL- } \\
\text { SIT }\end{array}$ & $\begin{array}{l}\text { p SL- } \\
\text { EXE }^{B}\end{array}$ \\
\hline $\begin{array}{l}\text { Estimated EE } \\
(\mathrm{MET} \times \mathrm{h} / \text { day) }\end{array}$ & $32.0(0.1)$ & $36.9(0.2)$ & $37.5(0.3)$ & $<0.001$ & $<0.001$ & $<0.001$ & 0.056 \\
\hline Energy intake (kJ) & 9340 (299) & $9367(284)$ & $\begin{array}{l}9351 \\
(293)\end{array}$ & 0.953 & 0.779 & 0.891 & 0.792 \\
\hline Carbohydrates (\%) & $52.1(0.7)$ & $52.4(0.6)$ & $52.5(0.6)$ & 0.332 & 0.400 & 0.253 & 0.315 \\
\hline Protein (\%) & $17.2(0.4)$ & $17.2(0.4)$ & $17.0(0.4)$ & 0.228 & 0.822 & 0.498 & 0.116 \\
\hline Fat (\%) & $30.5(0.9)$ & $30.3(0.8)$ & $30.2(0.8)$ & 0.438 & 0.560 & 0.253 & 0.590 \\
\hline Sitting (h/day) & $13.7(0.4)$ & $13.0(0.3)$ & $9.0(0.4)$ & $<0.001$ & 0.162 & $<0.001$ & $<0.001$ \\
\hline Walking (h/day) & $0.9(0.1)$ & $0.9(0.1)$ & $3.2(0.1)$ & $<0.001$ & 0.692 & $<0.001$ & $<0.001$ \\
\hline Standing (h/day) & $1.5(0.1)$ & $1.3(0.1)$ & $3.9(0.2)$ & $<0.001$ & 0.181 & $<0.001$ & $<0.001$ \\
\hline Cycling (h/day) & & $1.1(0.1)$ & & & & & \\
\hline Sleeping (h/day) & $7.9(0.3)$ & $7.7(0.2)$ & $8.0(0.3)$ & 0.372 & 0.444 & 0.886 & 0.169 \\
\hline Steps/day (n) & $4476(321)$ & 4595 (244) & $17993(654)$ & $<0.001$ & 0.708 & $<0.001$ & $<0.001$ \\
\hline Cadence (steps/min) & $84(2)$ & $84(2)$ & $95(2)$ & $<0.001$ & 0.826 & $<0.001$ & $<0.001$ \\
\hline
\end{tabular}

Data ( $n=19$ individuals) are presented as estimated means (SEM). Diet and activities (during last day of each activity regimen) were assessed via diary data and activPAL accelerometry respectively. P- values were generated using linear mixed model analyses for ${ }^{A}$ overall difference and ${ }^{B}$ pairwise comparisons between activity regimens. EE, Energy expenditure; EXE, Exercise; SIT, Sitting; SL, Sit Less. 


\section{Supplemental Fig. 1: Trial CONSORT diagram}

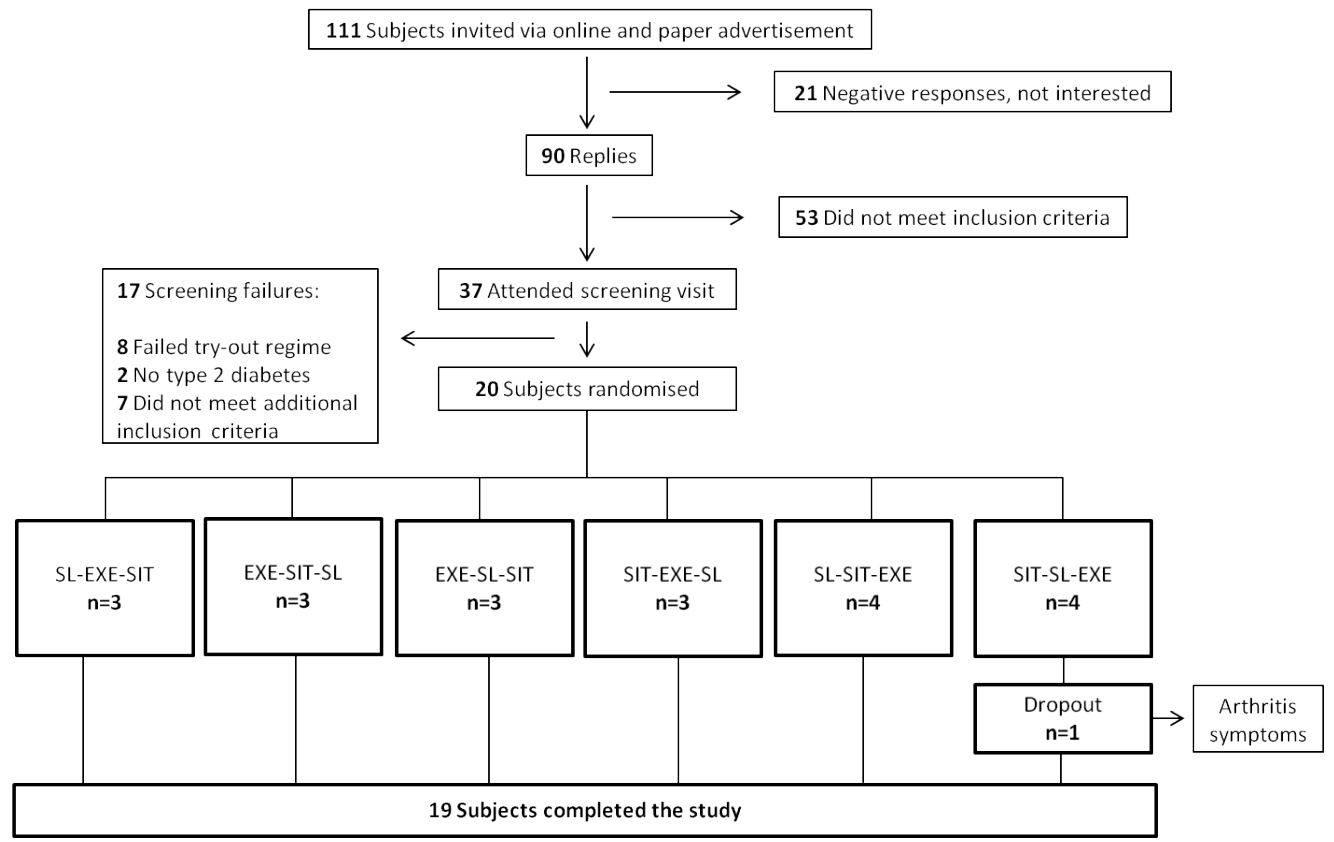

EXE, Exercise; SIT, Sitting; SL, Sit Less 



\section{CHAPTER 5}

REDUCING SITTING TIME VERSUS ADDING EXERCISE: DIFFERENTIAL EFFECTS ON BIOMARKERS OF ENDOTHELIAL DYSFUNCTION AND METABOLIC RISK

BERNARD M.F.M. DUVIVIER, JOHANNE E. BOLIJN, ANNEMARIE KOSTER, CASPER SCHALKWIJK, HANS H.C.M. SAVELBERG, NICOLAAS C. SCHAPER 


\section{Abstract}

Background Recent studies suggest that substituting sitting time with light physical activity has beneficial metabolic effects, but if this is associated with parallel changes in endothelial function is unclear.

Methods Data from three randomised cross-over studies, in which 61 subjects (with normal weight, overweight and type 2 diabetes) followed different activity regimens (Sit, SitLess and/or Exercise) of four days each, were analysed. Subjects were instructed to sit $14 \mathrm{~h} /$ day ('Sit'), to substitute $1 \mathrm{~h} /$ day of sitting with moderate-to-vigorous cycling ('Exercise') or to substitute 5-6 h/day sitting with light-intensity walking and standing ('SitLess'). The Exercise and SitLess regimens were designed to have comparable energy expenditure. Physical activity was assessed $24 \mathrm{~h}$ /day by accelerometry (ActivPAL) and diet was standardised. Fasted circulating biomarkers of endothelial dysfunction, lipids and insulin sensitivity (HOMA2-IR) were assessed the morning after each activity intervention. The endothelial dysfunction score (ED-score) was computed by averaging the Z-scores of the circulating biomarkers of endothelial dysfunction (sVCAM1, sICAM and sE-selectin).

Results Compared to Sit, Exercise resulted in a lower ED-score $(p=0.003)$, while no significant change was observed after SitLess and the ED-score after Exercise was lower compared to SitLess $(p=0.001)$. In contrast, compared to Sit, insulin sensitivity and plasma lipids (HDL-cholesterol, non-HDL-cholesterol, total cholesterol and Apo B) did not change significantly after Exercise but were improved after SitLess $(p<0.017)$.

Conclusions Light physical activity and moderate-to-vigorous physical activity had a differential effect on risk markers of cardio-metabolic health and suggest the need of both performing structured exercise as well as reducing sitting time on a daily basis. 


\section{Introduction}

Cardiovascular disease is one of the leading causes of morbidity and mortality in modern societies [3]. Lack of moderate-to-vigorous physical activity (MVPA) has been identified as one of the most important factors in the development of cardiovascular disease [3]. In parallel to a reduction in MVPA, sedentary behaviour is also increasing [2] and observational studies suggest that the average adult spends more than half of the waking day sedentary [20-22]. Although this is still debated [28, 124], several studies suggest that this rise in sedentary behaviour might be associated with increased risk of cardiovascular disease, independent of time spent in MVPA [22, 69, 125]. In line with these observational studies, we recently observed that reducing sitting time and substituting it with light physical activity (LPA) improved insulin sensitivity and plasma lipids but not after MVPA, when estimated energy expenditure was held constant $[82,98]$. These data suggest that the negative effects of prolonged sitting on glucose and lipid metabolism cannot be fully compensated by one daily bout of moderate-to-vigorous physical exercise but that more attention should be given to reducing sitting time. Moreover, one might also postulate that reducing sitting time by increasing light activities, such as standing or slow pace walking, might have the same beneficial cardiovascular effects as more vigorous activities, like running or cycling.

In addition to the importance of glucose and lipid metabolism for cardiovascular health, endothelial function is important as well to maintain cardiovascular health. Performing MVPA is an effective strategy to improve endothelial function [126-128] and could be related to changes in vasoactive and/or metabolic factors such as increased shear stress and nitric oxide (NO) or altered lipoproteins and enhanced insulin sensitivity [129]. In addition to lack of MVPA, sitting has been associated with endothelial dysfunction as well [130-132]. However, it remains to be elucidated, if substituting sitting with LPA affects endothelial function as well [133]. On one hand substituting sitting with LPA improved circulating lipids and insulin sensitivity as described above [82, 98], which could have beneficial effects on the vascular endothelium [133-135]. On the other hand, it can be questioned whether engaging in light-intensity activities, like standing and low pace walking, induces sufficient cardiovascular changes and raises shear stress to such a level that endothelial dysfunction can be improved.

In recent years we performed three separate intervention studies, which had a nearly identical protocol, in which we investigated the metabolic effects of substituting sitting with LPA and MVPA in sedentary subjects with normal weight, overweight and type 2 diabetes (T2D). Combining these 3 randomised clinical trials raised the unique opportunity to also determine the effects of these interventions on biomarkers of endothelial 
dysfunction in this particular study. Moreover, this enabled us to compare the differential effects of substituting sitting with LPA on biomarkers of endothelial dysfunction on one hand and metabolic risk factors on the other hand. Finally, as two of these studies also had an intervention arm with structured MVPA, we were also able to compare the effects of MVPA versus LPA on these variables.

\section{Methods}

\section{Study design}

Three counterbalanced randomised cross-over studies with comparable methods were carried out in which the subjects served as their own controls. The methods have been described previously in more detail $[82,98,136]$. The 'normal weight study' included healthy subjects without obesity (BMI $18-30 \mathrm{~kg} / \mathrm{m}^{2}$ ), the 'overweight study' and the 'diabetes study' included subjects with overweight/obesity (BMI of 25-35 kg/m²), respectively without $\mathrm{T} 2 \mathrm{D}$ and with $\mathrm{T} 2 \mathrm{D}$ treated with diet only or with diet and oral blood glucose lowering medication.

The subjects were instructed to follow two or three activity regimens for four days, each in a randomised order. Between regimens, there was a wash-out period of at least ten days. In two studies, the participants were instructed to sit $14 \mathrm{~h} /$ day ('Sit' regimen), to substitute $1 \mathrm{~h} /$ day of sitting with cycling ('Exercise' regimen) or to substitute 5-6 h/day sitting with 2-4 h/day light-intensity walking and 2-3 h/day standing ('SitLess' regimen). In the overweight study, the participants only followed the Sit and SitLess regimen.

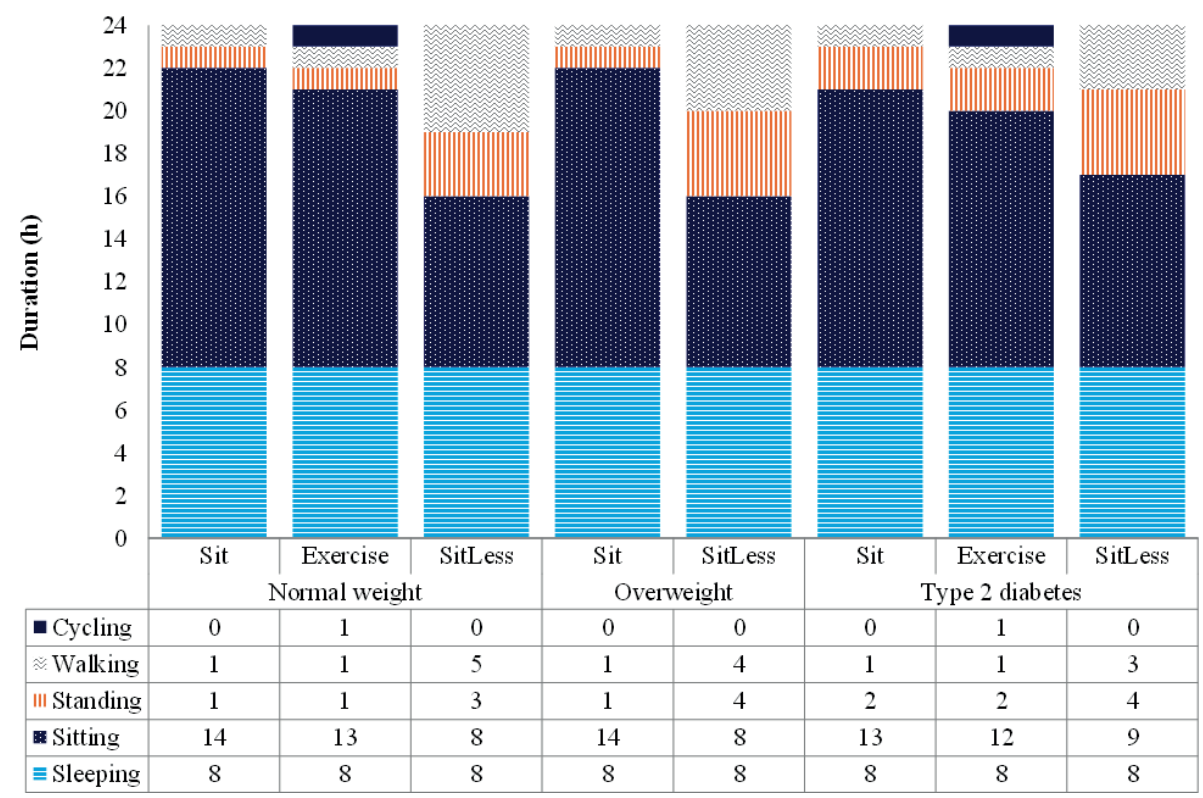

Fig. 1. Activities performed during the activity regimens in the three different studies. 
The activity regimens were performed under free-living conditions. The Sit and Exercise regimens differed only $1 \mathrm{~h} /$ day in sitting time, but the estimated energy expenditure differed significantly. The Exercise and SitLess regimens differed markedly in sitting time, but were designed to have comparable energy expenditure. To achieve a comparable daily energy expenditure during the Exercise and SitLess regimens, intensity/duration of the cycling during the Exercise regimen and duration of the additional standing/walking during the SitLess regimens were manipulated. During the Exercise regimen, approximately 1 $\mathrm{h} /$ day of sitting was replaced with cycling on an ergometer (Lode Excalibur, Groningen, the Netherlands) and supervised at the research centre. During the first regimen, participants carefully recorded everything they ate and drank. Subsequently, these records were returned to the participants, who were instructed to consume the same diet at the same time points during the following two regimens.

\section{Subjects}

Subjects were recruited via advertisements at the university and in newspapers. Exclusion criteria included more than $2.5 \mathrm{~h} /$ week of moderate-to-vigorous exercise based on selfreport, diseases that interfered with physical activity participation, alcohol abuse and in the subjects without diabetes drugs that interfered with insulin metabolism. A more detailed description of the in- and exclusion criteria has been described earlier [82, 98, 136].

\section{Assessment of physical activity}

Physical activity was measured $24 \mathrm{~h}$ /day using an activPAL3 monitor (PAL Technologies, Glasgow, Scotland). The monitor was waterproof wrapped and attached to the skin on the anterior aspect of the thigh using Tegaderm ( $\left.3 \mathrm{M}^{\mathrm{TM}}\right)$; non-wear was therefore not an issue. This accelerometer accurately discriminates between time spent inactive (sitting or lying), standing and walking [83]. In addition, subjects recorded their activities in a diary. This diary information was used to formulate tailor-made instructions on how to alter daily activities to guarantee optimal compliance with each activity regimen. Daily energy expenditure was estimated based on accelerometry and the heart rate/ workload (wattage) during the $1 \mathrm{~h}$ cycling exercise during the 'Exercise regimen'. A more detailed description of the energy expenditure calculations has been described previously [82, 98].

\section{Endothelial parameters, insulin sensitivity and plasma lipids}

Fasting blood was sampled via venepuncture on the morning after each 4-day regimen, at least $16 \mathrm{~h}$ after the last bout of cycling during the Exercise regimen. The endothelial markers analysed were soluble Intercellular Cell Adhesion Molecule 1 (sICAM1), soluble Vascular Adhesion Molecule 1 (sVCAM1) and soluble E-selectin (sE-selectin). The analysed metabolic markers were glucose, insulin, triglycerides, total cholesterol, high- (HDL) and low-density-lipoprotein (LDL) cholesterol, non-HDL-cholesterol and apolipoprotein B (Apo 
B). LDL-cholesterol was calculated using the Friedewald formula [49]. Insulin resistance was expressed as HOMA2-IR, calculated with the use of HOMA Calculator, version 2.2.3 (The University of Oxford 2013) [117]. sE-selectin was measured with a CD62 E ELISA Set (Diaclone SAS, Besancon Cedex, France). SICAM and SVCAM were measured with a sandwich multiplex-immunoassay based on electro-chemiluminescence technology (Meso Scale Discovery, Rockville MD, USA).

\section{Statistical analyses}

To reduce biological variability, random error of each parameter and to increase statistical efficiency, endothelial dysfunction was computed by a composite score (ED-score). The ED-score consisted of sICAM1, sVCAM1 and sE-selectin with a high ED-score reflecting endothelial dysfunction [137]. The ED-scores were computed by first calculating the Zscore for each individual ((individual value - sample mean)/sample SD), with the sample mean representing the mean of one parameter over all the activity regimens; and subsequently averaging the Z-score of all the included parameters. All statistical analyses were performed with the use of IBM SPSS Statistics, version 20 (SPSS, Inc.). Numeric values were represented as mean \pm standard error. Variables with a skewed distribution (sICAM1, sVCAM1, sE-selectin and HOMA2-IR) were natural logarithmic transformed before further analyses.

A mixed model analysis was used to determine interaction $(p \leq 0.10)$ between the three different studies for the activity regimens. When there was no statistically significant interaction between study and regimen, the data of the three studies were pooled and separately analysed with a mixed model analysis. Subsequently, differences between the different activity regimens for the cardio-metabolic and endothelial markers were determined with a mixed model analysis and considered significantly different with a pvalue $\leq 0.05$. When regimens were compared pairwise, $p$-values $\leq 0.017 \quad(=0.05 / 3$, Bonferroni correction) were considered statistically significant to account for multiple testing (three pairwise comparisons). Study, regimen order, sex and activity regimen were used as fixed factors in the mixed model analysis.

\section{Results}

\section{Subject characteristics}

In total 65 participants were included in the three studies. Before completing the protocol, 4 participants withdrew. The subject characteristics of the remaining 61 subjects ( 28 male, 33 female) are described in Table 1 . The participants in the normal weight study had a mean BMI of $22.6 \mathrm{~kg} / \mathrm{m}^{2}$ and were on average 21 years old; none of these participants used any medication. The subjects in the overweight study had mean BMI of $29.4 \mathrm{~kg} /$ and were on average of 64 years old. The subjects in the diabetes study had a mean BMI of 
$30.5 \mathrm{~kg} / \mathrm{m}^{2}$ and were on average 63 years old. The median (interquartile range) duration of type 2 diabetes in this study was 6 years (4-10) and diabetes was well-controlled with a mean (SD) $\mathrm{HbA} 1 \mathrm{c}$ of $6.7 \%$ (0.8). Anti-hypertensive and lipid lowering treatment was prescribed to several subjects in the overweight as well in the diabetes study, as summarised in Table 1. The patients with diabetes were treated with oral glucose lowering medication $(n=14)$ or diet only $(n=5)$. Psychopharmaca were prescribed in 3 overweight and 1 diabetic subjects. All medication was unaltered during the interventions, except the lipid lowering medication which was discontinued 2 weeks prior to the first intervention in the diabetic subjects. Physical activity (measured with the activPAL) was in accordance with the activity protocol (Fig. 1).

Table 1. Subject characteristics

\begin{tabular}{lllll}
\hline & \multicolumn{2}{l}{ Mean \pm Standard Deviation or $\mathbf{n}(\%)$} & & \\
Parameter & Pooled & Normal weight & Overweight & T2 diabetes \\
\hline $\mathbf{N}$ & 61 & 18 & 24 & 19 \\
Sex (male/female) & $28 / 33$ & $2 / 16$ & $13 / 11$ & $13 / 6$ \\
\hline Age (years) & $51 \pm 21$ & $21 \pm 2$ & $64 \pm 7$ & $63 \pm 9$ \\
\hline Height (m) & $1.70 \pm 0.08$ & $1.68 \pm 0.07$ & $1.72 \pm 0.08$ & $1.70 \pm 0.07$ \\
Weight (kg) & $80.8 \pm 14.8$ & $63.9 \pm 7.8$ & $87.1 \pm 9.7$ & $88.8 \pm 12.0$ \\
\hline BMI (kg/m ${ }^{2}$ ) & $27.8 \pm 4.3$ & $22.6 \pm 2.6$ & $29.4 \pm 2.3$ & $30.5 \pm 3.3$ \\
Waist circumference (cm) & & & $104 \pm 10^{\mathrm{C}}$ & $105 \pm 8$ \\
\hline Glucose (mmol/l) & $6.00 \pm 1.63^{\mathrm{A}}$ & $4.61 \pm 0.31^{\mathrm{B}}$ & $5.49 \pm 0.61$ & $7.88 \pm 1.51$ \\
\hline Triglycerides (mmol/I) & & $0.89 \pm 0.25^{\mathrm{B}}$ & & $1.51 \pm 0.55$ \\
\hline Lipid lowering drugs [n (\%)] & $18(30 \%)$ & $0(0 \%)$ & $5(21 \%)$ & $13(68 \%)$ \\
Diastolic BP (mmHg) & & & $83 \pm 9$ & $82 \pm 8$ \\
\hline Systolic BP (mmHg) & & & $143 \pm 17$ & $143 \pm 12$ \\
BP lowering drugs [n(\%)] & $17(28 \%)$ & $0(\%)$ & $6(25 \%)$ & $11(58 \%)$ \\
\hline
\end{tabular}

${ }^{A} n=60,{ }^{B}=17 ;{ }^{C} n=22 ; B P$, blood pressure; $T 2$ diabetes, type 2 diabetes

\section{Endothelial dysfunction}

In comparison to Sit, Exercise resulted in a significantly lower ED-score ( $p=0.003$ ); also the individual ED markers, sICAM1 $(p=0.010)$ and sE-selectin $(p=0.010)$ were lower after Exercise compared to Sit. In contrast, when Sit and SitLess (i.e. standing and light walking) were compared, no significant differences were observed in the ED-score or individual ED markers between the two regimens. When the Exercise and SitLess regimens were compared, the ED-score was lower in the Exercise regimen ( $p=0.001$; Fig. 2; Supplemental Fig. 1) and also sVCAM1 $(p=0.003)$ and sE-selectin $(p=0.011)$ were significantly lower after Exercise compared to SitLess (Fig. 2). 

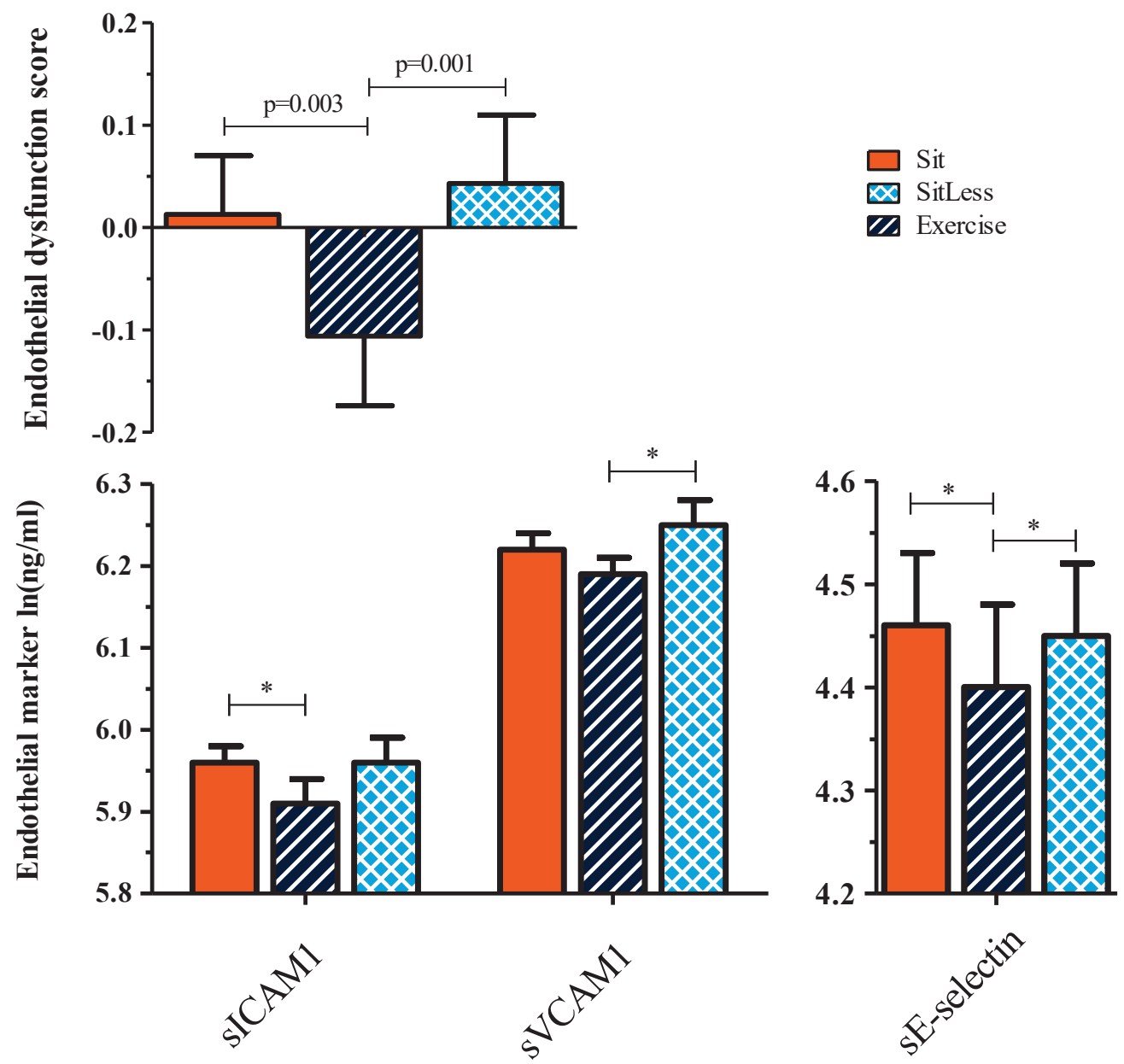

Fig. 2. Endothelial dysfunction score and biomarkers. Data pooled for the three studies after natural log transformation, measured on the morning after each activity regimen. Means and standard error bars are presented. SE-selectin, soluble E-selectin; sICAM1, soluble Intercellular Adhesion Molecule 1; sVCAM1, soluble Vascular Cell Adhesion Molecule 1. ${ }^{*} p \leq 0.017$.

\section{Insulin sensitivity and plasma lipids}

No significant differences were observed in insulin sensitivity and plasma lipids (total cholesterol, HDL-cholesterol, non-HDL-cholesterol and Apo B) between Sit and Exercise. In contrast, all these variables were improved when SitLess was compared with Sit ( $p \leq 0.017$; Fig. 3; Supplemental Table 1). When the Exercise and SitLess regimens were compared, no differences were observed in all these aforementioned variables. Since response in triglycerides to the activity the regimens differed between the studies, these data could not be pooled. Triglycerides were significantly lower after SitLess in comparison to Sit in all three studies $(p \leq 0.01)$, and significantly lower after Exercise in comparison to Sit in the 
diabetes study $(p \leq 0.01)$ but not in the normal weight study. No differences were observed in triglyceride level between SitLess and Exercise in the latter two studies.

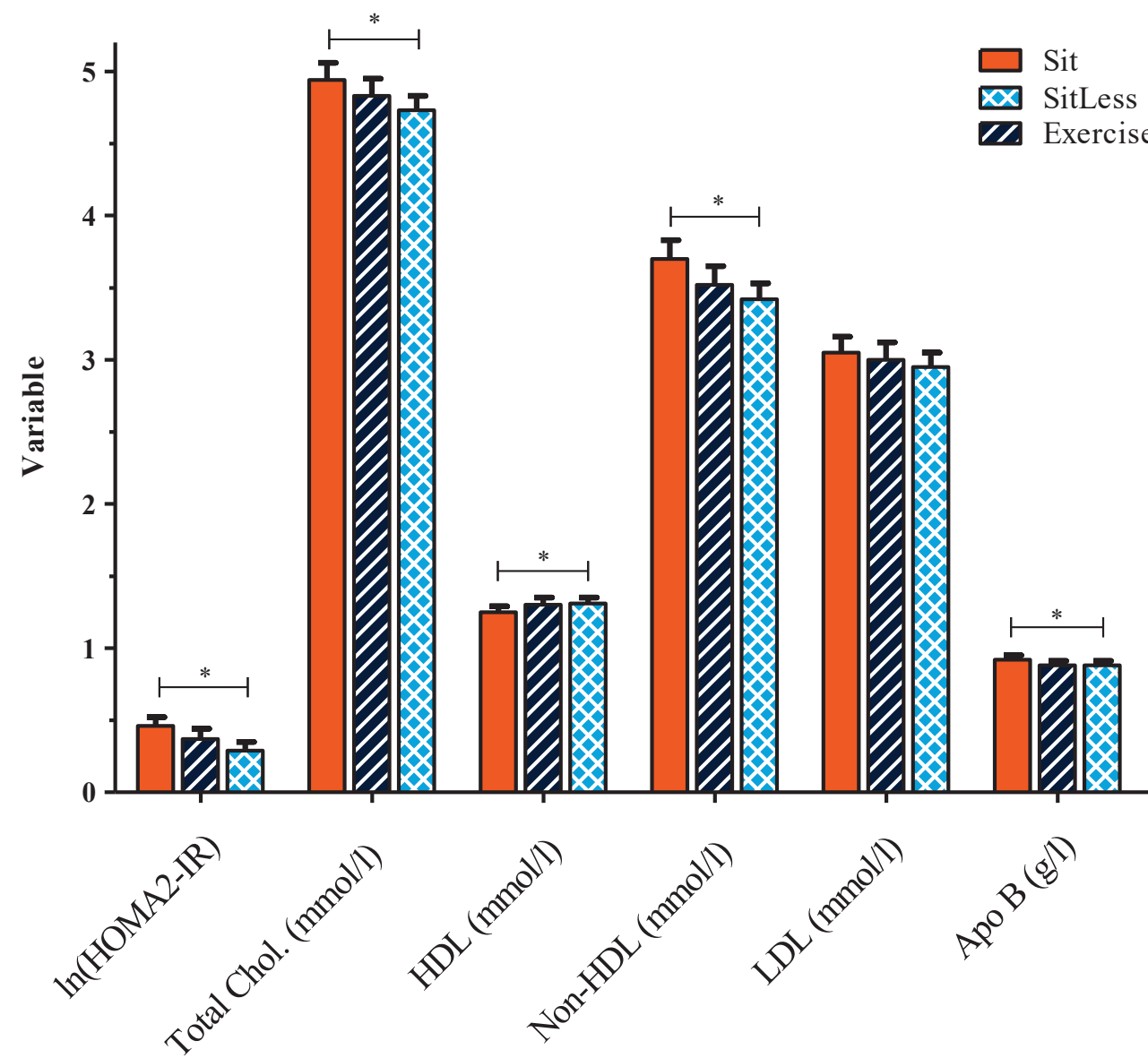

Fig. 3. Insulin sensitivity and fasting circulating lipids. Data pooled for the three studies, measured on the morning after each activity regimen. ${ }^{*} \mathrm{p} \leq 0.017$; Apo B, apolipoprotein; Chol., Cholesterol; HDL, high density lipoprotein cholesterol; HOMA2-IR, HOMA2 insulin resistance; LDL, low density lipoprotein cholesterol.

\section{Discussion}

We observed that a four day period of daily structured 60 min of MVPA improved circulating markers of endothelial dysfunction more than substituting sitting with 5-6 h/day of LPA. In contrast, substituting sitting with LPA improved circulating lipids and HOMA insulin resistance while no effect was observed of MVPA, under approximately equicaloric conditions. Our novel results suggest that daily structured MVPA can improve endothelial dysfunction despite a high sitting time ( $13 \mathrm{~h} /$ day), and vice versa that reducing 
sitting time by substituting it with LPA has more beneficial metabolic than endothelial effects.

A physical inactive lifestyle has been associated with several 'classic' cardiovascular risk factors such as increased blood pressure, central obesity, inflammation, endothelial dysfunction and insulin resistance [9]. Vascular endothelial dysfunction, which is accompanied by a reduced nitric oxide (NO) bioavailability and increased expression of vascular cell adhesion molecules like sICAM1, sVCAM1 and SE-selectin, is a key event in the subsequent development of cardiovascular risk [138]. MVPA increases nitric oxide (NO) bioavailability and alters sympathetic tone [139]. The increase in NO production is the consequence of blood flow-induced shear stress during MVPA which activates endothelial nitric oxide (NO) synthase and which subsequently attenuates the expression of adhesion molecules [140]. Our data suggest that LPA did not affect endothelial dysfunction, probably because these activities had too small effect on vascular shear stress. These results are in line with another recent study [133] which did not observe an improvement in flow-mediated dilatation when prolonged sitting was interrupted with LPA breaks. However, the authors reported that LPA did prevent a decline in flowmediated dilatation compared to prolonged sitting. Our results suggest that, on a short term basis ( 4 days), intermittent increases in shear stress during MVPA seem to be more important for endothelial function than the improvement in insulin sensitivity as observed after LPA. However, as shear stress was not measured in our experiments, this hypothesis remains to be further explored.

In line with earlier studies [32-34, 102, 141] substituting sitting with LPA resulted in marked improvements in insulin sensitivity and lipid parameters in the pooled analysis of our experiments, as also reported for each of the individual studies previously [82, 98, 136]. Structured MVPA did not result in significant improvements in insulin sensitivity and most lipid variables. Previous studies have clearly indicated that MVPA can improve the aforementioned cardiovascular risk factors, but most studies did not take the sitting time during the rest of the day into account. In our experiments sitting time was very high in the MVPA intervention arms (approximately $13 \mathrm{~h} /$ day sitting) possibly mitigating the positive effects of MVPA.

Given high inter-individual differences in time spent sitting and LPA in the general population [24], it is important to control for these variables when the effect of MVPA is investigated. For instance, when older-aged adults performed daily MVPA in line with current guidelines, total daily energy expenditure remained unaltered as the increase in energy expenditure by MVPA was compensated with longer periods of physical inactivity [59]. We measured physical activity $24 \mathrm{~h} /$ day and our study design is unique in that we manipulated sitting time and energy expenditure, independent of each other. During the 
SitLess regimen, estimated energy expenditure was comparable with the Exercise regimen, but sitting time was much lower. During the Exercise regimen, energy expenditure was high but sitting time was high as well. The Exercise regimen is reflective for the physical activity pattern of a "sedentary exerciser", for instance an office worker who meets the physical activity guidelines by exercising 30-60 min/day but is sedentary during the rest of the day. The SitLess regimen was reflective for a "physically active nonexerciser", for instance a salesclerk that spends many hours on his feet during working hours but does not engage in structured exercise. To our knowledge, our results are the first to show that structured exercise and reducing sitting time have a differential effect on risk markers of endothelial and metabolic health. Our findings suggest the need of both performing structured exercise as well as reducing sitting time on a daily basis in order to optimise cardiovascular health.

Strengths of our study include the strict adherence to the activity regimens in free-living conditions, which was objectively measured 24 h/day with accelerometry. Diet was standardised, and energy intake and macronutrient percentage did not differ between the activity regimens. Moreover, by combining three studies with a nearly identical study protocol, we were able to study three different populations (healthy volunteers, overweight individuals without diabetes and overweight type 2 diabetic subjects), increasing the generalisability of our results. Limitations of our study include the assessment of energy expenditure. Energy expenditure was indirectly estimated by accelerometry and heart rate/ workload of cycling during the 'Exercise' regimen. In addition to endothelial plasma markers, future studies also need to measure other function measurements of endothelial function such as flow-mediated vasodilatation of the brachial and femoral arteries. Since the volume of activities in our studies was high, the volume of LPA that is feasible in daily life also needs to be determined.

\section{Conclusions}

In summary, our results suggest that sitting and activity intensity have different effects on vascular and metabolic health. On one hand, reducing sitting time by increasing light physical activity seems important for insulin sensitivity and plasma lipids. On the other hand, moderate-to-vigorous physical activity had more beneficial effects than light physical activity on circulating endothelial parameters. To our knowledge, our results are the first to show that structured exercise and reducing sitting time have a differential effect on risk markers of cardio-metabolic health and suggest the need of both performing structured exercise as well as reducing sitting time on a daily basis. 
Supplemental Table 1. Effects of the activity regimens on endothelial markers, insulin resistance and circulating lipids

\begin{tabular}{|c|c|c|c|c|c|c|c|}
\hline \multirow{2}{*}{ Parameter } & \multicolumn{3}{|c|}{ Estimated Mean \pm SEM } & \multirow{2}{*}{$\begin{array}{l}P \text { - } \\
\text { value }\end{array}$} & \multicolumn{3}{|c|}{ 98.33\% Confidence interval } \\
\hline & SIT & EXE & SL & & EXE-SIT & SL-SIT & EXE-SL \\
\hline $\begin{array}{l}\text { sICAM1 }{ }^{\mathrm{A}} \\
\text { (ng/ml) }\end{array}$ & $5.96 \pm 0.02$ & $5.91 \pm 0.03$ & $5.96 \pm 0.03$ & 0.024 & $\begin{array}{l}-0.094 \\
-0.004\end{array}$ & $\begin{array}{l}-0.044 ; \\
0.039\end{array}$ & $\begin{array}{l}-0.095 ; \\
0.003\end{array}$ \\
\hline $\begin{array}{l}\text { sVCAM1 }{ }^{A} \\
\left(\mathrm{ng} / \mathrm{ml}^{2}\right)\end{array}$ & $6.22 \pm 0.02$ & $6.19 \pm 0.02$ & $6.25 \pm 0.03$ & 0.008 & $\begin{array}{l}-0.067 \\
0.006\end{array}$ & $\begin{array}{l}-0.014 ; \\
0.082\end{array}$ & $\begin{array}{l}-0.116 ; \\
-0.014\end{array}$ \\
\hline $\begin{array}{l}\text { sE-selectin }{ }^{A} \\
(\mathrm{ng} / \mathrm{ml})\end{array}$ & $4.46 \pm 0.07$ & $4.40 \pm 0.08$ & $4.45 \pm 0.07$ & 0.014 & $\begin{array}{l}-0.130 \\
-0.005\end{array}$ & $\begin{array}{l}-0.067 \\
0.044\end{array}$ & $\begin{array}{l}-0.108 \\
-0.004\end{array}$ \\
\hline ED-score & $0.01 \pm 0.06$ & $\begin{array}{l}-0.04 \\
\pm 0.07\end{array}$ & $0.11 \pm 0.07$ & 0.002 & $\begin{array}{l}-0.211 \\
-0.026\end{array}$ & $\begin{array}{l}-0.069 \\
0.130\end{array}$ & $\begin{array}{l}-0.257 \\
-0.041\end{array}$ \\
\hline HOMA2-IR ${ }^{A}$ & $0.46 \pm 0.06$ & $0.37 \pm 0.07$ & $0.29 \pm 0.06^{B}$ & 0.012 & $\begin{array}{l}-0.214 \\
0.048\end{array}$ & $\begin{array}{l}-0.307 ; \\
-0.022\end{array}$ & $\begin{array}{l}-0.004 ; \\
0.168\end{array}$ \\
\hline $\begin{array}{l}\text { Total chol. } \\
\text { (mmol/l) }\end{array}$ & $4.94 \pm 0.12$ & $4.83 \pm 0.12$ & $4.73 \pm 0.10$ & 0.003 & $\begin{array}{l}-0.329 \\
0.094\end{array}$ & $\begin{array}{l}-0.362 ; \\
-0.065\end{array}$ & $\begin{array}{l}-0.079 \\
0.272\end{array}$ \\
\hline $\begin{array}{l}\text { HDL-chol. } \\
\text { (mmol/l) }\end{array}$ & $1.25 \pm 0.04$ & $1.30 \pm 0.05$ & $1.31 \pm 0.04$ & 0.025 & $\begin{array}{l}-0.023 \\
0.127\end{array}$ & $\begin{array}{l}0.006 \\
0.117\end{array}$ & $\begin{array}{l}-0.084 ; \\
0.064\end{array}$ \\
\hline $\begin{array}{l}\text { Non-HDL- } \\
\text { chol.(mmol/l) }\end{array}$ & $3.70 \pm 0.13$ & $3.52 \pm 0.13$ & $3.42 \pm 0.11$ & $<0.001$ & $\begin{array}{l}-0.381 \\
0.026\end{array}$ & $\begin{array}{l}-0.395 \\
-0.156\end{array}$ & $\begin{array}{l}-0.063 ; \\
0.259\end{array}$ \\
\hline $\begin{array}{l}\text { LDL-chol. } \\
\text { (mmol/I) }\end{array}$ & $3.05 \pm 0.11$ & $3.00 \pm 0.12$ & $2.95 \pm 0.10$ & 0.100 & $\begin{array}{l}-0.252 ; \\
0.139\end{array}$ & $\begin{array}{l}-0.235 ; \\
0.220\end{array}$ & $\begin{array}{l}-0.101 ; \\
0.201\end{array}$ \\
\hline Apo B (g/l) & $0.92 \pm 0.03$ & $0.88 \pm 0.03$ & $0.88 \pm 0.03$ & 0.002 & $\begin{array}{l}-0.094 \\
0.015\end{array}$ & $\begin{array}{l}-0.072 ; \\
-0.015\end{array}$ & $\begin{array}{l}-0.049 ; \\
0.058\end{array}$ \\
\hline
\end{tabular}

\footnotetext{
${ }^{A}$ Analysed after natural logarithmic transformation; ${ }^{B} n=60$. Column five represents the level of statistical significance $(p \leq 0.05)$ between the activity regimens. Pairwise comparisons between the regimens (column seven to nine) were considered significantly different after Bonferroni correction $(p \leq 0.017)$. Apo B, apolipoprotein B; chol., cholesterol; ED-score, endothelial dysfunction score; EXE, Exercise; HOMA2-IR, HOMA2 insulin resistance; HDL, high density lipoprotein; LDL, low density lipoprotein; sE-selectin, soluble E-selectin; sICAM1, soluble Intercellular Adhesion Molecule 1; Sit, Sitting; SL, Sit Less; sVCAM1, soluble Vascular Cell Adhesion Molecule 1.
} 



\section{CHAPTER 6}

GENERAL DISCUSSION 


\section{Summary of main findings}

In this dissertation the results of three different intervention studies are presented. The major difference between these studies was in the populations included (adults with normal weight, overweight/obese adults and type 2 diabetic adults). In addition there were -to a relatively small degree- differences in protocol or measurements performed. Common in all three studies was that participants followed a sitting regimen ('Sit regimen') and a regimen in which a significant amount of sitting time was replaced with light physical activity (LPA) replaced ('SitLess regimen'). In two of the three studies, a third regimen was introduced which, compared to the Sit regimen, increased energy expenditure with moderate-to-vigorous physical activity (MVPA), but did hardly reduce sitting time ('Exercise regimen'). These studies allowed comparing the effect of reducing sitting time, independent of (estimated) energy expenditure. The overall results of these three studies were:

- Reducing sitting time with standing and light walking had a positive effect on insulin sensitivity, glucose regulation and circulating lipids (chapters 2-5).

- Reducing sitting time with standing and light walking improved insulin sensitivity more than moderate-to-vigorous cycling, when energy expenditure was comparable by design (chapters 2, 4 and 5).

- Moderate-to-vigorous cycling with only a minor reduction in sitting time had no significant effect on insulin sensitivity, glucose homeostasis and most circulating lipids (chapters 2, 4 and 5).

- Moderate-to-vigorous cycling improved circulating markers of endothelial dysfunction more than standing and light walking, when energy expenditure was comparable by design (chapter 5).

\section{How do our results match with existing knowledge?}

From an energy-balance perspective, it may be somewhat surprising that we did not observe a positive effect of the Exercise regimen on insulin sensitivity and most circulating lipids which is in contrast with a large body of evidence. I do not expect that the volume of MVPA was too low since it was twice as high as the recommended amount of daily MVPA ( $1 \mathrm{~h} /$ day), neither do I expect a power problem in our studies as similar results were observed when the data of the studies was pooled (chapter 5 ). Given the reproducibility of our data, it is reasonable to assume that other factors may be of importance to understand our results. In contrast to the Exercise regimen, the SitLess regimen did result in improved insulin sensitivity, glycaemic control and circulating lipids, despite the comparable estimated energy expenditure between these two interventions. On the other 
hand, the Exercise regimen resulted in lower circulating markers of endothelial dysfunction, while the SitLess regimen did not. These results suggest that the positive metabolic effects of physical activity are not solely driven by the increase in energy expenditure and that light-intensity activities might be preferable to high-intensity activities (i.e. MVPA) when energy expenditure is held constant, on short term basis. On the other hand, for endothelial function, MVPA seems preferable. How can these results be interpreted? The SitLess and Exercise regimens differed in three aspects: activity intensity (higher intensity in the Exercise regimen), activity pattern (activities spread over the day in the SitLess regimen versus one continuous activity bout in the Exercise regimen), and activity duration (longer duration in the Sitless regimen) and thus complementary also sitting time (longer in the Exercise regimen). We will discuss below how these factors may have affected our results.

\section{Activity intensity}

When physical activity is performed in one continuous bout and activity duration is equal, previous evidence indicates that its effectiveness in improving glycaemic control and insulin levels increases with its intensity [142]. As a result, when activity duration is equal, energy expenditure is higher during an MVPA bout than during a LPA bout. However, under equicaloric conditions, Manders and colleagues observed that a light-intensity exercise bout (cycling at $35 \% \mathrm{VO}_{\max }$ ) was more effective in lowering 24 -h glucose levels than a high-intensity exercise bout (cycling at 70\% VO2 max) in adults with type 2 diabetes [113]. In line with these results, our results suggest that -under equicaloric conditions- LPA is more effective than MVPA in improving insulin sensitivity and at least equal in improving glycaemic control and circulating lipids. In contrast, we observed that MVPA was more effective than LPA in improving endothelial markers, under equicaloric conditions. These results suggest that the intensity of the activity is important for endothelial function but seems less important for insulin sensitivity, glycaemic control and circulating lipids. In line with our short-term observations on circulating biomarkers of endothelial dysfunction, observational work suggests that the intensity of the activity seems important for the prevention of hypertension, cardiovascular disease and premature mortality, independent of an increase in energy expenditure [143-146].

\section{Activity pattern}

Dunstan et al. compared the effect of an LPA intervention (walking $3.2 \mathrm{~km} / \mathrm{h}$ ) with an MVPA intervention (walking $5.8-6.4 \mathrm{~km} / \mathrm{h}$ ) on postprandial metabolic responses in an experimental laboratory setting in overweight/obese subjects [33]. In the latter study, activity duration of LPA and MVPA was equal and the LPA/MVPA activities were performed in bouts of $2 \mathrm{~min}$, every $20 \mathrm{~min}$. Although the energy expenditure of walking was approximately $30-50 \%$ lower during the LPA intervention, the improvements in postprandial glucose and insulin were equal between the LPA and the MVPA intervention. 
These results suggest that when activities are spread over the day, in other words when sitting is interrupted regularly, the intensity of the activity seems less important for postprandial glucose and insulin levels. In addition, Peddie and collaborators observed that, when activity duration and intensity were equal, breaking up prolonged sitting every 30 min with $\sim 2$ min walking bouts lowered postprandial glucose and insulin responses more than one continuous 30 min walking bout [35]. Thus, the latter study in healthy normal weight subjects suggests that, independent of energy expenditure, also activity pattern is important for glucose metabolism. In line with these results, Henson et al. recently observed that breaking up sitting with standing (for 5 min every $30 \mathrm{~min}$ ) was effective in lowering postprandial glucose and insulin levels in overweight/obese, dysglycaemic women. In the studies described in this dissertation, we compared one continuous MVPA bout with a regimen in which the activities were spread over the day. Based on the studies described in this paragraph, breaking up sitting time regularly in our studies may have contributed to the positive effects observed on cardiovascular risk factors following the SitLess regimen. However, we did not measure the activity pattern in most of our studies (chapter 2 and 4). In addition to breaking up prolonged sitting regularly, timing of the activity in relation to meal consumption is also of importance. A recent study suggests that timing of walking in relation to the meals can enhance the beneficial effects of walking on postprandial glucose levels in adults with type 2 diabetes [147]. In the latter cross-over study, participants were asked to either walk 30 minutes at any time point of the day or to walk 10 minutes after each meal [147]. Post-meal walking resulted in lower postprandial glucose excursions, in particular after diner. The data of our studies suggest that reducing sitting time by increasing walking does not only have immediate effects on glycaemia, as we observed in type 2 diabetic participants, but also has positive effects on glucose homeostasis and insulin sensitivity the next day. To which extent these data, as well as our observations, translate into long-term improvement of overall glucose control, i.e. lower Hba1c values, remains to be determined.

\section{Sitting time / activity duration}

When energy expenditure is comparable, as discussed above, duration of physical activity may be of more importance than activity intensity according to the study of Manders et al. [113]. Our observations of the effect of LPA versus MVPA on insulin sensitivity, glycaemic control and circulating lipids are in line with these results. While activity duration is nearly always reported in earlier studies on the cardiometabolic effects of physical activity, the time spent sitting during the rest of the day is usually not controlled. In the studies described in this dissertation, the SitLess regimen was characterised by low sitting time while the Exercise regimen was high in sitting time. From a use-it-or-lose-it perspective, and in line with observational studies $[22,24]$, including the recent data from The Maastricht Study [148], I expect that the positive cardiometabolic effect of MVPA was partly mitigated by the negative effect of sitting during the rest of the day. In The 
Maastricht Study, physical activity was objectively measured with accelerometry in 2213 subjects, using the same device and technique as in the studies presented in this dissertation [148]. Using an isotemporal substitution modelling approach, substituting every 30 minutes per day of sitting with standing was associated with lower odds for type 2 diabetes, metabolic syndrome and more favourable metabolic profile, including improved waist circumference, cholesterol, triglycerides, and insulin levels. Thus, I expect that the difference in sitting time in our studies is of high importance to explain the beneficial effects of the SitLess regimen in insulin sensitivity, glycaemic control and circulating lipids.

\section{Biological mechanisms}

The health effects of MVPA have been investigated for over 50 years and therefore, many health benefits as well as the molecular pathways underlying these benefits have been revealed. Given the little knowledge on sedentary behaviour and LPA, most of the biological pathways underlying its health effects still need to be explored.

\section{Lipid metabolism}

In our studies, we observed marked improvements in triglycerides and HDL-cholesterol after the SitLess regimen. Animal studies suggest that changes in lipoprotein lipase may be responsible for the beneficial effects of LPA on triglycerides and HDL-cholesterol [36]. Lipoprotein lipase is responsible for triglyceride uptake from the blood and plays a role in HDL-cholesterol regulation [36]. Bey et al. observed, in an animal study, that muscle inactivity decreased muscle LPL activity several times compared to standing and slow walking [36]. Although it has been established that MVPA increases LPL activity in humans [149], to my knowledge, human studies comparing the effect of LPA on LPL-activity have not been performed so far. Another possibility for the HDL increase observed after the SitLess regimen is a decrease in cholesteryl ester transfer protein (CETP), which typically occurs after MVPA [150]. In addition to triglycerides and HDL-cholesterol, we also observed a decrease in non-HDL cholesterol after the SitLess regimen. In line with this result, apolipoprotein $B$, which is responsible for non-HDL cholesterol transport and which is an important cardiovascular risk factor [151], also decreased after the SitLess regimen. Since we did not observe significant differences in LDL-cholesterol, I expect that the SitLess regimen resulted in a decrease in larger-dense (VLDL and IDL) cholesterol.

\section{Insulin sensitivity and glucose metabolism}

As discussed above, I conclude that activity intensity, activity pattern as well as activity duration/sitting time are important determinants for the positive effect of physical activity on glycaemic control. I will discuss their mechanisms below. The duration of physical activity was more than two times longer during the SitLess regimen compared to the 
Exercise regimen in the studies described in this dissertation. Insulin stimulates the uptake of glucose in muscle and various other insulin-sensitive tissues by stimulating the translocation of the glucose transporter 4 (GLUT4) from intracellular vesicles site to the cell wall [152]. Once inserted into the cellular membrane, GLUT4 enables facilitated diffusion of extracellular glucose into the muscle cell down its concentration gradient. Muscle contraction also stimulates this process of GLUT4 translocation, independent of the circulating insulin levels. Moreover, physical activity also increases the expression of GLUT4 in skeletal muscle [153] and is associated with an improvement in insulinstimulated glucose uptake [152]. Since in our studies, duration of physical activity seemed more important for insulin sensitivity than its intensity, it is likely that the duration of the muscle contractions is more important than the intensity of these contractions for a sustained effect on GLUT4 translocation and expression. The same would apply when prolonged periods of sitting are frequently interrupted with brief periods of standing or walking. Therefore, the longer duration as well as regularly interrupting sitting time may be responsible for the positive effects on insulin sensitivity observed after the SitLess regimen in the studies reported in this dissertation. It is also possible that LPA affects other insulin signalling pathways. Indeed, an experimental laboratory study in which sitting was interrupted every 20-30 min with light walking observed improvements in other insulin signalling pathways (protein kinase B/AKT) in muscle tissue after 3 days [102].

During the Exercise regimen, insulin sensitivity did not improve in the studies described in this dissertation. Sitting time was about 5-6 h/day longer during the Exercise regimen compared to the SitLess regimen. I expect that prolonged sitting ( $13 \mathrm{~h} /$ day) induced changes in insulin signalling pathways which could not be reversed by $1 \mathrm{~h} /$ day of structured MVPA, but how and which pathways are affected remains to be determined. Finally, the beneficial effects of LPA on insulin sensitivity might also be, perhaps in part, be mediated by changes in oxidative capacity of the skeletal muscles. Skeletal mitochondrial dysfunction is currently presumed to be one of the important causes of insulin resistance in type 2 diabetes, although this relationship needs to be further explored [154]. Exercise training, usually MVPA, was in several intervention studies associated with a marked improvement in mitochondrial function $[155,156]$ and insulin sensitivity $[157,158]$. However, when sedentary subjects with type 2 diabetes increased the number of daily steps from a mean of approximately 6000 to 12000 steps/days, basal ATP use or phosphocreatine recovery after an acute MVPA bout remained unaltered. Whether LPA improves oxidative capacity of the skeletal muscles in parallel with changes in glucose uptake in sedentary subjects remains to be determined.

Based on the aforementioned studies [102, 152-156], it is reasonable to assume that adaptations in GLUT4 recruitment and other insulin signalling pathways underlie the 
results of our studies that showed higher insulin sensitivity after the SitLess regimen than after the Exercise regimen. However, further studies will be necessary to confirm these assumptions.

\section{Methodology}

\section{Study design}

Cross-sectional studies provide the opportunity to investigate associations between lifestyle determinants and diseases. However, these studies do not provide the possibility to prove causality. Therefore, intervention studies are needed. Ideally, long-term randomised clinical trials need to be carried out to investigate whether a decrease in sitting time results in a lower incidence of cardiometabolic diseases. However, these studies are difficult to carry out due to many reasons including the long duration (often over 10 years) and high number of participants needed. As an alternative, interventions of shorter duration can be carried out which investigate the effect of a lifestyle change on risk factors for developing a disease, such as the studies described in this dissertation. However, while these studies are able to reveal the underlying biological mechanisms of an intervention, these short-term studies do not provide an answer whether these changes in cardiovascular risk factors will result in lower rates of cardiometabolic disease in the longer-term. Therefore, both observational as intervention studies are needed to determine and understand the health effects of an intervention.

The studies described in this dissertation were short-term intervention studies, performed under highly standardised conditions, which investigated the effect of a lifestyle change on cardiovascular risk factors. Our studies had a randomised cross-over design; this implicated that each participant carried out three activity regimens (Sit, SitLess and Exercise) in a randomised order. In order to avoid carry-over effects, a wash-out period of at least 10 days was scheduled between the activity regimens. To correct for regimen order, blocked randomisation was performed to make sure that each regimen order was carried out approximately the same number of times in each study. In addition, we corrected for regimen order in the statistical models in chapters 3-5.

We took several measures to guarantee strict adherence to the study protocol. Before the start of the study, the participants performed a try-out day of the SitLess regimen (in chapters 3 and 4 ) as well as a cycling test (chapter 4) in order to include only those participants that were able to adhere to the activity protocol. During the 4-day activity regimens, physical activity was recorded with the activPAL, a pedometer, a stopwatch and a diary (chapters 2-4). During the study, the participants visited the research institute on the second and fourth day of each activity regimen to receive feedback on adherence to physical activity and diet requirements. When diet or physical activity requirements were 
not followed per protocol, participants visited the research institute for additional feedback and instructions. This approach resulted in strict adherence to physical activity levels and diet according to the research protocol as reported in chapters 2, 3 and 4.

\section{Selection bias}

Selection bias occurs when the selection of individuals is carried out in such a way that the sample obtained is not representative of the population intended to be investigated. We selected participants by advertisements in different kinds of media, including poster advertisements at the university and the hospital but also in newspapers and via online websites. In- and exclusion criteria were used to select only participants who were able to carry out the activity regimens in daily life circumstances. This approach may have resulted in a selection of participants who were on average healthier than a random sample of the population. However, the participants served as their own control and an important strength is that comparable results were observed in three different studies in three different populations ranging from young adults with normal weight to overweight/obese adults with type 2 diabetes. As demonstrated in chapter 5, no major differences in insulin sensitivity and circulating lipids in response to the activity regimens were observed between these different populations. Therefore, we expect to observe similar effects in a less healthy population.

\section{Information bias}

Information bias is defined as bias that occurs in the collection or measurement of data. I will discuss below the different types of information bias that were of importance in our study design.

\section{Physical activity}

In order to measure physical activity in our studies, we used the activPAL. The activPAL is an accelerometer which is accurate in objectifying sitting/lying, standing and stepping in free-living conditions [83]. The activPAL was waterproof attached to the upper leg and enabled us to measure physical activity $24 \mathrm{~h} /$ day; non-wear time was therefore not an issue. A disadvantage of the use of this accelerometer is that it is not able to discriminate between sitting and lying and thus not able to estimate sleeping time. Therefore, a diary was used in chapters 2 and 4 and a validated algorithm [85] was used in chapter 3 in order to estimate sleeping time.

\section{Energy expenditure}

Whilst the activPAL is accurate in objectifying posture and activity, it is not accurate in measuring energy expenditure. In comparison to other accelerometers, the measurement error of the activPAL for energy expenditure is low for sedentary and light-intensity activities [115]. However, the activPAL is not accurate in estimating energy expenditure 
when the intensity of the activity is high, such as during running or cycling. In order to provide a valid estimation of the energy expenditure during cycling, we used heart rate (chapter 2) or workload (in wattage) of cycling (chapter 4). In comparison with the gold standard (doubly labelled water), these methods are accompanied by a larger measurement error and therefore reflect only a proxy of true energy expenditure. Thus, while the SitLess and Exercise regimens in chapters 2 and 4 were designed to have comparable energy expenditure, I cannot rule out that differences in energy expenditure existed between the SitLess and Exercise regimens. If this would be the case, I can still conclude that performing light activities (LPA) during a longer period over the day (5-6 $\mathrm{h}$ /day) is equally or more beneficial for insulin sensitivity, glycaemic control and circulating lipids than $1 \mathrm{~h}$ /day of MVPA combined with sitting the rest of the day. Vice versa, $1 \mathrm{~h} /$ day of MVPA seems more effective than longer periods of LPA for circulating endothelial markers.

\section{Outcome measures}

We estimated insulin sensitivity by means of the Matsuda-index based on an oral glucose tolerance test or by means of HOMA-IR based on fasting blood values. These methods have a higher measurement error compared to the gold standard (hyperinsulinaemiceuglycaemic clamp). However, both the Matsuda index ( $r=0.73$ ) [95] as the HOMA-IR ( $r=$ -0.59 till -0.73$)[159,160]$ highly correlate with the clamp, and therefore provide a valid estimation of insulin sensitivity.

We used a continuous glucose monitoring system (CGM) to measure 24-h glucose levels in type 2 diabetic participants. This method provides the opportunity to measure glucose in the interstitial fluid every 5 minutes. Physiological differences between interstitial and venous blood glucose levels and signal stability are factors that require consideration when interpreting CGM data [161, 162]. However, the device used in our studies has a high accuracy [163] and the difference in intra-individual coefficient of variation between venous blood samples and CGM measurements has been reported to be low $133.4 \%$ respectively $44.9 \%)$ [164].

\section{Clinical implications and recommendations for further research}

The results described in this dissertation build further on observational $[21,22,24,25$, $148,165]$ and experimental studies in laboratory conditions [32-35, 74, 102, 141, 166]. Our studies were proof-of-concept studies, and therefore the amounts of physical activity during the SitLess and Exercise regimens were high compared to the average amount of physical activity in a Western population. The number of steps during the Sit Less regimens (> 17000 steps/day) was well above what is on average observed in a healthy population (6000 - 13000 steps/day) [108] and the duration of MVPA (1 h/day cycling) 
was also twice as high as the recommended $30 \mathrm{~min} /$ day of MVPA [3]. However, observational work reported that substituting a low amount of sitting ( $30 \mathrm{~min} /$ day) with standing or stepping was associated with lower risk for type 2 diabetes, metabolic syndrome and cardiovascular risk factors [148]. Thus, the next logical step is to perform dose-response studies to inform about the optimal duration and pattern of non-sitting time as well as time spent in LPA. Especially, long-term studies are needed to define the optimal LPA dose and pattern that is feasible in real life circumstances. In parallel, more fundamental research is necessary to understand the underlying biological mechanisms of the acute and chronic effect of our interventions on cardiometabolic health.

The main outcome measures in the studies presented in this dissertation included insulin sensitivity, glycaemic control, lipid metabolism and endothelial markers. We also investigated the effects of LPA on mood and cognition in one study. However, as these findings were exploratory, more research is needed on these outcome measures. To provide more information on the different aspects of health, future studies should also address markers of inflammation, liver function and bone metabolism. In addition to risk factors of disease, RCT's are needed to investigate the long-term effect of increasing LPA on incidences of cardiometabolic diseases and mortality.

The combination of the findings of observational [21, 22, 24, 25, 148, 165], laboratory [32$35,74,102,141,166]$ and our intervention studies in free-living conditions strongly suggest that substituting sitting with LPA seems important for cardiometabolic health. However, it will probably take several decades before the optimal LPA dose and pattern on cardiometabolic health will become clear. In the meantime, in addition to MVPA recommendations, many guidelines including these from the World Health Organization (WHO) [3] and U.S. Government [167] need an update (and will be updated soon) based on the knowledge collected in the last decade on LPA and sedentary behaviour. Other more recent guidelines from The Netherlands, UK and Australia have added that sitting should be reduced and/or recommend to break up sitting regularly [168-170]. While it is still debated whether prolonged sitting bouts are a cardiovascular risk factor, independent of total sitting time [21, 171], breaking up sitting regularly can be an effective tool to accumulate more daily physical activity. While the ideal amount of non-sitting time still needs to be determined, the recent position statement from Buckley and colleagues provides a good guideline for non-sitting time at work [172]. These authors recommend that at least $2 \mathrm{~h} /$ day of sitting should be replaced by standing and stepping. While this might seem a large amount of activity in comparison to the recommended $30 \mathrm{~min} /$ day of MVPA in the WHO guidelines, simple changes like replacing a sitting desk by a sit-to-stand desk seem effective to reduce sitting time in the long-term [173]. Not only new guidelines are necessary but also governmental agencies and companies will need to take their responsibility to make these guidelines feasible in our daily life. 


\section{Summary}

In summary, the results described in this dissertation suggest that sitting time and activity intensity seem to have different effects on cardiovascular and metabolic health. On one hand, reducing sitting time by increasing light physical activity seems important for insulin sensitivity, glycaemic control and plasma lipids. On the other hand, moderate-to-vigorous activity seems more important for circulating markers of endothelial dysfunction. As a consequence, reducing sitting time by light activities as well as regularly performing more strenuous physical activities seem both important to maintain cardiometabolic health. 



\title{
CHAPTER 7
}

\author{
VALORISATION \\ SUMMARY \\ SAMENVATTING \\ REFERENCES \\ DANKWOORD \\ CURRICULUM VITAE \\ LIST OF PUBLICATIONS
}



VALORISATION 


\section{Social relevance}

In the 21st century, people in westernised countries are living in a sedentary-promoting environment. Urbanisation promotes the use of motorised vehicles and labour-saving devices have been developed in order to increase the 'efficiency' of daily tasks at the expense of human locomotion. Examples include cars, dishwashers and elevators. In the last decades, the use of screens (e.g. TV's, laptops and smartphones) is making us even more sedentary. As a result, sedentary behaviour has increased and physical activity levels have dropped since the begin of the $20^{\text {th }}$ century.

The increase in sedentary time has been associated with an increased risk of cardiometabolic diseases, depression and premature mortality, independent of the time spent in moderate-to-vigorous physical activity (e.g. structured exercise). The societal and economic burden of these diseases is high and can be partially prevented. Worldwide, government parties developed physical activity guidelines in order to increase physical activity. These guidelines advise to perform 30 minutes of moderate-to-vigorous physical activity (e.g. exercise) five times per week. However, these guidelines do not provide guidance on what to do the other 15.5 waking hours of the day. Is it for instance also healthy to be sitting $15.5 \mathrm{~h} /$ day because you perform 30 minutes of exercise daily? What about the non-exercise activities (standing, cooking, doing groceries, dishwashing, vacuuming)? Epidemiological studies observed that we perform on average about $8 \mathrm{~h} /$ day of light-intensity activities. Is its health effect negligible? The results of the studies presented in this dissertation suggest that the negative effects of sitting the entire day cannot be fully compensated by daily moderate-to-vigorous physical activity (e.g. exercise) only. We observed that substituting sitting with daily (light) activities was at least as important as moderate-to-vigorous physical activity to improve cardiovascular risk factors. Moderate-to-vigorous physical activity had additional health benefits which cannot be achieved by performing light activities only. Vice versa, light physical activity was more effective than moderate-to-vigorous physical activity for some cardiovascular risk factors. Thus, not only moderate-to-vigorous physical activity but also light physical activity seems important to improve cardiovascular risk factors.

\section{Physical activity guidelines}

A body of observational evidence suggests that sedentary behaviour is an important risk factor for cardiometabolic health. It is important that society gets informed about the negative health effects of too much sitting and about strategies to decrease sedentary behaviour. Indeed, in recent years, governments have formulated 'sedentary behaviour guidelines'. Physical activity guidelines from The Netherlands, UK and Australia advise now to reduce daily sitting time. Other physical activity guidelines will be updated soon. 
While we spend on average about $8 \mathrm{~h}$ of our day in light physical activity, the physical activity guidelines do not or hardly provide guidance on light physical activity. The studies presented in this thesis underline the importance of substituting sitting with light physical activity for cardiometabolic health. In addition to epidemiological evidence, our studies are supported by a rapidly expanding amount of intervention studies. Based on the evidence available, in my opinion, the physical activity guidelines should also advise to increase light physical activity. In contrast to most physical activity guidelines, a position statement from an international group of experts recommends people with a desk based job 'to accumulate at least $2 \mathrm{~h}$ /day of standing and light activity (light walking) during working hours'. While it must be admitted that further research is necessary to determine the optimal dose of daily light physical activity (e.g. standing and ambulatory activities), it is better to have some kind of guidance based on non-conclusive evidence than to have no guideline at all. For instance, in line with recent guidelines on sedentary behaviour, guidelines can also advise to increase light physical activity without the need to specify its duration.

\section{Translation into practice}

In addition to guidelines, there are many possibilities for government agencies and companies to provide people with the opportunity to decrease sedentary behaviour and increase physical activity on a daily basis. As our society is 'built to sit', there are many possibilities to encourage daily physical activity in all age groups, for instance by making streets walk and bike friendly, (re)building schools with more (green) playgrounds and replacing sitting desks by sit-to-stand/walk desks. People with a high daily sitting time are often people who need to perform their work in a seated position. Based on the evidence available, spending about $8 \mathrm{~h} /$ day seated at work seems an important work-related health risk. Replacing 'normal' sitting desks with sit-to-stand/walk desks provides employees at least the choice between sitting and standing. Unfortunately, the opposite is true in most countries, many employees are now obligated to perform their work in a seated position.

The results from this dissertation may encourage people at individual level to decrease sitting time in various ways at work and in their leisure time. As a day counts 16 waking hours, there are many possibilities to incorporate more physical activity into daily life; examples include biking to work, parking the car further from work, taking the stairs instead of the elevator, walking during lunch breaks, phone calls and meetings while standing or stepping, walking the dog, etc. Whilst screens in general seem to increase sedentary behaviour, screens can be a friend as well to decrease sedentariness. For instance, the popularity of 'activity watches' and activity applications on smartphones is increasing rapidly. These devices are in general not able to identify posture (sitting/standing/lying) but are accurate in the measurement of physical activity. Given the 
wide use of activity trackers, the possibility to be carried $24 \mathrm{~h} /$ day and immediate feedback options, they provide a unique opportunity to reduce sedentary time at a personalised level.

\section{Recommendations for further research}

Studies carried out so far have identified prolonged sitting as a cardiovascular risk factor and intervention studies of short duration found that substituting sitting with light physical activity improved cardiovascular risk factors. Dose-response studies are now needed to inform about the optimal intensity, duration and pattern of non-sitting as well as time spent in light physical activity. For instance, the health effects of different types of sedentary behaviour (sitting in a couch versus sitting at a desk versus sitting on a fitness ball) have yet to be identified. Especially, long-term studies are needed to define the optimal dose and pattern that is effective and feasible in real life circumstances. In parallel, more fundamental research is necessary to understand the underlying biological mechanisms of light physical activity on cardiometabolic health.

In addition to risk factors and biological mechanisms of disease, RCT's are needed to investigate the long-term effect of increasing light physical activity on the incidence of cardiometabolic diseases. Along with the focus of this dissertation on cardiometabolic health, further research should shed light on the effect of sedentary behaviour and light physical activity on other health aspects including bone metabolism, liver function, inflammation, mood, cognition and mortality. 

SUMMARY 
In the last decades, our society has become increasingly more sedentary. The majority of the western population spends approximately half of the waking day sedentary, e.g. driving the car, doing office work and watching TV. In order to increase physical activity, the World Health Organization advises to perform $150 \mathrm{~min} /$ week of moderate-to-vigorous physical activity (MVPA). Despite its positive health benefits, adherence to the physical activity guidelines is low. Even for people adhering to these guidelines, there are about 15.5 waking $\mathrm{h} /$ day left that can be spent sitting. Epidemiological studies suggest that prolonged sitting is detrimental to health, independent of the time spent in MVPA. In addition to sitting and MVPA, the other part of our waking day is spent in light physical activity (LPA). However, in contrast to MVPA, little is known about LPA. Observational studies reported that increased time spent in LPA, like standing and light walking, has been associated with lower risk of cardiovascular disease and mortality. However, few intervention studies have been performed on the health effects of substituting sitting with LPA. Moreover, it was not known whether the health effects of prolonged sitting were independent of energy expenditure. Therefore in this dissertation, I compared the effects of substituting sitting with LPA (standing and slow pace walking) and MVPA (cycling on ergometer at $50-60 \% W_{\max }$ ) on cardiovascular risk factors when estimated energy was comparable between LPA and MVPA. The studies described in this dissertation had a comparable design but the investigated population and/or the outcome measures differed between the studies. In all studies, the participants followed a Sit and a SitLess (LPA) regimen in a randomised order (chapters 2-4). In two of the three studies, the participants also followed an Exercise (MVPA) regimen (chapters 2 and 4). Each intervention lasted 4 days; physical activity (objectively measured with accelerometry), energy expenditure and diet were standardised during each intervention.

In Chapter 2, we investigated the effects of substituting sitting with LPA (standing and light walking) and MVPA (cycling) on biomarkers of glucose and lipid metabolism. In this study, we observed that substituting sitting with LPA improved plasma insulin and lipids (triglycerides, non-HDL cholesterol and apolipoprotein B) in healthy young subjects with normal weight. In contrast, this study showed that 1 hour of daily MVPA combined with a high sitting time did not significantly improve biomarkers of glucose and lipid metabolism compared to a sitting regimen. These results suggest that substituting sitting with standing and light walking is an effective approach to improve cardiovascular risk factors. In addition, these results suggest that the negative effects of prolonged sitting on glucose and lipid metabolism cannot be fully compensated by MVPA only.

In Chapter 3, we investigated the effects of substituting sitting with LPA in overweight/obese subjects on blood pressure, glucose, and lipid metabolism. In this study, we observed that substituting sitting with standing and light walking improved insulin sensitivity (Matsuda index), several biomarkers of lipid metabolism (triglycerides, free 
fatty acids, HDL-cholesterol, non-HDL cholesterol and apolipoprotein B) and diastolic blood pressure. We also explored the effects of LPA on mood and cognition but only observed a small improvement in mood after the LPA intervention.

In Chapter 4, we investigated the effects of substituting sitting with LPA and MVPA in overweight/obese subjects with type 2 diabetes. Outcome measures included 24-hour glucose regulation (measured with continuous glucose monitoring), insulin sensitivity (HOMA2-IR) and biomarkers of lipid metabolism. Substituting sitting with LPA (standing and walking) for 4 days improved 24-hour glucose regulation and plasma lipids (triglycerides and free fatty acids) to a comparable degree as MVPA (cycling). Moreover, LPA improved insulin sensitivity more than MVPA. The results observed in this study are promising as many patients with type 2 diabetes have difficulties to perform MVPA.

In Chapter 5, we combined the results of the studies described in chapters 2-4 and compared the effects of LPA vs. MVPA on circulating biomarkers of endothelial function, insulin sensitivity and lipid metabolism. In line with the results previously described, we observed that LPA -but not MVPA- was effective in improving insulin sensitivity and biomarkers of lipid metabolism. Interestingly, however, MVPA -but not LPA- improved biomarkers of endothelial function. These data indicate that reducing sitting time with LPA and MVPA have differential effects on cardiovascular risk factors.

In Chapter 6, I discussed the main findings, methodological considerations and clinical implications of the studies presented in this dissertation by relating them to existing literature. The studies described in this dissertation investigated the effect of different activity strategies on cardiovascular risk factors. Strengths of my studies include the strict adherence to the activity regimens in free-living conditions, objective measurement of physical activity by accelerometry and standardisation of diet. Limitations of the studies include the estimation of energy expenditure and the short duration of the intervention studies. Future studies are needed to investigate underlying biological mechanisms and the feasibility and cardiovascular effects of light activities on the longer-term.

In conclusion, the results described in this dissertation suggest that the negative health effects of too much sitting cannot be compensated by structured exercise only. The results suggest that interrupting sitting regularly with light activities improves cardiovascular risk factors, independent of an increase in energy expenditure. Moreover, the results suggest that substituting sitting with light versus moderate-to-vigorous physical activity have different effects on cardiovascular and metabolic health. As a consequence, not only structured exercise but also reducing sitting time and substituting it with light activities seem also important to improve cardiometabolic health. In one short sentence: sit less and move more! 

SAMENVATTING 
Te veel zitten is een belangrijke risicofactor voor het ontstaan van hart- en vaatziekten, suikerziekte en vroegtijdig overlijden. Om deze effecten tegen te gaan adviseert de Wereldgezondheidsorganisatie dagelijks 30 minuten matig tot zwaar intensieve activiteit (bv. sporten). Ondanks de vele gezondheidsvoordelen van sporten lukt dit veel mensen niet. Daarnaast is het onduidelijk wat iemand de overige 15,5 uur van de dag moet doen: mogen we de rest van de dag blijven zitten? Epidemiologische studies suggereren dat het negatieve gezondheidseffect van zitten onafhankelijk is van de hoeveelheid sport die iemand uitvoert. Er zijn echter slechts weinig interventiestudies die het gezondheidseffect van zitten en lichte activiteiten (bv. staan en langzaam wandelen) hebben onderzocht. In het bijzonder zijn er weinig studies die onderzocht hebben of de positieve gezondheidseffecten van lichte activiteiten onafhankelijk zijn van een stijging in het calorieverbruik. Daarom heb ik in dit proefschrift de effecten vergeleken van sporten versus lichte activiteiten, bij een gelijk calorieverbruik. De proefpersonen volgden een 'minder zitten' (zitten vervangen door lichte activiteiten) interventie en een 'sport' interventie (matig tot zwaar intensieve activiteit) waarbij het calorieverbruik gelijk was tussen beide interventies. Ter controle volgde alle proefpersonen ook een 'zit' interventie. Elke interventie duurde 4 dagen, beweging en houding werden gemeten met een activiteitenmeter en het dieet werd gestandaardiseerd tijdens elke interventie. De effecten van deze beweeginterventies werden onderzocht in drie verschillende studies. De studies hadden een vergelijkbaar design en verschilden met name in de onderzochte populatie en/of uitkomstmaten.

In Hoofdstuk 2 hebben we het effect van lichte activiteit (staan en langzaam wandelen) versus matig tot zwaar intensieve activiteit (fietsen) op de suiker- en vetstofwisseling onderzocht. De resultaten van deze studie tonen aan dat wanneer zitten vervangen wordt door lichte activiteiten, de insuline- en vetwaarden in het bloed verminderen bij gezonde proefpersonen met een normaal gewicht. In vergelijking, 1 uur (matig tot zwaar intensief) sporten en de rest van de dag stil zitten had geen statistisch significant effect op deze waarden. De resultaten van deze studie suggereren dat zitten vervangen door lichte activiteiten zoals staan en langzaam wandelen een effectieve manier is om risicofactoren voor hart- en vaatziekten te verminderen. Daarnaast suggereren de resultaten ook dat de negatieve effecten van veel zitten niet volledig gecompenseerd kunnen worden door iedere dag 1 uur te sporten.

In Hoofdstuk 3 hebben we het effect van lichte activiteit (staan en langzaam wandelen) op de suiker- en vetstofwisseling en de bloeddruk onderzocht bij mensen met overgewicht en obesitas. De resultaten van deze studie suggereren dat zitten vervangen door lichte activiteiten leidt tot een verbetering van de insulinegevoeligheid, de vetten in het bloed en de diastolische bloeddruk. Tevens hebben we in deze studie de effecten van lichte 
activiteit op stemming en cognitie onderzocht, waarbij we enkel bij vrouwen een verbetering vonden in stemming als respons op lichte activiteit.

In Hoofdstuk 4 hebben we het effect van lichte activiteit (staan en langzaam wandelen) en matig tot zwaar intensieve activiteit (fietsen) onderzocht bij mensen met diabetes mellitus (suikerziekte) type 2. De uitkomstmaten in deze studie waren de 24-uur glucosewaarden, insulinegevoeligheid (HOMA2-IR) en vetwaarden in het bloed. De resultaten van deze studie suggereren dat, bij een gelijk calorieverbruik, zitten vervangen door lichte activiteiten even effectief is voor de glucosewaarden als (matig tot zwaar intensief) sporten. Daarnaast bleek lichte activiteit meer effectief dan sport in het verbeteren van de insulinegevoeligheid. De resultaten van deze studie kunnen belangrijk zijn voor mensen met diabetes omdat zij vaak minder goed in staat zijn om te sporten dan mensen zonder diabetes.

In Hoofdstuk 5 hebben we de effecten van lichte versus matig tot zwaar intensieve activiteit op endotheelmarkers onderzocht in de drie hiervoor beschreven populaties (proefpersonen zonder overgewicht, proefpersonen met overgewicht en proefpersonen met suikerziekte type 2 ). De resultaten van de endotheelmarkers heb ik vergeleken met de effecten op de insulinegevoeligheid en vetwaarden in het bloed. In lijn met de bovenstaande resultaten, suggereren de resultaten dat lichte activiteit de insulinegevoeligheid en vetwaarden in het bloed verbetert en dat (matige tot zwaar intensief) sporten deze waarden niet verbetert in combinatie met veel zitten. In tegenstelling tot deze resultaten verbeterde sporten wel de endotheelmarkers in het bloed, terwijl dit niet het geval was voor lichte activiteit. Deze data suggereren dat zitten vervangen door lichte versus matig tot zwaar intensieve activiteit verschillende effecten heeft op risicofactoren voor hart- en vaatziekten.

In Hoofdstuk 6 beschrijf ik de belangrijkste bevindingen, methodologische overwegingen en klinische implicaties van de gepresenteerde studies. De studies beschreven in dit proefschrift onderzochten het effect van verschillende soorten lichamelijke activiteiten op risicofactoren voor hart- en vaatziekten. Een sterk methodologisch punt van de studies was dat de proefpersonen zich strikt hielden aan de opgelegde activiteitenregimes en dat dit objectief werd gemeten door een activiteitenmeter gedurende $24 \mathrm{u} / \mathrm{dag}$. Tevens werd het dieet strikt gecontroleerd en werden de activiteitenregimes uitgevoerd in de thuissituatie waardoor de resultaten beter te vertalen zijn naar de dagdagelijkse praktijk. Beperkingen van de studies omvatten onder meer de korte duur van de studies en de schatting van het calorieverbruik, waardoor verschillen in calorieverbruik tussen de twee activiteitenregimes niet kunnen worden uitgesloten. $\mathrm{Er}$ dient vervolgonderzoek te gebeuren om de onderliggende biologische mechanismen te ontrafelen en om de 
haalbaarheid en de gezondheidseffecten van lichte activiteit op lange termijn te onderzoeken.

De resultaten beschreven in dit proefschrift suggereren dat het negatieve gezondheidseffect van een hele dag stil zitten niet gecompenseerd kan worden door enkel te sporten. De resultaten suggereren dat het ook belangrijk is om het zitten te vervangen door lichte activiteiten, en dat dit effect optreedt onafhankelijk van het calorieverbruik. Tevens suggereren de resultaten dat lichte activiteit andere effecten heeft op risicofactoren voor hart- en vaatziekten dan (matig tot zwaar intensief) sporten. Samenvattend lijkt het daarom niet alleen belangrijk om meer te sporten maar ook om minder te zitten en het zitten te vervangen door lichte activiteiten zoals staan en langzaam wandelen. Mijn advies luidt dus als volgt: zit minder en beweeg meer! 

REFERENCES 
1. Mendis, S., et al., Organizational update: the world health organization global status report on noncommunicable diseases 2014; one more landmark step in the combat against stroke and vascular disease. Stroke, 2015. 46(5): p. e121-2.

2. Ng, S.W. et al., Time use and physical activity: a shift away from movement across the globe. Obes Rev, 2012. 13(8): p. 659-80.

3. World Health Organization. Global recommendations on physical activity for health. WHO Press, 2010. Geneva, Switzerland.

4. Naci, $\mathrm{H}$. et al., Comparative effectiveness of exercise and drug interventions on mortality outcomes: metaepidemiological study. Br J Sports Med, 2015. 49(21): p. 1414-22.

5. O'Donovan, G., et al., Association of "weekend warrior" and other leisure time physical activity patterns with risks for all-Cause, cardiovascular disease, and cancer mortality. JAMA Intern Med, 2017. 177(3): p. 335-342.

6. Hamer, M. et al., Walking and primary prevention: a meta-analysis of prospective cohort studies. Br J Sports Med, 2008. 42(4): p. 238-43.

7. Metkus, T.S., et al., Exercise prescription and primary prevention of cardiovascular disease. Circulation, 2010. 121(23): p. 2601-4.

8. Powell, K.E., et al., Physical activity and the incidence of coronary heart disease. Annu Rev Public Health, 1987. 8: p. 253-87.

9. Thompson, P.D., et al., Exercise and physical activity in the prevention and treatment of atherosclerotic cardiovascular disease: a statement from the Council on Clinical Cardiology (Subcommittee on Exercise, Rehabilitation, and Prevention) and the Council on Nutrition, Physical Activity, and Metabolism (Subcommittee on Physical Activity). Circulation, 2003. 107(24): p. 3109-16.

10. Jolliffe, J.A., et al., Exercise-based rehabilitation for coronary heart disease. Cochrane Database Syst Rev, 2001(1): p. CD001800.

11. Centers for Disease Control and Prevention. 2014 National Diabetes Statistics Report, 2014. Available from https://www.cdc.gov/diabetes/data/, accessed 28 February 2017.

12. Wojtaszewski, J.F., et al., Insulin signaling and insulin sensitivity after exercise in human skeletal muscle. Diabetes, 2000. 49(3): p. 325-31.

13. Knowler, W.C., et al., Reduction in the incidence of type 2 diabetes with lifestyle intervention or metformin. N Engl J Med, 2002. 346(6): p. 393-403.

14. Tuomilehto, J., et al., Prevention of type 2 diabetes mellitus by changes in lifestyle among subjects with impaired glucose tolerance. N Engl J Med, 2001. 344(18): p. 1343-50.

15. Pai, L.W., et al., The effectiveness of regular leisure-time physical activities on long-term glycemic control in people with type 2 diabetes: A systematic review and meta-analysis. Diabetes Res Clin Pract, 2016. 113: p. 77-85.

16. van Dijk, J.W., et al., Both resistance- and endurance-type exercise reduce the prevalence of hyperglycaemia in individuals with impaired glucose tolerance and in insulin-treated and non-insulin-treated type 2 diabetic patients. Diabetologia, 2012. 55(5): p. 1273-82.

17. Carlson, S.A., et al., Trend and prevalence estimates based on the 2008 Physical Activity Guidelines for Americans. Am J Prev Med, 2010. 39(4): p. 305-13.

18. Marques, A., et al., Prevalence of physical activity in European adults - Compliance with the World Health Organization's physical activity guidelines. Prev Med, 2015. 81: p. 333-8.

19. Tucker, J.M., et al., Physical activity in U.S.: adults compliance with the Physical Activity Guidelines for Americans. Am J Prev Med, 2011. 40(4): p. 454-61.

20. Matthews, C.E., et al., Amount of time spent in sedentary behaviors in the United States, 2003-2004. Am J Epidemiol, 2008. 167(7): p. 875-81.

21. van der Berg, J.D., et al., Associations of total amount and patterns of sedentary behaviour with type 2 diabetes and the metabolic syndrome: The Maastricht Study. Diabetologia, 2016. 59(4): p. 709-18. 
22. Biswas, A., et al., Sedentary time and its association with risk for disease incidence, mortality, and hospitalization in adults: a systematic review and meta-analysis. Ann Intern Med, 2015. 162(2): p. 123-32.

23. Koster, A., et al., Association of sedentary time with mortality independent of moderate to vigorous physical activity. PLoS One, 2012. 7(6): p. e37696.

24. Matthews, C.E., et al., Accelerometer-measured dose-response for physical activity, sedentary time, and mortality in US adults. Am J Clin Nutr, 2016. 104(5): p. 1424-1432.

25. Proper, K.I., et al., Sedentary behaviors and health outcomes among adults: a systematic review of prospective studies. Am J Prev Med, 2011. 40(2): p. 174-82.

26. Schuna, J.M., et al., Adult self-reported and objectively monitored physical activity and sedentary behavior: NHANES 2005-2006. Int J Behav Nutr Phys Act, 2013. 10: p. 126.

27. Pate, R.R., et al., The evolving definition of "sedentary". Exerc Sport Sci Rev, 2008. 36(4): p. 173-8.

28. Young, D.R., et al., Sedentary behavior and cardiovascular morbidity and mortality: A science advisory from the American Heart Association. Circulation, 2016. 134(13): p. e26279.

29. Buman, M.P., et al., Reallocating time to sleep, sedentary behaviors, or active behaviors: associations with cardiovascular disease risk biomarkers, NHANES 2005-2006. Am J Epidemiol, 2014. 179(3): p. 323-34.

30. Kim, J., et al., Objectively measured light-intensity lifestyle activity and sedentary time are independently associated with metabolic syndrome: a cross-sectional study of Japanese adults. Int J Behav Nutr Phys Act, 2013. 10: p. 30.

31. van der Ploeg, H.P., et al., Standing time and all-cause mortality in a large cohort of Australian adults. Prev Med, 2014. 69: p. 187-91.

32. Dempsey, P.C., et al., Benefits for type 2 diabetes of interrupting prolonged sitting with brief bouts of light walking or simple resistance activities. Diabetes Care, 2016. 39(6): p. 964-72.

33. Dunstan, D.W., et al., Breaking up prolonged sitting reduces postprandial glucose and insulin responses. Diabetes Care, 2012. 35(5): p. 976-83.

34. Henson, J., et al., Breaking up prolonged sitting with standing or walking attenuates the postprandial metabolic response in postmenopausal women: a randomized acute study. Diabetes Care, 2016. 39(1): p. 130-8.

35. Peddie, M.C., et al., Breaking prolonged sitting reduces postprandial glycemia in healthy, normal-weight adults: a randomized crossover trial. Am J Clin Nutr, 2013. 98(2): p. 358-66.

36. Bey, L., et al., Suppression of skeletal muscle lipoprotein lipase activity during physical inactivity: a molecular reason to maintain daily low-intensity activity. J Physiol, 2003. 551(Pt 2): p. 673-82.

37. Haskell, W.L., et al., Physical activity and public health: updated recommendation for adults from the American College of Sports Medicine and the American Heart Association. Med Sci Sports Exerc, 2007. 39(8): p. 1423-1434

38. Katzmarzyk, P.T., et al., Sitting time and mortality from all causes, cardiovascular disease, and cancer. Med Sci Sports Exerc, 2009. 41(5): p. 998-1005

39. Bey, L. et al., Suppression of skeletal muscle lipoprotein lipase activity during physical inactivity: a molecular reason to maintain daily low-intensity activity. J. Physiol., 2003. 551(2): p. 673-682.

40. Healy, G.N., et al., Television time and continuous metabolic risk in physically active adults. Med Sci Sports Exerc, 2008. 40(4): p. 639-45.

41. Healy, G.N., et al., Objectively measured sedentary time, physical activity, and metabolic risk: the Australian Diabetes, Obesity and Lifestyle Study (AusDiab). Diabetes Care, 2008. 31(2): p. 369-71. 
42. Bankoski, A., et al., Sedentary activity associated with metabolic syndrome independent of physical activity. Diabetes Care, 2011. 34(2): p. 497-503.

43. Krogh-Madsen, R., et al., A 2-wk reduction of ambulatory activity attenuates peripheral insulin sensitivity. J Appl Physiol (1985), 2010. 108(5): p. 1034-40.

44. Stephens, B.R., et al., Effects of 1 day of inactivity on insulin action in healthy men and women: interaction with energy intake. Metabolism, 2011. 60(7): p. 941-9.

45. Hawley, J.A., et al., What's new since Hippocrates? Preventing type 2 diabetes by physical exercise and diet. Diabetologia, 2012. 55(3): p. 535-9.

46. Tucker, J.M., et al., Physical activity in U.S. Adults: compliance with the Physical Activity Guidelines for Americans. Am J Prev Med, 2011. 40(4): p. 454-461.

47. Grant, P.M., et al., The validation of a novel activity monitor in the measurement of posture and motion during everyday activities. Br J Sports Med, 2006. 40(12): p. 992-7.

48. Hiilloskorpi, H.K., et al., Use of heart rate to predict energy expenditure from low to high activity levels. Int J Sports Med, 2003. 24(5): p. 332-6.

49. Friedewald, W.T., et al., Estimation of the concentration of low-density lipoprotein cholesterol in plasma, without use of the preparative ultracentrifuge. Clin Chem, 1972. 18(6): p. 499-502.

50. Matsuda, M., et al., Insulin sensitivity indices obtained from oral glucose tolerance testing: comparison with the euglycemic insulin clamp. Diabetes Care, 1999. 22(9): p. 1462-1470.

51. Ainsworth, B.E., et al., 2011 Compendium of Physical Activities: a second update of codes and MET values. Med Sci Sports Exerc, 2011. 43(8): p. 1575-1581

52. Tudor-Locke, C. et al., How many steps/day are enough? Preliminary pedometer indices for public health. Sports Med, 2004. 34(1): p. 1-8.

53. Blanc, S., et al., Fuel homeostasis during physical inactivity induced by bed rest. J Clin Endocrinol Metab, 2000. 85(6): p. 2223-33.

54. Yanagibori, R., et al., The effects of 20 days bed rest on serum lipids and lipoprotein concentrations in healthy young subjects. J Gravit Physiol, 1997. 4(1): p. S82-90.

55. Magkos, F., et al., No effect of menstrual cycle phase on basal very-low-density lipoprotein triglyceride and apolipoprotein B-100 kinetics. Am J Physiol Endocrinol Metab, 2006. 291(6): p. E1243-9.

56. Yeung, E.H., et al., Longitudinal study of insulin resistance and sex hormones over the menstrual cycle: the BioCycle Study. J Clin Endocrinol Metab, 2010. 95(12): p. 5435-42.

57. Praet, S.F., et al., Brisk walking compared with an individualised medical fitness programme for patients with type 2 diabetes: a randomised controlled trial. Diabetologia, 2008. 51(5): p. 736-46.

58. van Sloten, T.T., et al., Peripheral neuropathy, decreased muscle strength and obesity are strongly associated with walking in persons with type 2 diabetes without manifest mobility limitations. Diabetes Res Clin Pract, 2011. 91(1): p. 32-9.

59. Meijer, E.P., et al., Effect of exercise training on total daily physical activity in elderly humans. Eur J Appl Physiology Occup Physiol, 1999. 80(1): p. 16-21.

60. Healy, G.N., et al., Objectively measured light-intensity physical activity is independently associated with 2-h plasma glucose. Diabetes Care, 2007. 30(6): p. 1384-9.

61. Matthews, C.E., et al., Amount of time spent in sedentary behaviors and cause-specific mortality in US adults. Am J Clin Nutr, 2012. 95(2): p. 437-45.

62. van der Ploeg, H.P., et al., Sitting time and all-cause mortality risk in 222497 Australian adults. Arch Intern Med, 2012. 172(6): p. 494-500.

63. Yanagibori, R., et al., Carbohydrate and lipid metabolism after 20 days of bed rest. Acta Physiol Scand Suppl, 1994. 616(suppl): p. 51-7.

64. Bergouignan, A., et al., Physical inactivity as the culprit of metabolic inflexibility: evidence from bed-rest studies. J Appl Physiol (1985), 2011. 111(4): p. 1201-10. 
65. Dunstan, D.W., et al., Breaking up prolonged sitting reduces postprandial glucose and insulin responses. Diabetes Care, 2012. 35(5): p. 976-983.

66. Hamilton, M.T., et al., Role of low energy expenditure and sitting in obesity, metabolic syndrome, type 2 diabetes, and cardiovascular disease. Diabetes, 2007. 56(11): p. 26552667.

67. Pate, R.R., et al., The evolving definition of "sedentary". Exerc Sport Sci Rev, 2008. 36(4): p. 173-178.

68. Ekblom-Bak, E., et al., Are we facing a new paradigm of inactivity physiology? Br J Sports Med, 2010. 44(12): p. 834-5.

69. Chastin, S.F., et al., Combined effects of time spent in physical activity, sedentary behaviors and sleep on obesity and cardio-metabolic health markers: a novel compositional data analysis approach. PLoS One, 2015. 10(10): p. e0139984.

70. de Rooij, B.H., et al., Physical activity and sedentary behavior in metabolically healthy versus unhealthy obese and non-obese individuals - The Maastricht Study. PLoS One, 2016. 11(5): p. e0154358.

71. Levine, J.A., et al., Interindividual variation in posture allocation: possible role in human obesity. Science, 2005. 307(5709): p. 584-6.

72. Hubert, H.B., et al., Obesity as an independent risk factor for cardiovascular disease: a 26year follow-up of participants in the Framingham Heart Study. Circulation, 1983. 67(5): p. 968-77.

73. Mokdad, A.H., et al., Prevalence of obesity, diabetes, and obesity-related health risk factors, 2001. J Am Med Assoc, 2003. 289(1): p. 76-9.

74. Bailey, D.P., et al., Breaking up prolonged sitting with light-intensity walking improves postprandial glycemia, but breaking up sitting with standing does not. J Sci Med Sport, 2015. 18(3): p. 294-8.

75. McElroy, S.L., et al., Are mood disorders and obesity related? A review for the mental health professional. J Clin Psychiatry, 2004. 65(5): p. 634-51, quiz 730.

76. Smith, E., et al., A review of the association between obesity and cognitive function across the lifespan: implications for novel approaches to prevention and treatment. Obes Rev, 2011. 12(9): p. 740-55.

77. Lamport, D.J., et al., Impairments in glucose tolerance can have a negative impact on cognitive function: a systematic research review. Neurosci Biobehav Rev, 2009. 33(3): p. 394-413.

78. Heni, M., et al., Impaired insulin action in the human brain: causes and metabolic consequences. Nat Rev Endocrinol, 2015. 11(12): p. 701-11.

79. Kim, B., et al., Insulin resistance in the nervous system. Trends Endocrinol Metab, 2012. 23(3): p. 133-41.

80. Brown, A.K., et al., The effect of group-based exercise on cognitive performance and mood in seniors residing in intermediate care and self-care retirement facilities: a randomised controlled trial. Br J Sports Med, 2009. 43(8): p. 608-14.

81. Smith, P.J., et al., Aerobic exercise and neurocognitive performance: a meta-analytic review of randomized controlled trials. Psychosom Med, 2010. 72(3): p. 239-52.

82. Duvivier, B.M., et al., Minimal intensity physical activity (standing and walking) of longer duration improves insulin action and plasma lipids more than shorter periods of moderate to vigorous exercise (cycling) in sedentary subjects when energy expenditure is comparable. PLoS One, 2013. 8(2): p. e55542.

83. Berendsen, B.A., et al., Which activity monitor to use? Validity, reproducibility and user friendliness of three activity monitors. BMC Public Health, 2014. 14: p. 749.

84. Ryan, C.G., et al., The validity and reliability of a novel activity monitor as a measure of walking. Br J Sports Med, 2006. 40(9): p. 779-84. 
85. van der Berg, J.D., et al., Identifying waking time in 24-h accelerometry data in adults using an automated algorithm. J Sports Sci, 2016. 34(19): p. 1867-73.

86. van Ommen, B., et al., Phenotypic flexibility as key factor in the human nutrition and health relationship. Genes Nutr, 2014. 9(5): p. 423.

87. Russell J.A., et al., Affect Grid: A single-item scale of pleasure and arousal. J Pers Soc Psychol, 1989. 57(3): p. 493-502.

88. van der Elst, W., et al., Rey's verbal learning test: normative data for 1855 healthy participants aged 24-81 years and the influence of age, sex, education, and mode of presentation. J Int Neuropsychol Soc, 2005. 11(3): p. 290-302.

89. Bowie, C.R., et al., Administration and interpretation of the Trail Making Test. Nat Protoc, 2006. 1(5): p. 2277-81.

90. Oosterman, J.M., et al., Assessing mental flexibility: neuroanatomical and neuropsychological correlates of the Trail Making Test in elderly people. Clin Neuropsychol, 2010. 24(2): p. 203-19.

91. Fan, J., et al., The activation of attentional networks. Neuroimage, 2005. 26(2): p. 471-9.

92. Gill, D.L., et al., Physical activity and quality of life. J Prev Med Public Health, 2013. 46 Suppl 1: p. S28-34.

93. Buysse, D.J., et al., The Pittsburgh Sleep Quality Index: a new instrument for psychiatric practice and research. Psychiatry Res, 1989. 28(2): p. 193-213.

94. Brouns, F., et al., Glycaemic index methodology. Nutr Res Rev, 2005. 18(1): p. 145-71.

95. Matsuda, M., et al., Insulin sensitivity indices obtained from oral glucose tolerance testing: comparison with the euglycemic insulin clamp. Diabetes Care, 1999. 22(9): p. 1462-70.

96. Owen, N., et al., Too much sitting: the population health science of sedentary behavior. Exerc Sport Sci Rev, 2010. 38(3): p. 105-13.

97. Blankenship, J.M., et al., Effects of subtracting sitting versus adding exercise on glycemic control and variability in sedentary office workers. Appl Physiol Nutr Metab, 2014. 39(11): p. 1286-93.

98. Duvivier, B.M., et al., Breaking sitting with light activities vs structured exercise: a randomised crossover study demonstrating benefits for glycaemic control and insulin sensitivity in type 2 diabetes. Diabetologia, 2017. 60(3): p. 490-498.

99. Kodama, S., et al., Effect of aerobic exercise training on serum levels of high-density lipoprotein cholesterol: a meta-analysis. Arch Intern Med, 2007. 167(10): p. 999-1008.

100. Troiano, R.P., et al., Physical activity in the United States measured by accelerometer. Med Sci Sports Exerc, 2008. 40(1): p. 181-8.

101. Martin, A., et al., Interventions with potential to reduce sedentary time in adults: systematic review and meta-analysis. Br J Sports Med, 2015. 49(16): p. 1056-63.

102. Bergouignan, A., et al., Frequent interruptions of sedentary time modulates contractionand insulin-stimulated glucose uptake pathways in muscle: Ancillary analysis from randomized clinical trials. Sci Rep, 2016. 6: p. 32044.

103. Seip, R.L., et al., Induction of human skeletal muscle lipoprotein lipase gene expression by short-term exercise is transient. Am J Physiol, 1997. 272(2 Pt 1): p. E255-61.

104. Zhang, B., et al., Therapeutic approaches to the regulation of metabolism of high-density lipoprotein. Novel HDL-directed pharmacological intervention and exercise. Circ J, 2013. 77(11): p. 2651-2663.

105. Bilet, L., et al., Exercise-induced modulation of cardiac lipid content in healthy lean young men. Basic Res Cardiol, 2011. 106(2): p. 307-15.

106. Jocken, J.W., et al., Catecholamine-induced lipolysis in adipose tissue and skeletal muscle in obesity. Physiol Behav, 2008. 94(2): p. 219-30.

107. McDowell, C.P., et al., Sex-related differences in mood responses to acute aerobic exercise. Med Sci Sports Exerc, 2016. 48(9): p. 1798-802. 
108. Tudor-Locke, C.E., et al., Methodological considerations for researchers and practitioners using pedometers to measure physical (ambulatory) activity. Res Q Exerc Sport, 2001. 72(1): p. 1-12.

109. Hordern, M.D., et al., Exercise prescription for patients with type 2 diabetes and prediabetes: a position statement from Exercise and Sport Science Australia. J Sci Med Sport, 2012. 15(1): p. 25-31.

110. Church, T., Exercise in obesity, metabolic syndrome, and diabetes. Prog Cardiovasc Dis, 2011. 53(6): p. 412-8.

111. Gill, J.M., et al., Physical activity and prevention of type 2 diabetes mellitus. Sports Med, 2008. 38(10): p. 807-24.

112. Dempsey, P.C., et al., Benefits for type 2 diabetes of interrupting prolonged sitting with brief bouts of light walking or simple resistance activities. Diabetes Care, 2016. 39(6): p. 964-72.

113. Manders, R.J., et al., Low-intensity exercise reduces the prevalence of hyperglycemia in type 2 diabetes. Med Sci Sports Exerc, 2010. 42(2): p. 219-25.

114. Food and Agriculture Organization of the United Nations: Human energy requirements. Report of a Joint FAO/WHO/UNU Expert Consultation. Rome, Italy, FAO, 2004.

115. Kim, Y., et al., Criterion validity of competing accelerometry-based activity monitoring devices. Med Sci Sports Exerc, 2015. 47(11): p. 2456-63.

116. Ainsworth, B.E., et al., 2011 Compendium of Physical Activities: a second update of codes and MET values. Med Sci Sports Exerc, 2011. 43(8): p. 1575-81.

117. Levy, J.C., et al., Correct homeostasis model assessment (HOMA) evaluation uses the computer program. Diabetes Care, 1998. 21(12): p. 2191-2.

118. Temelkova-Kurktschiev, T.S., et al., Postchallenge plasma glucose and glycemic spikes are more strongly associated with atherosclerosis than fasting glucose or HbA1c level. Diabetes Care, 2000. 23(12): p. 1830-4.

119. Morrato, E.H., et al., Physical activity in U.S. adults with diabetes and at risk for developing diabetes, 2003. Diabetes Care, 2007. 30(2): p. 203-9.

120. Nelson, K.M., et al., Diet and exercise among adults with type 2 diabetes: findings from the third national health and nutrition examination survey (NHANES III). Diabetes Care, 2002. 25(10): p. 1722-8.

121. Jennersjo, P., et al., Pedometer-determined physical activity level and change in arterial stiffness in Type 2 diabetes over 4 years. Diabet Med, 2016. 33(7): p. 992-7.

122. Gill, J.M., et al., Effects of a brisk walk on lipoprotein lipase activity and plasma triglyceride concentrations in the fasted and postprandial states. Eur J Appl Physiol, 2003. 89(2): p. 184-90.

123. Cryer, P.E., et al., Hypoglycemia in diabetes. Diabetes Care, 2003. 26(6): p. 1902-12.

124. Ekelund, U., et al., Does physical activity attenuate, or even eliminate, the detrimental association of sitting time with mortality? A harmonised meta-analysis of data from more than 1 million men and women. Lancet, 2016. 388(10051): p. 1302-10.

125. Henson, J., et al., Associations of objectively measured sedentary behaviour and physical activity with markers of cardiometabolic health. Diabetologia, 2013. 56(5): p. 1012-20.

126. Pearson, M.J., et al., Effect of exercise training on endothelial function in heart failure patients: A systematic review meta-analysis. Int J Cardiol, 2017. 231: p. 234-243.

127. Tonjes, A., et al., Beneficial effects of a 4-week exercise program on plasma concentrations of adhesion molecules. Diabetes Care, 2007. 30(3): p. e1.

128. Zoppini, G., et al., Effects of moderate-intensity exercise training on plasma biomarkers of inflammation and endothelial dysfunction in older patients with type 2 diabetes. Nutr Metab Cardiovasc Dis, 2006. 16(8): p. 543-9.

129. Zheng, C., et al., Vascular function, insulin action, and exercise: an intricate interplay. Trends Endocrinol Metab, 2015. 26(6): p. 297-304. 
130. Carter, S., et al., Sedentary behavior and cardiovascular disease risk: mediating mechanisms. Exerc Sport Sci Rev, 2017. 45(2): p. 80-86.

131. Restaino, R.M., et al., Endothelial dysfunction following prolonged sitting is mediated by a reduction in shear stress. Am J Physiol Heart Circ Physiol, 2016. 310(5): p. H648-53.

132. Suboc, T.B., et al., Associations of reducing sedentary time with vascular function and insulin sensitivity in older sedentary adults. Am J Hypertens, 2016. 29(1): p. 46-53.

133. Thosar, S.S., et al., Effect of prolonged sitting and breaks in sitting time on endothelial function. Med Sci Sports Exerc, 2015. 47(4): p. 843-9.

134. Cersosimo, E., et al., Insulin resistance and endothelial dysfunction: the road map to cardiovascular diseases. Diabetes Metab Res Rev, 2006. 22(6): p. 423-36.

135. Thosar, S.S., et al., Sitting and endothelial dysfunction: the role of shear stress. Med Sci Monit, 2012. 18(12): p. RA173-80.

136. Duvivier, B.M., et al., Benefits of substituting sitting with standing and walking in freeliving conditions for cardiometabolic risk markers, cognition and mood in overweight adults. Front Physiol, 2017. 8: p. 353.

137. van Bussel, B.C., et al., Endothelial dysfunction and low-grade inflammation are associated with greater arterial stiffness over a 6-year period. Hypertension, 2011. 58(4): p. 588-95.

138. Huveneers, S., et al., Between $\mathrm{Rho}(\mathrm{k})$ and a hard place: the relation between vessel wall stiffness, endothelial contractility, and cardiovascular disease. Circ Res, 2015. 116(5): p. 895-908.

139. Padilla, J., et al., Vascular effects of exercise: endothelial adaptations beyond active muscle beds. Physiology (Bethesda), 2011. 26(3): p. 132-45.

140. Aksoy, S., et al., Effect of 10-week supervised moderate-intensity intermittent vs. continuous aerobic exercise programs on vascular adhesion molecules in patients with heart failure. Am J Phys Med Rehabil, 2015. 94(10 Suppl 1): p. 898-911.

141. Miyashita, M., et al., Interrupting sitting time with regular walks attenuates postprandial triglycerides. Int J Sports Med, 2016. 37(2): p. 97-103.

142. van Dijk, J.W., et al., Effect of moderate-intensity exercise versus activities of daily living on 24-hour blood glucose homeostasis in male patients with type 2 diabetes. Diabetes Care, 2013. 36(11): p. 3448-53.

143. Paffenbarger, R.S., et al., Intensity of physical activity related to incidence of hypertension and all-cause mortality: an epidemiological view. Blood Press Monit, 1997. 2(3): p. 115123.

144. Lee, I.M., et al., Relative intensity of physical activity and risk of coronary heart disease. Circulation, 2003. 107(8): p. 1110-6.

145. Tanasescu, M., et al., Exercise type and intensity in relation to coronary heart disease in men. J Am Med Assoc, 2002. 288(16): p. 1994-2000.

146. Lee, I.M., et al., Exercise intensity and longevity in men. The Harvard Alumni Health Study. J Am Med Assoc, 1995. 273(15): p. 1179-84.

147. Reynolds, A.N., et al., Advice to walk after meals is more effective for lowering postprandial glycaemia in type 2 diabetes mellitus than advice that does not specify timing: a randomised crossover study. Diabetologia, 2016. 59(12): p. 2572-2578.

148. van der Berg, J.D., et al., Replacement effects of sedentary time on metabolic outcomes: The Maastricht Study. Med Sci Sports Exerc, 2017. 49(7): p. 1351-1358.

149. Seip, R.L., et al., Skeletal muscle lipoprotein lipase: molecular regulation and physiological effects in relation to exercise. Exerc Sport Sci Rev, 1998. 26: p. 191-218.

150. Zhang, B., et al., Therapeutic approaches to the regulation of metabolism of high-density lipoprotein. Novel HDL-directed pharmacological intervention and exercise. Circ J, 2013. 77(11): p. 2651-63. 
151. Thanassoulis, G., et al., Relations of change in plasma levels of LDL-C, non-HDL-C and apoB with risk reduction from statin therapy: a meta-analysis of randomized trials. J Am Heart Assoc, 2014. 3(2): p. e000759.

152. Ojuka, E.O., et al., Mechanisms in exercise-induced increase in glucose disposal in skeletal muscle. Med Sport Sci, 2014. 60: p. 71-81.

153. Hussey, S.E., et al., Exercise increases skeletal muscle GLUT4 gene expression in patients with type 2 diabetes. Diabetes Obes Metab, 2012. 14(8): p. 768-71.

154. Hesselink, M.K., et al., Skeletal muscle mitochondria as a target to prevent or treat type 2 diabetes mellitus. Nat Rev Endocrinol, 2016. 12(11): p. 633-645.

155. Phielix, E., et al., Exercise training increases mitochondrial content and ex vivo mitochondrial function similarly in patients with type 2 diabetes and in control individuals. Diabetologia, 2010. 53(8): p. 1714-21.

156. van Tienen, F.H., et al., Physical activity is the key determinant of skeletal muscle mitochondrial function in type 2 diabetes. J Clin Endocrinol Metab, 2012. 97(9): p. 3261-9.

157. Way, K.L., et al., The effect of regular exercise on insulin sensitivity in type 2 diabetes mellitus: a systematic review and meta-analysis. Diabetes Metab J, 2016. 40(4): p. 253-71.

158. Conn, V.S., et al., Insulin sensitivity following exercise interventions: systematic review and meta-analysis of outcomes among healthy adults. J Prim Care Community Health, 2014. 5(3): p. 211-22.

159. Emoto, M., et al., Homeostasis model assessment as a clinical index of insulin resistance in type 2 diabetic patients treated with sulfonylureas. Diabetes Care, 1999. 22(5): p. 818-22.

160. Katsuki, A., et al., Homeostasis model assessment is a reliable indicator of insulin resistance during follow-up of patients with type 2 diabetes. Diabetes Care, 2001. 24(2): p. 362-5.

161. Wagner, J., et al., Continuous glucose monitoring: a review for behavioral researchers. Psychosom Med, 2012. 74(4): p. 356-65.

162. Damiano, E.R., et al., A comparative effectiveness analysis of three continuous glucose monitors: the Navigator, G4 Platinum, and Enlite. J Diabetes Sci Technol, 2014. 8(4): p. 699-708.

163. Bailey, T.S., et al., Accuracy and acceptability of the 6-day Enlite continuous subcutaneous glucose sensor. Diabetes Technol Ther, 2014. 16(5): p. 277-83.

164. Vrolix, R., et al., Variability of the glycemic response to single food products in healthy subjects. Contemp Clin Trials, 2010. 31(1): p. 5-11.

165. Healy, G.N., et al., Replacing sitting time with standing or stepping: associations with cardio-metabolic risk biomarkers. Eur Heart J, 2015. 36(39): p. 2643-9.

166. Dempsey, P.C., et al., Interrupting prolonged sitting with brief bouts of light walking or simple resistance activities reduces resting blood pressure and plasma noradrenaline in type 2 diabetes. J Hypertens, 2016. 34(12): p. 2376-2382.

167. Department of Health and Human Services. U.S. Physical activity guidelines for Americans, 2008. Available from https://health.gov/paguidelines/guidelines/default.aspx, accessed 26 March 2017.

168. UK Government, Department of Health. UK Physical activity guidelines, 2011. Available from https://www.gov.uk/government/publications/uk-physical-activity-guidelines, accessed 26 March 2017.

169. Australian Government, Department of Health. Australia's physical activity and sedentary behaviour guidelines, 2014. Availabe from

http://www.health.gov.au/internet/main/publishing.nsf /Content/health-pubhlth-strategphys-act-guidelines, accessed 26 March 2016.

170. De Nederlandse Overheid, Gezondheidsraad. Beweegrichtlijnen 2017, publicatienr. 2017/08. Availabe from https://www.gezondheidsraad.nl/nl/taakwerkwijze/werkterrein/preventie/beweegrichtlijnen-2017, accessed 3 September 2017. 
171. Healy, G.N., et al., Breaks in sedentary time: beneficial associations with metabolic risk. Diabetes Care, 2008. 31(4): p. 661-6.

172. Buckley, J.P., et al., The sedentary office: an expert statement on the growing case for change towards better health and productivity. Br J Sports Med, 2015. 49(21): p. 1357-62.

173. Healy, G.N., et al., A cluster randomized controlled trial to reduce office workers' sitting time: effect on activity outcomes. Med Sci Sports Exerc, 2016. 48(9): p. 1787-97. 

DANKWOORD 
Hierbij wil ik graag iedereen bedanken die op welke wijze dan ook heeft bijgedragen aan de totstandkoming van dit proefschrift. In het bijzonder wil ik een aantal mensen bedanken.

Allereerst mijn promotoren Hans en Nicolaas! In mijn $2^{\mathrm{e}}$ jaar geneeskunde wilde ik graag onderzoek gaan doen naar leefstijl en diabetes en kwam op die manier via een Honours programme bij jullie terecht. Vervolgens hebben we samen een onderzoeksidee uitgewerkt dat na mijn geneeskunde opleiding verder gezet werd in een promotietraject.

Hans, bedankt voor de leuke samenwerking de afgelopen jaren. Je was mijn rots in de branding, je was er altijd als ik je nodig had. Ook al had je het druk, toch kon ik altijd even binnenvallen. Je hebt in je kamer een mooie levenswijsheid aan de muur hangen: 'wat je ook doet, doe het goed'. Daar ben je zelf het mooie voorbeeld van. Je moedigde mij aan om mijn eigen weg te zoeken en zelf met ideeën te komen. Ik ben je erg dankbaar voor de vrijheid die je me gaf om mezelf ten volle te kunnen ontplooien en er volledig mijn project van te kunnen maken. Helaas voor jou had ik soms enorm veel onderzoeksideeën. Desondanks heb je naar me geluisterd en eruit gepikt wat potentieel had. Ik ben dan ook erg blij dat we die onderzoeksideeën momenteel verder vorm kunnen geven. Bedankt voor het vertrouwen dat je mij hebt gegeven om mijn onderzoeksavontuur verder te zetten in een postdoc.

Nicolaas, bij jou is het mooie onderzoeksavontuur begonnen. Je passie voor onderzoek is erg aanstekelijk en ik heb nog elke dag bewondering voor de vurige passie die je in je werk steekt. Soms had je wat veel ideeën en zag ik na een vergadering door de bomen het bos niet meer. Gelukkig werd het bos met het verstrijken van de tijd steeds beter zichtbaar. Je bent een perfectionistisch persoon, wat je doet doe je heel grondig wat de kwaliteit van mijn onderzoek ten goede is gekomen. Je had me verteld dat een PhD door de modder kruipen was met veel vallen en opstaan. Hoewel ik relatief weinig modder ben tegengekomen tijdens de eerste jaren van mijn PhD ben ik de modder met name in het laatste jaar tegengekomen. Gelukkig strooide je niet alleen modder maar was je er vooral ook om mij uit de modder te halen en af te remmen als ik weer wat veel hooi op de vork wilde nemen. Ik heb ontzettend veel van je geleerd en pluk nog elke dag de vruchten hiervan.

Annemarie, wat was het fijn om jou als co-promotor te hebben! Je bent een bewonderenswaardig sterke onderzoeker; je bent uiterst betrouwbaar, snel en blijft altijd kritisch. Doordat je altijd doorvraagt tot je het begrijpt kwam ik vaak tot het besef dat ik het nog niet helemaal begrepen had. Naast je onderzoekskwaliteiten ben je ook een bijzonder vriendelijk persoon met veel empathie. Je had steeds een oprechte interesse in mij als persoon, ook in de dingen die me buiten het werk om bezig hielden. Ik heb dan ook 
erg genoten van onze gesprekken na de vergaderingen en van je steun als de werkdruk hoog was.

Matthijs, je behandelde me steeds als een gelijke waardoor ik erg laagdrempelig bij je terecht kon om vragen te stellen en mee te kunnen profiteren van je ontzettend uitgebreide kennis. Met name bedankt voor alle hulp bij SitLess2 wat geleid heeft tot een ontzettend mooi artikel! Je sterk gevoel voor humor zorgt ervoor dat elke gesprek gezellig is met jou.

Patrick, bedankt voor het vertrouwen en alle hulp tijdens mijn PhD, onder meer tijdens het SitLess3 project! Je bent een sterke leidersfiguur, adequaat en betrouwbaar. Je bent altijd uiterst snel en zorgvuldig met je feedback op stukken. Ik ben erg blij dat ik verder met jullie kan gaan werken aan ons nieuwe SitLess4 project!

De beoordelingscommissie, Prof. dr. E.E. Blaak, Prof. dr. J.M.M. Chin A Paw, Prof. dr. L.J.C. van Loon, Prof. dr. J.W.M. Muris, and Dr. T. Yates, wil ik bedanken voor het lezen en beoordelen van dit proefschrift. De leden van de corona bedank ik voor hun aanwezigheid en het lezen van mijn proefschrift. Ik heb een grote bewondering voor jullie professionele verdiensten en heb veel inspiratie gehaald uit jullie artikels.

Dr. Thomas Yates, many thanks for your willingness to assess my PhD dissertation! I admire your academic work and I learned a lot from your publications.

Mijn paranimfen, Eric en Linh. Veel dank voor jullie bijdrage aan de totstandkoming van dit proefschrift en al het geregel rondom de promotie. Wat had ik zonder jullie hulp moeten doen! Eric, we hebben elkaar 10 jaar geleden leren kennen in het eerste jaar geneeskunde. Sinds die tijd is er een unieke vriendschap ontstaan en hebben we ontelbare uren samen gestudeerd, zij aan zij, in de bib of op jouw kamer. In het tweede jaar geneeskunde zijn we samen de onderzoekswereld ingedoken om vervolgens beide een PhD te gaan doen. Dank voor je steun en je luisterend oor voor alle uitdagingen die ik tijdens en buiten het onderzoek ben tegengekomen. Ik ben er van overtuigd dat we samen nog onvergetelijke avonturen zullen beleven en weet dat je in de toekomst ook altijd op mij kan rekenen. Linh, je bent begonnen als mijn eerste student die ik mocht begeleiden met een Master thesis. Vervolgens ben je verder kunnen groeien als onderzoeksassistent. Daardoor hebben we samen SitLess2 en SitLess3 kunnen uitvoeren. Bedankt voor al je hulp, ook voor het minder leuke administratieve werk dat er soms bij kwam kijken. Dankzij jouw organisatietalent en nauwkeurigheid hebben we beide projecten tot een mooi einde kunnen brengen. Zonder jou was het mij nooit gelukt om mijn promotieonderzoek in 3,5 jaar te kunnen afronden. Door onze nauwe samenwerking hebben we een mooie vriendschap kunnen uitbouwen waardoor het altijd gezellig was op en buiten het werk om. Samen met de andere studenten hebben we onvergetelijke herinneringen 
opgebouwd en heb je mij wat meer kunnen bijbrengen over de Nederlandse en Maastrichtse cultuur. We hebben zo ontzettend veel afgelachen dat er terug een glimlach op mijn gezicht komt nu ik dit opschrijf.

Mijn oude kamergenoten van de legendarische kamer 2.220, Brenda, Pieter, Michiel en Wai-Yan. Toen ik als jonge telg bij jullie gezelschap kwam was het even wennen maar al snel leerden we elkaar beter kennen en hebben we samen veel leuke momenten gedeeld. Brenda, jij was een beetje de moeder van ons gezelschap. Je bakte niet alleen lekkere taarten maar zorgde er ook voor dat we regelmatig samen kwamen voor leuke uitstappen en etentjes. Je hebt voor ontzettend veel gezelligheid gezorgd en we hebben je dan ook gemist toen je promotie afgerond was. Pieter, jij was altijd de rust en vriendelijkheid zelve. Omdat ik zelf nogal eens gestrest rond kon lopen als er iets niet lukte was het fijn dat jij altijd bereid was te luisteren. Bedankt ook voor alle hulp die je me gegeven hebt als er weer iets niet lukte met een of ander computerprogramma. Jouw oneindige geduld is een bijzondere gave. Michiel, doordat onze muzieksmaak verschilde, verschuilde ik me in begin al snel achter een koptelefoon. Echter, ik ben erg blij voor de tijd die we samen hebben kunnen doorbrengen in en buiten het werk om. Gezelligheid was altijd troef bij jou, in en buiten Eindhoven. Jouw lach zal mij altijd bij blijven, je kon zo bulderend en aanstekelijk lachen en dat typeerde ook de persoon die je was: optimistisch en energiek. Wai-Yan, je bent een altijd vrolijke en lieve collega met een luisterend oor. Ik heb genoten van al onze gesprekken op en buiten de borrels om. Tom, jij was een beetje het verlengde van kamer 2.220. Bedankt voor al je carrièretips en de gezelligheid die meestal naar boven kwam buiten het werk om.

Mijn nieuwe kamergenoten van 2.220, Hans E., Chris, Li-Juan en HQ. Te beginnen met Hans E., ik zal je eeuwig dankbaar blijven voor het zit-sta-bureau die je voor mij gevonden hebt. Wat was die zit-sta-bureau geweldig, je hebt me zo geholpen om mijn onderzoek in de praktijk te brengen en mijn eigen gezondheid (en productiviteit) te boosten. Je bent een unieke collega, we hebben veel leuke momenten samen gedeeld, zowel met het oude als het nieuwe kamerteam. Bedankt voor je luisterend oor bij alle uitdagingen die ik tijdens mijn PhD ben tegengekomen en bedankt ook voor alle gezelligheid. Je hebt een uitzonderlijke gave voor humor waardoor je letterlijk iedereen aan het lachen krijgt. Je bent ook een enorm loyale en behulpzame collega, bedankt voor alles Hans. Chris, I have a lot of admiration for your passion for research. You are born for research and if there is one person who has the capability to become a professor, it's you. You are also a very kind person and it was always nice to discuss our research and career plans. You will become a good father, enjoy your time with Alexander and Christina! Li-Juan, het was erg leuk je te leren kennen. Je hebt een lieve persoonlijkheid en bent een ambitieuze collega, je zult in het onderzoek ongetwijfeld nog ver komen. Een dikke dankjewel om je werkplek met mij te delen zodat ik nog steeds in kamer 2.220 kan blijven werken. HQ, you are a very kind 
person (sometimes too kind) and always so sincerely interested in everything that is going on in my life. I'm so happy that you're working further on a topic that is related to my research.

De andere HB/BW collega's! Wouter, gelukkig was jij er om mezelf weer een beetje Belg te kunnen voelen tussen al die Nederlanders;-). Je bent soms een stoere kerel maar je hebt een hart van goud. Je prikkelde me vaak om de flauwe plezante uit te hangen en je hebt mij al veel doen lachen. Bedankt ook voor alle hulp met de activPAL data en dat we nog veel mogen lachen samen. Thamar, eerste kende ik je als mr. T. Het laatste jaar heb ik je leren kennen als Thamar! Wat heb ik genoten van al onze sportsessies tijdens de lunchpauze. Het was een moment om de gezondheid te boosten en te kunnen praten over alles wat ons bezighield in het leven. Bedankt daarvoor, zeker in de laatste maanden van mijn PhD heeft dat vaak veel deugd gedaan. Kenneth, vanaf het begin af aan behandelde je me al als een gelijke en zo heb je mij gelijk een plekje geregeld in kamer 2.220. Je bent een open en ontzettend sociaal persoon waardoor het altijd gezellig is met je. Désirée en Yolanda, wat was het ontzettend leuk om met jullie samen te kunnen werken. Jullie zijn altijd te vinden voor een grapje waardoor het altijd een plezier is om binnen te lopen bij jullie. Bedankt ook voor alle ondersteuning. Paul, je bent een ontzettend vriendelijk en behulpzaam persoon. Bedankt voor de hulp bij mijn activPAL data en de aangename gesprekken over niet-werk gerelateerde zaken. Harry, ontzettend bedankt voor alle technische ondersteuning. Je stond altijd met open armen klaar om te helpen op korte termijn als ik weer een probleem had met de ICT. Guy, dank voor alle hulp bij mijn eerste studie toen ik nog als student bij je binnenliep. Dank ook voor alle gezelligheid en hulp die ik in de afgelopen jaren heb mogen ervaren! Jan-Willem, bedankt bij de hulp bij het opzetten van SitLess2, dit heeft de studie mede doen slagen. Jos A., je bent altijd de vriendelijkheid zelve! Bedankt voor de prettige samenwerking, onder andere tijdens SitLess3. Anne, dank voor de leuke gesprekken die we hebben gehad in en buiten de koffiekamer. Dank ook voor alle tips en hulp bij het afronden van mijn proefschrift. Je bent een ontzettend slimme meid en een ontzettend harde werker, met deze eigenschappen zul je nog ver komen in het onderzoek. Dirk, doordat je gestart was met een gelijkaardig onderzoeksproject hebben we elkaar al in het begin van mijn PhD leren kennen. Het was erg leuk met je te kunnen sparren over onderzoeksideeën en ervaringen te kunnen delen. Daarnaast ben je een ontzettend sociaal persoon waardoor elke sociale activiteit gezellig wordt als jij van de partij bent. Marike, dank voor het meedenken over onderzoeksmogelijkheden, het was erg leuk om met je te kunnen samenwerken. Annemieke, ik ben blij je op het einde van mijn PhD te hebben kunnen ontmoeten. Door onze gemeenschappelijke interesse in bewegen en gezondheid hebben we leuke gesprekken gehad en wellicht dat er in de toekomst nog gelegenheden zullen komen om samen te werken. Carlijn, Lena en Esther P., erg leuk dat we samen SitLess4 kunnen uitvoeren, ik kijk er erg naar uit om dit project samen tot een goed einde te brengen! Gert, 
bedankt voor alle labgerelateerde hulp en de gezellige gesprekken in en buiten de VS. Esther K., Martine en Johanna, dank voor de prettige samenwerking en de uitvoering van de bepalingen tijdens het SitLess3 project! Jogchum en Maurice: dank voor de CETP bepalingen en ideeën voor vervolgonderzoek! Dank ook aan alle overige HB/BW collega's waar ik veel gezellige weekendjes mee heb gehad in de Ardennen, in het bijzonder Jos Stegen.

De collega's buiten HB/BW. Michelle, je was mijn eerste partner in crime tijdens de uitvoering van ons gezamenlijk onderzoeksproject. Dankzij onze goede samenwerking heeft dit uiteindelijk mogen uitmonden in een mooie publicatie. Het is erg leuk dat we nog steeds contact hebben kunnen houden. Glenn, we zijn vrienden geworden tijdens de geneeskunde studie en sindsdien hebben we twee mooie onderzoeksprojecten samen kunnen afronden. Je bent een goede vriend geworden en we zullen wellicht nog veel leuke dingen meemaken samen. Marleen, hartelijk dank voor al je hulp bij de uitvoering van mijn eerste onderzoeksproject. Ik heb erg veel van je mogen leren. Hanny, dank voor alle hulp bij het inplannen van vergaderingen. Je hebt altijd je uiterste best gedaan om een gaatje te zoeken in de agenda van Nicolaas, ook als Nicolaas het wat druk had. Martijn, dank voor je hulp en advies gedurende mijn PhD, in het bijzonder bij het endotheel artikel. Judith, Nancy, Loe en meneer Menheere, dank voor alle labanalyses en de fijne samenwerking met jullie. Prof. Schalkwijk en Marjo van de Waarenburg, dank voor de prettige samenwerking en de analyses van de endotheel- en inflammatiemarkers! Bjorn, bedankt voor alle statistische hulp en je geduldige manier van uitleggen. Jeroen van der Velde en Eline van Roekel, dank om samen te kunnen sparren over SitLess ideeën. Dankjewel ook aan alle collega's van de Nutrim PhD council, fijn dat we zo'n leuke projecten samen hebben kunnen realiseren. Bedankt aan alle huidige collega's van Huisartsenpraktijk Posterholt en collega's van de Huisartsenopleiding. Bedankt voor jullie luisterend oor en begrip tijdens de laatste maanden van mijn proefschrift. Dank ook aan alle sponsors: MUMC, Unilever, Novo Nordisk BV, Medtronic, Roche, Dutch Heart Foundation en Maastricht Instruments BV! In het bijzonder wil ik Harry Peters bedanken, we hebben veel vergaderd en hebben een mooi SitLess3 project kunnen realiseren. De samenwerking met jou was altijd heel prettig en ik hoop nog verder te kunnen samenwerken in de toekomst. Hierbij ook een welgemeende dankjewel aan alle proefpersonen, zonder jullie was dit onderzoek nooit mogelijk geweest!

Aan alle (ex-) studenten die mij geholpen hebben, een welgemeende dankjewel. In het bijzonder een dankjewel aan Nathalie S. en Annelies. Jullie waren allebei heel getalenteerde studenten en ik heb naast een collegiale band ook een vriendschappelijke band met jullie kunnen opbouwen. Nathalie S., met jou erbij is het altijd lachen. Wat ontzettend fijn ook dat we collega's in het huisartsenvak zijn mogen worden! Hopelijk mogen we nog veel gemeenschappelijke avonturen in en buiten Maastricht meemaken. 
Annelies, erg fijn dat je naast je bachelor thesis ook als Master bij mij aan de slag kon. Bedankt voor al je hulp bij het endotheelartikel! Je bent een erg lief persoon en ik wens je veel succes met je psychologie studie! Daarnaast ook een dikke dankjewel aan Lonne, Joost K., Nathalie T., Simon, Rob, Joost G., Stella, Amber, Ralph, Elham en Antonis. Jullie hebben allemaal een belangrijk steentje bijgedragen om de SitLess puzzel compleet te maken.

Daarnaast wil ik ook al mijn vrienden en familie bedanken die mij gesteund hebben buiten het onderzoek om. Jullie betekenen erg veel voor mij en ik hoop nog veel leuke avonturen samen met jullie te mogen meemaken. In het bijzonder papa en mama, jullie hebben mij steeds gesteund in al mijn beslissingen. Dank voor alle vrijheid en steun, zonder jullie was ik nooit zo ver geraakt.

An-Katrien, ge zijt al 10 jaar mijn steun en toeverlaat. Ik zie u zo ontzettend graag en ik hoop dat ons sprookje de rest van ons leven mag blijven duren. 

CURRICULUM VITAE 


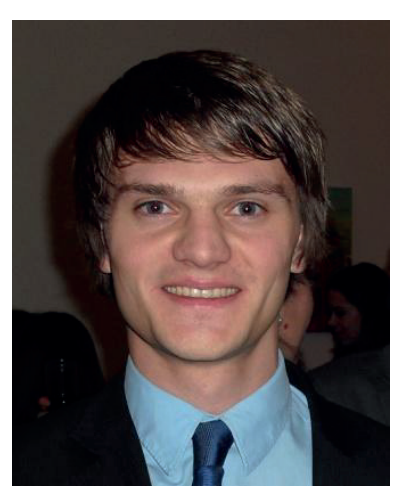

Bernard was born on the $24^{\text {th }}$ of March in 1988 in Hasselt, Belgium. He attended secondary school at SintFranciscuscollege in Heusden-Zolder and graduated in 2006. He studied Medicine at Maastricht University and followed an Honours programme Scientific Research where he graduated in 2013. Studying Medicine, he was awarded several times the top 3\% award for his exam results and he received the Hippocrates studiefonds for best Master thesis. After graduation, Bernard obtained a Kootstra Talent Fellowship to start a PhD under supervision of Prof. dr. H.H.C.M. Savelberg, Prof. dr. N.C. Schaper and Dr. ir. A. Koster at the departments of Human Movement Sciences and Internal Medicine (Endocrinology). During his PhD, Bernard performed three intervention studies on the health effects of reducing sedentary behaviour. For the presentation of his research, he received the 'KNMG poster price', 'LIMSC best oral session I price' and a travel grant from 'The American Physiological Society'.

Bernard currently combines a general practitioner traineeship and postdoctoral fellowship at Maastricht University. His research project continues on the findings presented in this dissertation, aiming to unravel the biological mechanisms underlying the effects of substituting sitting with light physical activity. 

LIST OF PUBLICATIONS 


\section{Published articles}

1. Duvivier BMFM, Schaper NC, Hesselink MKC, van Kan L, Stienen N, Winkens B, Koster A, Savelberg HHCM. Breaking sitting with light activities vs structured exercise: a randomised crossover study demonstrating benefits for glycaemic control and insulin sensitivity in type 2 diabetes. Diabetologia 2017;60(3):490-498. (IF: 6.2)

2. Duvivier BMFM, Schaper NC, Koster A, van Kan L, Peters HP, Adam JJ, Giesbrecht T, Kornips E, Hulsbosch M, Willems P, Schrauwen P, Savelberg HHCM. Benefits of substituting sitting with standing and walking in free-living conditions for cardiometabolic risk markers, cognition and mood in overweight adults. Frontiers in Physiology 2017;8(353). (IF: 4.4)

3. Chastin SF, De Craemer M, Lien N, ..., Cardon G and DEDIPAC Consortium. The SOSframework (Systems of Sedentary behaviours): an international transdisciplinary consensus framework for the study of determinants, research priorities and policy on sedentary behaviour across the life course: a DEDIPAC-study. International Journal of Behavioral Nutrition and Physical Activity 2016;13(1). (IF: 4.4)

4. Duvivier BMFM, Schaper NC, Bremers MA, van Crombrugge G, Menheere PP, Kars M, Savelberg HHCM. Minimal intensity physical activity (standing and walking) of longer duration improves insulin action and plasma lipids more than shorter periods of moderate to vigorous exercise (cycling) in sedentary subjects when energy expenditure is comparable. PLoS One 2013;8(2):e55542. (IF: 3.7)

5. Van Crombrugge G, Duvivier BMFM, Van Crombrugge K, Bellemans J, Peers K. Hamstring injury prevention in Belgian and English elite football teams. Acta Orthopedica Belgica, accepted for publication.

6. Duvivier BMFM, Schaper NC, Savelberg HHCM. Minder zitten of meer sporten bij diabetes? Nederlands Tijdschrift voor Diabetologie 2017;15(3).

7. Savelberg HHCM, Duvivier BMFM, Kremers S. Opstaan misstaat niet. Tijdschrift voor Ergonomie 2014;39(3).

8. Duvivier BMFM. Is slenteren beter dan sporten? Gezond Idee Online 2014. https://gezondidee.mumc.nl/blog/slenteren-beter-dan-sporten

9. Duvivier BMFM. The truth about exercise. Cheers Magazine 2012;3(3).

\section{Submitted and in preparation}

10. Duvivier BMFM, Bolijn JE, Koster A, Schalkwijk CG, Savelberg HHCM, Schaper NC. Reducing sitting time versus adding exercise: differential effects on biomarkers of endothelial function and metabolic risk. Submitted

11. Duvivier BMFM, Savelberg HHCM, van Crombrugge G, Korver S, van Dongen MC, Winkens B, Schaper NC, Koster A. The impact of physical inactivity on plasma lipids: a systematic review of intervention studies. In preparation 


\section{Published abstracts}

12. Duvivier BMFM, Schaper NC, Hesselink MKC, van Kan L, Stienen N, Winkens B, Koster A, Savelberg HHCM. Breaking sitting with light activities versus structured exercise: benefits for glycemic control and insulin sensitivity in type 2 diabetes. The Physiologist 2017;60(1).

13. Duvivier BMFM, Schaper NC, Hesselink MKC, van Kan L, Peters H, Adam JJ, Giesbrecht T, Koster A, Schrauwen P, Savelberg HHCM. Effects of interrupting sitting by light-intensity activities on insulin sensitivity, plasma lipids, cognition and mood. Nederlands Tijdschrift voor Diabetologie 2016;14(4).

14. Bolijn JE, Duvivier BMFM, Koster A, Schalkwijk CG, Savelberg HHCM, Schaper NC. Benefits of sitting less versus more exercise on endothelial dysfunction in healthy, overweight and subjects with type 2 diabetes. Nederlands Tijdschrift voor Diabetologie 2016;14(4).

15. Duvivier BMFM, Schaper NC, Koster A, van Kan L, Stienen N, Winkens B, Hesselink MKC, Savelberg HHCM. Low intense walking and standing reduces 24 hour blood glucose to a similar extent as moderate intense cycling in type 2 diabetes patients during similar energy expenditure. Nederlands Tijdschrift voor Diabetologie 2015;13(4).

16. Duvivier BMFM, Schaper NC, Bremers MA, van Crombrugge G, Jeuken R, Antoniou A, Kars $\mathrm{M}$, Savelberg HHCM. Slow walking decreases cardiovascular risk factors more than high intense cycling during similar energy expenditure. Medical Science Educator Volume 2013;23(180)

17. Duvivier BMFM, Schaper NC, Bremers MA, van Crombrugge G, Jeuken R, Antoniou A, Kars $M$, Savelberg HHCM. Light intense physical activity increases insulin sensitivity and decreases lipids more than exercise. KNMG Schelmenstreek, District Limburg 2012;14. 
ntx管 